\section{Pacific Northwest}

National Laboratory

Operated by Battelle for the

U.S. Department of Energy

\title{
Laboratory Studies on the Effects of Shear on Fish
}

\section{Final Report 2000}

\author{
DA Neitzel RA Moursund \\ MC Richmond CS Abernethy \\ DD Dauble GR Guensch \\ RP Mueller \\ Pacific Northwest National Laboratory \\ Richland, Washington \\ GF Cada \\ Oak Ridge National Laboratory \\ Oak Ridge, Tennessee
}

September 2000

Prepared for the U.S. Department of Energy

Idaho Operations Office

under Contract DE-AC05-76RL01830 


\title{
DISCLAIMER
}

This report was prepared as an account of work sponsored by an agency of the United States Government. Neither the United States Government nor any agency thereof, nor Battelle Memorial Institute, nor any of their employees, makes any warranty, express or implied, or assumes any legal liability or responsibility for the accuracy, completeness, or usefulness of any information, apparatus, product, or process disclosed, or represents that its use would not infringe privately owned rights. Reference herein to any specific commercial product, process, or service by trade name, trademark, manufacturer, or otherwise does not necessarily constitute or imply its endorsement, recommendation, or favoring by the United States Government or any agency thereof, or Battelle Memorial Institute. The views and opinions of authors expressed herein do not necessarily state or reflect those of the United States Government or any agency thereof.

\author{
PACIFIC NORTHWEST NATIONAL LABORATORY \\ operated by \\ BATTELLE \\ for the \\ UNITED STATES DEPARTMENT OF ENERGY \\ under Contract DE-AC05-76RL01830
}

Printed in the United States of America
Available to DOE and DOE contractors from the Office of Scientific and Technical Information,
P.O. Box 62, Oak Ridge, TN 37831-0062;
ph: (865) 576-8401
fax: $(865) 576-5728$
email: reports@adonis.osti.gov

\footnotetext{
Available to the public from the National Technical Information Service, U.S. Department of Commerce, 5285 Port Royal Rd., Springfield, VA 22161 ph: (800) 553-6847 fax: $(703) 605-6900$ email: orders@ntis.fedworld.gov online ordering: http://www.ntis.gov/ordering.htm
}

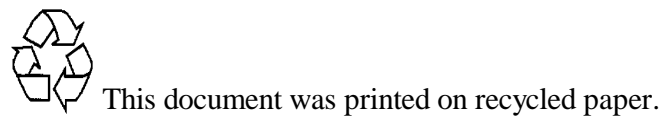


PNNL-13323

\title{
Laboratory Studies on the Effects of Shear on Fish
}

\section{Final Report 2000}

\author{
D. A. Neitzel \\ R. A. Moursund \\ M. C. Richmond \\ C. S. Abernethy \\ D. D. Dauble \\ G. R. Guensch \\ R. P. Mueller
}

Pacific Northwest National Laboratory

Richland, Washington

G. F. Čada

Oak Ridge National Laboratory

Oak Ridge, Tennessee

September 2000

Prepared for

U.S. Department of Energy

Idaho Operations Office 


\section{Summary}

The overall objective of our studies was to specify an index describing the hydraulic force that fish experience when subjected to a shear environment. Fluid shear is a phenomenon that is important to fish. However, elevated levels of shear may result in strain rates that injure or kill fish. At hydroelectric generating facilities, concerns have been expressed that strain rates associated with passage through turbines, spillways, and fish bypass systems may adversely affect migrating fish. Development of fish friendly hydroelectric turbines requires knowledge of the physical forces (injury mechanisms) that impact entrained fish and the fish's tolerance to these forces. It requires up-front, pre-design specifications for the environmental conditions that occur within the turbine system; in other words, determining or assuming conditions known to injure fish will assist engineers in the design of a fish friendly turbine system. These biological specifications must be carefully and thoroughly documented throughout the design of an advanced turbine. To address the development of biological specifications, we designed and built a test facility where juvenile fish could be subjected to a range of shear environments and quantified their biological response.

Test fish included juvenile rainbow trout, Oncorhynchus mykiss, spring and fall chinook salmon, O. tshawytscha, and American shad, Alosa sapidissima. Fish were exposed to a shear environment produced by a submerged jet over a range of exit velocities from 0 to $21.3 \mathrm{~m} / \mathrm{s}$ ( 0 to $70 \mathrm{ft} / \mathrm{s})$. They were introduced in either a headfirst or tailfirst orientation and to the edge of the jet stream (slow-fish-to-fastwater scenario) or within and upstream of the jet stream (fast-fish-to-slow-water scenario). Test fish were captured after leaving the shear environment and specific biological responses noted (i.e., injury and mortality). The behavior or reaction of fish in the shear environment was recorded on high-speed video cameras. Fluid velocities were measured in the jet with a Pitot tube and a Laser Doppler Velocimeter (LDV). Statistical tests were applied to the fish data to estimate the lowest observed effect level and no observed effect level, or the strain rate at which fish were not injured after being subjected to the shear environment.

The Pitot tube provided mean velocity information in the axial direction. The mean-flow velocity measurements obtained using the Pitot tube were used to describe the jet centerline velocity and fluid strain rate. This report refers to the mean change in water velocity (u) over distance (y) as strain rate (e).

$$
\text { Exposure Strain Rate }=e=\frac{\partial \bar{u}}{\partial y}
$$


We used strain rate as an index of the physical force that fish experience when subjected to the shear environment in our test facility. The rate of strain experienced by test fish varied from $0 \mathrm{~cm} / \mathrm{s} / \mathrm{cm}^{1}$ to $1185 \mathrm{~cm} / \mathrm{s} / \mathrm{cm}$, based on a spatial resolution of $\Delta y=1.8 \mathrm{~cm}$. This interval was based on the minimum width of the salmonids tested. The values reported here are not equivalent to a strain rate computed at a finer scale resolution.

The LDV was used to measure velocity fluctuations and provide information about turbulence intensities. These measurements showed that the turbulence intensity in the area of the jet where fish were subjected to the shear environment was +3 to $6 \%$ of the estimated strain rate.

Our test results indicate that fish entering a shear environment may be killed, injured, or their experience may cause increased susceptibility to predation. Fish in our tests were subjected to rates of strain up to $1185 \mathrm{~cm} / \mathrm{s} / \mathrm{cm}, \Delta \mathrm{y}=1.8 \mathrm{~cm}$. There were no significant injuries to any fish subjected to rates of strain of less than $517 \mathrm{~cm} / \mathrm{s} / \mathrm{cm}, \Delta y=1.8 \mathrm{~cm}$ (Table S.1). Of the fish tested, American shad were the most susceptible to injury while steelhead and rainbow trout were the most resistant. Predation susceptibility tests also were conducted with rainbow trout. Rainbow trout only received minor injuries at strain rates

Table S.1. Summary of the strain rate exposures that did not injure or kill fish.

\begin{tabular}{|c|c|c|c|c|}
\hline \multirow[b]{2}{*}{ Test Fish } & \multirow[b]{2}{*}{ Test Orientation } & \multicolumn{3}{|c|}{ Strain Rate $(\mathrm{cm} / \mathrm{s} / \mathrm{cm}[\Delta \mathrm{y}=1.8 \mathrm{~cm}])$} \\
\hline & & $\begin{array}{c}\text { No Significant } \\
\text { Injury }\end{array}$ & $\begin{array}{l}\text { No Significant } \\
\text { Major Injury }\end{array}$ & $\begin{array}{c}\text { No Significant } \\
\text { Deaths }\end{array}$ \\
\hline Fall chinook (age- 0 ) & Headfirst & 517 & 852 & 1008 \\
\hline Fall chinook (age-1) & Headfirst & 517 & 517 & 852 \\
\hline Spring chinook & Headfirst & 517 & 688 & 1008 \\
\hline Rainbow trout & Headfirst & 688 & 1008 & 1008 \\
\hline Steelhead & Headfirst & 517 & 1008 & 1008 \\
\hline American shad & Headfirst & 517 & 517 & 517 \\
\hline Fall chinook (age-1) & Tailfirst & 688 & 1008 & 1008 \\
\hline Spring chinook & Tailfirst & 688 & 1008 & 1008 \\
\hline Steelhead & Tailfirst & 852 & 1008 & 1008 \\
\hline Rainbow trout & $\begin{array}{l}\text { Headfirst w/ } \\
\text { predators }\end{array}$ & 517 & NA & NA \\
\hline
\end{tabular}

\footnotetext{
${ }^{1}$ Throughout this report, the strain rate is presented in units of $\mathrm{cm} / \mathrm{s} / \mathrm{cm}$ to emphasize that the rate of strain is the mean change in velocity (distance divided by time $[\mathrm{cm} / \mathrm{s}]$ ) divided by distance). When $\mathrm{cm} / \mathrm{s} / \mathrm{cm}$ is carried through algebraically, rate of strain can be represented as $1 / \mathrm{s}$. We choose to leave the units as $\mathrm{cm} / \mathrm{s} / \mathrm{cm}$ to emphasize our assumption of strain occurring over a distance of $1.8 \mathrm{~cm}$ (the average width of the test fish). Additionally, we did not convert any of the strain rates to English units. Converting to English units does not change the numerical value of any calculated strain rates. For example, $1008 \mathrm{~cm} / \mathrm{s} / \mathrm{cm}$ is equal to $1008 \mathrm{in} . / \mathrm{s} / \mathrm{in}$.
} 
near $900 \mathrm{~cm} / \mathrm{s} / \mathrm{cm}, \Delta y=1.8 \mathrm{~cm}$. However, rainbow trout subjected to rates of strain of $688 \mathrm{~cm} / \mathrm{s} / \mathrm{cm}$, $\Delta y=1.8 \mathrm{~cm}$ were more susceptible to predation than control fish in the same test.

Development of advanced, fish friendly turbines requires knowledge of the physical forces that impact entrained fish and quantitative descriptions of the intensity of these forces. The test data reported here provide quantified strain rates and the relationship of these forces to direct and indirect biological effects on fish. We conclude that juvenile salmonids and American shad should survive shear environments where strain rates do not exceed $500 \mathrm{~cm} / \mathrm{s} / \mathrm{cm}$ at a $\Delta y$ of $1.8 \mathrm{~cm}$. Additional studies are planned with a sensor fish to better link hydraulic conditions found within the laboratory and field environments. 


\section{Acknowledgments}

We thank many people for their contributions to the results reported here, particularly Peggy Brookshier, Chair of the U.S. Department of Energy Advanced Turbine System Program, for her leadership and support. We also thank John Flynn, U.S. Department of Energy and Ben Rinehart and Garold Sommers of the Idaho National Engineering and Environmental Laboratory for their active participation and support. We thank Mike Sale of the Oak Ridge National Laboratory; Bill Christman, Larry Moore, Steve Brown, Steve Doret, Paul Willis, Lee Sheldon, Steve Wenke, Tom Murphy, Paul Bernhardt, John Ferguson, Ed Meyer, Mufeed Odeh, Charles Liston, Si Whitman, Peter Christensen, and Doug Dixon of the Technical Committee of the U.S. Department of Energy's Advanced Hydropower Turbine System Program; and Thomas Carlson, Geoffrey McMichael, and Brett Amidan of Pacific Northwest National Laboratory. These individuals provided comments and advice during the development of the methods and protocols used to accomplish this work and reviewed draft reports.

The work was conducted at the Pacific Northwest National Laboratory (PNNL) in Richland, Washington. PNNL is managed by Battelle Memorial Institute for the U.S. Department of Energy. The work was conducted under a Related Services Agreement with the U.S. Department of Energy, Contract DE-AC06-76RLO 1830. 


\section{Contents}

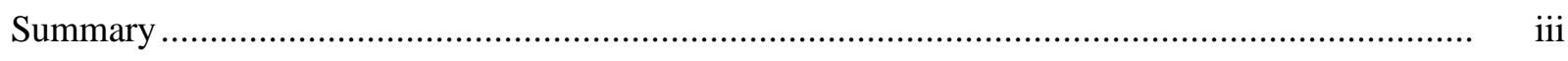

Acknowledgments ................................................................................................. vii

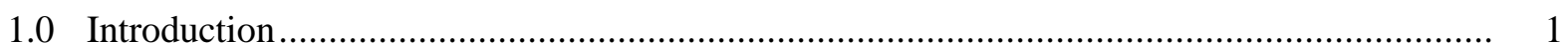

$2.0 \quad$ Shear Stress and Turbulence Terminology ............................................................ 3

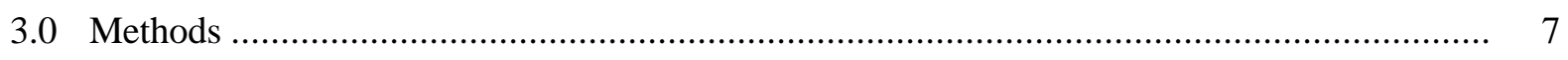

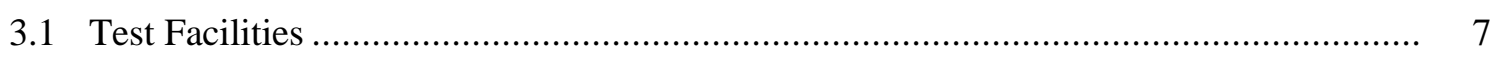

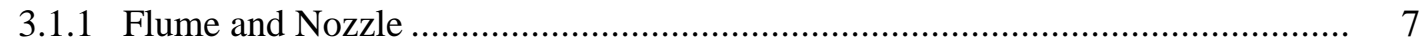

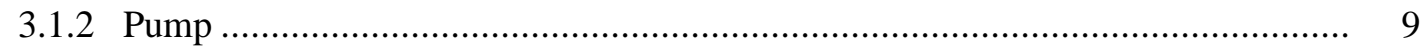

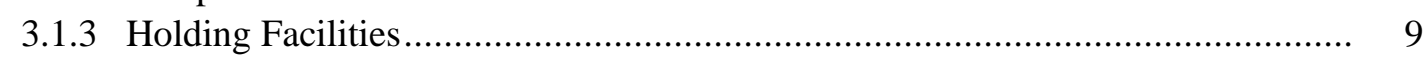

3.2 Hydraulic Characterization of the Jet Used to Generate Shear Exposure ....................... 9

3.2.1 Methods and Equipment...................................................................... 10

3.2.2 Mean-Velocity Measurements - Pitot Tube ................................................... 10

3.2.3 Velocity Measurements - Laser Doppler Velocimeter ................................... 11

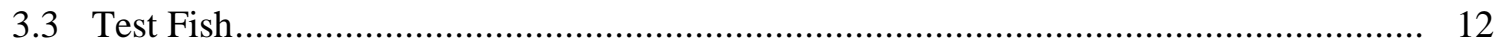

3.3.1 Handling and Maintenance of Test Fish..................................................... 14

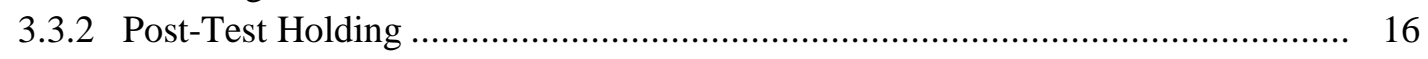

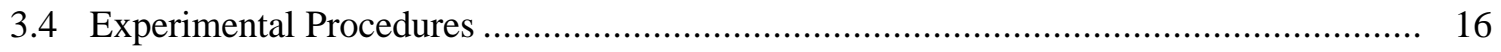

3.4.1 Characterization of Direct Injury and Mortality ......................................... 18

3.4.2 Indirect Mortality (Predation) Tests ............................................................... 19

3.4.3 High-Speed Video System............................................................................ 19

3.4.4 Recording the Paths of Fish in the Jet Plume .............................................. 19

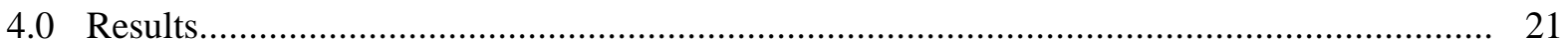

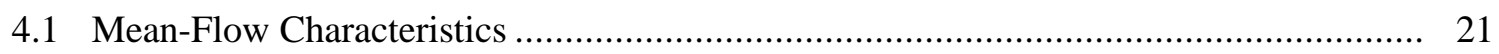

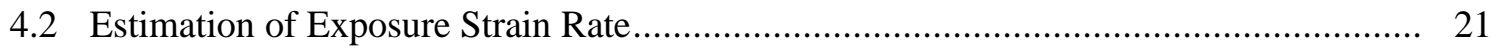

4.3 Turbulence Characteristics............................................................................... 23

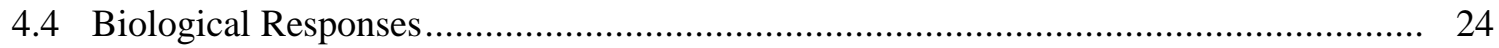

4.4.1 Direct Injury and Mortality .................................................................. 28

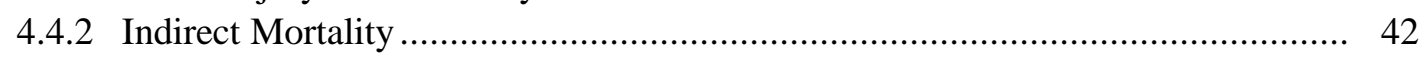




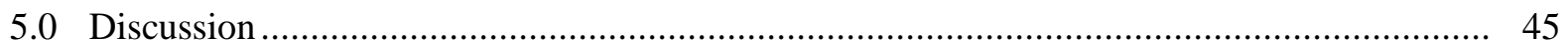

5.1 Natural Shear Environments and Those Associated with Hydroelectric Power ............. 45

5.2 Strain Rate and Shear Stress at Hydroelectric Power Plants .................................... 46

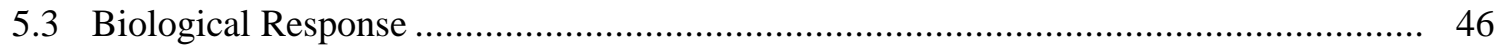

5.4 Comparison to Previous Studies................................................................... 48

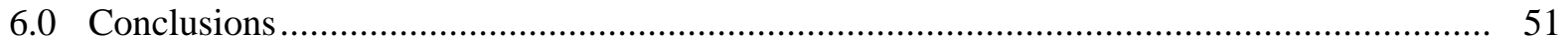

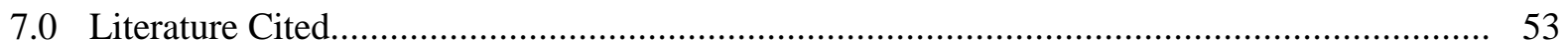

Appendix A: Shear and Turbulence Descriptions …............................................................ A.1

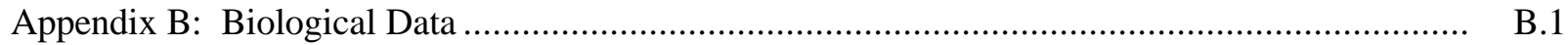

Appendix C: Kinematic Profiles and Video Data.......................................................... C.1

Appendix D: Pitot Tube Data and Plots............................................................................ D. 1

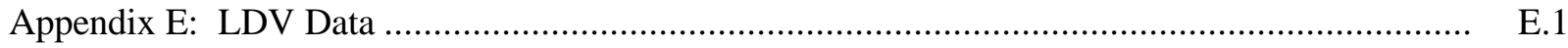




\section{Figures}

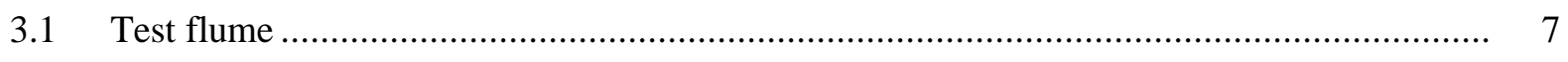

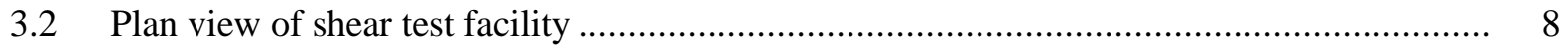

3.3 Placement of deployment tube in relation to the $6.35-\mathrm{cm}$ nozzle ..................................... 8

3.4 Gantry used to collect velocity measurements in the test facility ................................ 10

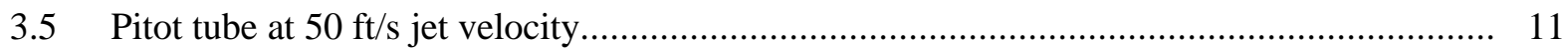

3.6 Photograph of nozzle, mounting shaft, and laser beams......................................... 12

3.7 Schematic of nozzle showing coordinate system ................................................... 13

3.8 Transfer cartridge used to capture test fish before being subjected

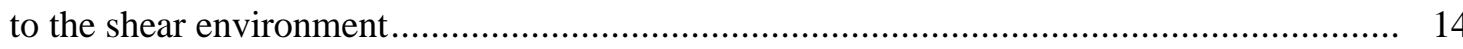

3.9 Fish release method just before entering the shear environment...................................... 14

3.10 Test apparatus used to deploy fish during the fast-fish-to-slow-water tests ...................... 15

3.11 Rainbow trout before entering nozzle during a fast-fish-to-slow-water test ...................... 16

3.12 Digitized images of American shad showing their position and

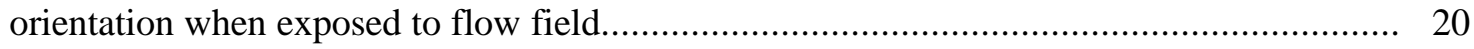

4.1 Comparison of nondimensional centerline jet velocity data with previous investigations reported in Fischer et al. (1979) .......................................................... 22

4.2 Diagram of shear layers as measured at a velocity of $60 \mathrm{ft} / \mathrm{s}$ showing both near and far location of deployment tube .................................................................... 23

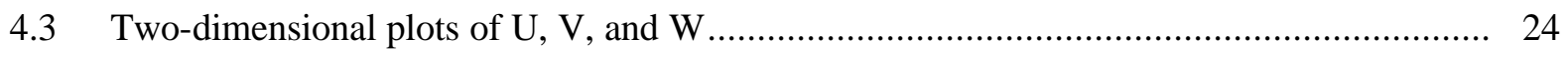

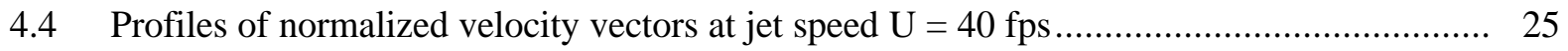

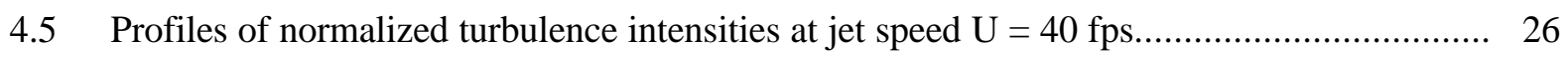

4.6 Profiles of TKE, LAMSHEAR, and TURBSHEAR at jet speed $U=40 \mathrm{fps} \ldots \ldots \ldots \ldots \ldots \ldots \ldots . . . . . . . . . .27$ 
4.7 Profiles of normalized axial and vertical velocities, turbulence fluctuations, and

Reynolds stresses for jet speed $U=10$ fps plotted with data from Sami et al. (1967)

4.8 Steelhead smolt introduced headfirst to a jet with a strain rate of $852 \mathrm{~cm} / \mathrm{s} / \mathrm{cm}$, $\Delta \mathrm{y}=1.8 \mathrm{~cm}$

4.9 Juvenile fall chinook salmon injuries resulting from headfirst exposure to a jet with a strain rate of $1008 \mathrm{~cm} / \mathrm{s} / \mathrm{cm}, \Delta \mathrm{y}=1.8 \mathrm{~cm}$

4.10 Percentage of age- 0 fall chinook salmon injured or killed during headfirst exposure to a jet with different strain rates

4.11 Percentage of age-1 fall chinook salmon injured or killed during headfirst exposure to a jet with different strain rates

4.12 Percentage of spring chinook salmon smolts injured or killed during headfirst exposure to different strain rates

4.13 Percentage of juvenile rainbow trout injured or killed during headfirst exposure to different strain rates

4.14 Percentage of steelhead smolts injured or killed during headfirst exposure to different strain rates

4.15 Percentage of American shad injured or killed during headfirst exposure to different strain rates

4.16 Percentage of age-1 fall chinook salmon injured or killed during tailfirst exposure to different strain rates

4.17 Percentage of spring chinook salmon smolts injured or killed during tailfirst exposure to different strain rates

4.18 Percentage of steelhead smolts injured or killed during tailfirst exposure to different strain rates

4.19 Percentage of rainbow trout injured or killed during fast-fish-to-slow-water exposure to shear stresses of different intensities

4.20 Example of rainbow trout bruising immediately after exposure to a rate of strain of $1150 \mathrm{~cm} / \mathrm{s} / \mathrm{cm}$ during a fast-fish-to-slow-water test

4.21 Digitized image of rainbow trout illustrating opercal flare upon exiting the nozzle during a fast-fish-to-slow-water test. 
4.22 Percentage of injured control and strain rate exposed juvenile rainbow trout for 10 test runs.

4.23 Percentage of injured control and exposed juvenile rainbow trout for 8 test runs

4.24 Percentage of juvenile rainbow trout injured or killed during headfirst exposure to different strain rates.

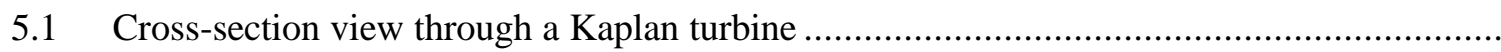




\section{Tables}

S.1 Summary of the strain rate exposures that did not injure or kill fish

iv

3.1 Fish species used for tests

4.1 Comparison of injuries to fall chinook salmon (age-1) from two deployment distances from the jet that produced shear stress in the test facility.....

4.2 Proportions and P-values for Chi-square proportion tests performed on the effects of headfirst strain rate exposure on injury and death in age-0 fall chinook salmon

4.3 Proportions and P-values for Chi-square proportion tests performed on the effects of headfirst strain rate exposure on injury and death in age- 1 fall chinook salmon

4.4 Proportions and P-values for Chi-square proportion tests performed on the effects of headfirst strain rate exposure on injury and death in spring chinook salmon smolts

4.5 Proportions and P-values for Chi-square proportion tests performed on the effects of headfirst strain rate exposure on injury and death in juvenile rainbow trout

4.6 Proportions and P-values for Chi-square proportion tests performed on the effects of headfirst strain rate exposure on injury and death in steelhead smolts

4.7 Proportions and P-values for Chi-square proportion tests performed on the effects of headfirst strain rate exposure on injury and death in American shad

4.8 Proportions and P-values for Chi-square proportion tests performed on the effects of tailfirst strain rate exposure on injury and death in fall chinook salmon

4.9 Proportions and P-values for Chi-square proportion tests performed on the effects of tailfirst strain rate exposure on injury and death in spring chinook salmon smolts.

4.10 Proportions and P-values for Chi-square proportion tests performed on the effects of tailfirst strain rate exposure on injury and death in steelhead smolts

4.11 Proportions and P-values for Chi-square proportion tests performed on the effects of shear stress exposure on injury and death in rainbow trout exposed during fast-fish-to-slowwater tests

4.12 Analysis of variance results for predator challenge tests with juvenile rainbow trout that were exposed to a strain rate of $688 \mathrm{~cm} / \mathrm{s} / \mathrm{cm}(\Delta y=1.8 \mathrm{~cm})$ 
4.13 Analysis of variance results for predator challenge tests with juvenile rainbow trout that were exposed to a strain rate of $517 \mathrm{~cm} / \mathrm{s} / \mathrm{cm}(\Delta y=1.8 \mathrm{~cm})$

5.1 Published estimates of shear stress in natural and man-altered aquatic environments .......... 45

5.2 Estimated probabilities of ranges of shear stress in the draft tube of a bulb turbine ............. 46

5.3 Description of turbine environment and expected shear and turbulence strains to be encountered by a fish passing through a turbine ........................................................ 48

5.4 Summary of the strain rate exposures from our tests that did not injure or kill fish ............. 49

5.5 Comparison of jet exit velocities and estimated strain rates for PNNL study and our estimates of strain rate applied in four other fish/shear studies. 


\subsection{Introduction}

Of the many environmental issues facing the hydropower industry today, turbine passage mortality of fish remains one of the most difficult to resolve (Ñada et al. 1997; USACE 1995). It is well established that the physical stresses associated with turbine passage (pressure changes, shear and turbulence, striking the turbine blade or other mechanical structures) can cause injury or mortality. For example, turbine passage is estimated to kill 5\% of entrained fish in the best existing turbines (RMC and Skalski 1995), and mortality may exceed $30 \%$ in other designs (Bell 1981). A wide variety of downstream passage and protection measures have been used to prevent fish from becoming entrained, ranging from spill flows to pass fish over the dam to complicated physical screening and light- or sound-based guidance measures. However, no downstream passage/protection system has yet been demonstrated to be biologically effective, practical to install and operate, and acceptable to regulatory agencies under a wide range of site conditions. Even well-designed screening and bypass systems may protect only a portion of the fish susceptible to entrainment; the remainder will pass around the screens and through the turbines. Consequently, it is also desirable to maximize the survival of turbine-passed fish.

The U.S. Department of Energy (DOE), through its Advanced Hydropower Turbine System (AHTS) program, supports development of "fish friendly" turbines, i.e., turbine systems in which environmental attributes such as entrainment survival are emphasized (Brookshier et al. 1995). Advanced turbines would be suitable for installation at new hydropower facilities and for replacing aging turbines at existing plants. It is expected that fish friendly turbines could permit the efficient generation of electricity while minimizing damage to fish and their habitats.

Development of fish friendly hydroelectric turbines requires knowledge of the physical forces (injury mechanisms) that impact entrained fish and the fish's tolerance of these forces. It requires up-front, predesign specifications for the environmental conditions that occur within the turbine system; in other words, determining or assuming conditions known to injure fish will assist engineers in the design of a fish friendly turbine system. These biological specifications must be carefully and thoroughly documented throughout the design of an advanced turbine. The approach we used to address the development of biological specifications was to answer the question: "What will kill or injure a fish?" Using the methods described in this report, we attempted to replicate specific environmental conditions of the turbine environment in a laboratory setting and conducted tests to evaluate the response of fish subjected to those conditions.

Fisheries biologists and hydraulic engineers from the Idaho National Engineering Laboratory (INEEL), Oak Ridge National Laboratory (ORNL), and Pacific Northwest National Laboratory (PNNL) set up a facility at PNNL in Richland, Washington, to conduct the tests reported here. The INEEL is DOE's lead laboratory for its Hydropower Program, and ORNL is the lead laboratory for environmental research on hydropower-related issues. Since 1978, the Environmental Sciences Division at ORNL has provided technical assistance to DOE and conducted research on the environmental effects of hydropower development. During 1996-97, ORNL continued its environmental research on major issues critic al to development, concentrating primarily on DOE's Advanced Hydropower Turbine System. 
The purpose of tests we conducted was to specify an index describing the hydraulic force that fish experience when subjected to a shear environment. To determine the response of fish to the types and magnitudes of fluid stresses experienced during turbine passage, a series of six related tasks were described. The tasks were to

1. define and estimate (quantify) the fluid environment of a hydroelectric turbine

2. define non-engineering test components and priorities to conduct the shear and turbulence tests

3. design and construct a facility to measure velocities in a submerged water jet

4. observe fish subjected to the shear environment at the edge of the water jet

5. quantify the biological responses of the test fish

6. relate the biological responses to exposure history and turbulence-time exposure history.

This report describes the results of laboratory experiments that tested the response of fish subjected to a shear environment. Specifically, it quantifies and assesses the significance of potential injury mechanisms resulting from a defined subset of hydraulic forces. An earlier report by Neitzel et al. (1998) provided details on the first three tasks. The report contains seven sections and five appendices. Section 2.0 describes some terminology used in the report. Section 3.0 describes methods used to measure velocities in the test facility and conduct the fisheries tests. Section 4.0 describes results of the tests. Section 5.0 discusses shear environments in nature and in turbines and the biological responses of the test fish to a shear environment, and compares data collected during this study with previous studies. Conclusions are provided in Section 6.0, and references cited in Section 7.0. Appendix A discusses and lists shear and turbulence equations used in this report and in other hydraulic texts to describe fluid dynamics. Appendix B includes a comprehensive listing of the biological data collected during these tests. Appendix $\mathrm{C}$ includes examples of the kinematic profiles and video data collected during these tests. Appendix D includes the Pitot tube data collected during the tests. Appendix E includes a summary of the Laser Doppler Velocimeter (LDV) data collected during the tests. 


\subsection{Shear Stress and Turbulence Terminology}

The fluid forces of interest in this report, i.e., strain rate, shear stress, and turbulence, are fundamental expressions of changes in water velocity. Velocity (u) is measured in distance (y) per unit time, e.g., $\mathrm{cm} / \mathrm{s}$. Water velocity is important for transporting organisms or their food and for creating aquatic habitats. Uniform velocities typically present in a stream or artificial conduit do not harm fish. For example, a fish moving $0.3 \mathrm{~m} / \mathrm{s}$ or $30 \mathrm{~m} / \mathrm{s}(\sim 1.0$ or $\sim 100 \mathrm{fps})$ will not be injured or disoriented if velocities of the water mass in which the fish is traveling are relatively uniform. However, when water velocities change abruptly at measurement scales comparable to the size of a fish, shear stress and turbulence forces can cause damage to aquatic organisms.

An organism that passes between two adjacent (or intersecting) water masses of different velocities experiences a change in velocity with distance. A number of terms have been used in the literature to describe this change in fluid velocity over distance, including shear, strain rate, rate of deformation, rate of fluid deformation, and rate of fluid strain deformation. For simplicity, this report refers to the change in water velocity (u) over distance (y) as strain rate (Equation 1).

$$
\text { Exposure Strain Rate }=e=\frac{\partial \bar{u}}{\partial y}
$$

Units for quantifying strain rate are $\mathrm{cm} / \mathrm{s} / \mathrm{cm}$, which simplifies to $1 / \mathrm{s}$. However, to emphasize the change of velocity over distance, we express strain rate in the expanded form of $\mathrm{cm} / \mathrm{s} / \mathrm{cm}$. For example, if velocities of two adjacent water masses differed by $60 \mathrm{~cm} / \mathrm{s}(23.6 \mathrm{in} . / \mathrm{s})$ over a distance of $2 \mathrm{~cm}(0.79 \mathrm{in}$.), the resultant strain rate would be $30 \mathrm{~cm} / \mathrm{s} / \mathrm{cm}$. If there were no resistance to flow (no viscosity), a fish would just spin freely in response to the different velocities. The fish would probably not experience any injury (other than disorientation). However, since the water in which the fish is traveling has viscosity, force is exerted on the fish because of encountering a mass of water moving at different velocities. Depending on its magnitude, this force may be harmful or inconsequential. Defining force, mathematically or with prose, is essential to understanding communications related to biological specifications.

Force is defined as mass multiplied by acceleration and is expressed in Newtons (N). For a fish striking a wall, the force would be the mass of the fish multiplied by the deceleration. A large fish rapidly decelerating, upon hitting a solid object, from $10 \mathrm{~m} / \mathrm{s}$ to $0 \mathrm{~m} / \mathrm{s}$ (32.8 fps to $0 \mathrm{fps}$ ) would experience more force than would a small fish. This same relationship is true if, instead of a solid object, the fish encounters another water mass of different velocity. Important factors that govern the effect of force are size of the fish, life stage, and the way in which the fish strikes the wall or water mass. This last factor leads to a consideration of pressure. Pressure is force per unit area, applied perpendicular to the body surface, expressed in $\mathrm{N} / \mathrm{m}^{2}$. If the force (fish's mass multiplied by acceleration) of striking a solid object is focused on one small point (eyeball), there would be much greater pressure and injury than if an entire side of a fish's body strikes the object. Again, this same relationship is true if, instead of a solid object, a fish strikes another water mass of different velocity. The force associated with the different water mass 
could be distributed relatively uniformly over the whole body, or it could be experienced at a point on its body. The location and amount of the fish's body upon which the forces are focused have a bearing on the resultant damage.

Shear stress, like pressure, is force per unit area. In laminar flow, it is estimated by Newton's equation (Equation 2):

$$
\tau_{\text {laminar }}=\mu \frac{\partial \overline{\mathrm{u}}}{\partial \mathrm{y}}
$$

where $\mu$ is dynamic (laminar) viscosity. Values of $\mu$ for different fluids at different temperatures may be obtained from tables (Munson et al. 1994).

The difference between pressure and shear stress is the direction in which the force is applied. In pressure, the force acts perpendicular to the surface, whereas a shear force acts parallel to it (Gordon et al. 1992). Shear stress has the same units as pressure, $N / \mathrm{m}^{2}$. Shear stress can be experienced by a fish passing between two water masses of different velocities or when a fish slides along a solid structure such as a wall or turbine blade (commonly termed abrasion). Damage from passage near a structure may occur from very high shear stress within the fluid boundary layer, even without physical contact with the solid surface. The same considerations associated with pressure also apply to shear stress, i.e., a given amount of shear force is expected to be more damaging if applied to a small area of the body than a large area.

Because of high water velocities and edge effects of structures, flows in a hydroelectric turbine are turbulent, rather than laminar. Shear stress can also be estimated for turbulent flows, but it is more complicated. For turbulent flows, Equation (2) is modified to incorporate another term, eddy viscosity $(\varepsilon)$ (Equation 3):

$$
\tau_{\text {turbulent }}=(\mu+\varepsilon)(\mathrm{du} / \mathrm{dy})
$$

Unlike $\mu$, there are no tables of values for $\varepsilon$. Eddy viscosity is dependent on how vigorous the turbulence is and must be found by experimentation. If the flow is entirely laminar, $\varepsilon$ is 0 and Equation (3) reduces to Equation (2). For fully turbulent flow, effects due to dynamic viscosity are negligible $(\mu<<$ $\varepsilon$ ), and Equation (3) reduces to Equation (4):

$$
\tau_{\text {turbulent }}=\varepsilon(\mathrm{du} / \mathrm{dy})
$$

Turbulence can also be described by the term turbulence intensity (Gordon et al. 1992). If we think of local velocity in a turbulent region as composed of a mean value plus a component that represents fluctuation about the mean, turbulence intensity is a measure of the magnitude of the turbulent fluctuations about the mean. Greater fluctuations from the mean flow equals greater turbulence intensity. If a series of instantaneous velocity measurements are made at a point, the turbulence intensity at that point can be expressed as the root mean square of these measured values.

Throughout this report, we refer to the edge of the submerged jet as a shear environment. We define the hydraulic conditions encountered by the test fish in terms of rate of strain. The units used to quantify 
strain rate are $\mathrm{cm} / \mathrm{s} / \mathrm{cm}$. The strain rate calculations were done at the spatial resolution of $1.8 \mathrm{~cm}(0.7 \mathrm{in}$. $)$ or about the minimum width of the salmonids tested. It is not equivalent to the local fluid-strain rate computed at a finer scale. For example, a decrease in velocity from $1800 \mathrm{~cm} / \mathrm{s}$ to $0 \mathrm{~cm} / \mathrm{s}$, expressed over a distance of $50 \mathrm{~cm}$, results in a strain rate of $36 \mathrm{~cm} / \mathrm{s} / \mathrm{cm}$. If that same change in velocity occurs over a distance of $4 \mathrm{~cm}$, the calculated strain rate would equal $450 \mathrm{~cm} / \mathrm{s} / \mathrm{cm}$. Thus, quantifying the strain rate experienced by a fish subjected to a shear environment is dependent on the spatial resolution or scale used. We chose one that was consistent with the measurement scale that test fish encountered during exposure. The variability in the estimated rate of strain in the test facility is described using the turbulence intensity estimates. 


\subsection{Methods}

The tests required that fish be exposed to a standard, quantified shear environment. The tests also required that a time-averaged flow environment with a large range of strain rates be generated and that it be repeatable for multiple fish exposures. A high-velocity submerged jet produced a flow environment that met these needs. A tube, set a $45^{\circ}$ angle to the edge of the jet, served as a repeatable means of subjecting fish to the same portion of the jet. To meet test requirements, the test fish were recovered immediately after tests. The test facility included high-speed video cameras to record the behavior of test fish and had instruments to measure water velocities in and near the jet.

\subsection{Test Facilities}

The test facilities and equipment are located at PNNL in Richland, Washington.

\subsubsection{Flume and Nozzle}

The test flume (Figures 3.1 and 3.2) was designed to get reproducible results and identify the effects (i.e., biological response) of the shear environment at the levels expected within hydroelectric turbines. The rectangular flume was $9 \mathrm{~m}$ long x $1.2 \mathrm{~m}$ wide $\times 1.2 \mathrm{~m}$ deep $(29.5 \mathrm{ft} \times 3.9 \mathrm{ft}$ x $3.9 \mathrm{ft})$ when filled with water. One end of the flume had a reservoir from which water was pumped to the opposite end of the flume through a submerged nozzle. An electric pump with a programmable drive was used to generate the desired flow condition. A conical stainless-steel nozzle $25.4 \mathrm{~cm}$ (10 in.) diameter constricting to a circular $6.35 \mathrm{~cm}$ ( 2.5 in.) diameter over $50.8 \mathrm{~cm}$ (20 in.) in length was bolted to a flange inside the flume. A clear polycarbonate deployment tube was fastened above the nozzle at an angle of $30^{\circ}$ (Figure 3.3). The terminus of the deployment tube was just above the terminus of the nozzle with a 1-cm ( 0.4-in.) separation. Viewing windows were located on the side and bottom at the nozzle end of the flume to facilitate recording fish reactions as they were subjected to test flow fields.

The jet (Figure 3.3) had a 25.4-cm (10-in.) diameter base and a 6.4-cm (2.5-in.) exit diameter. This provided a contraction ratio of 5:1, accelerated the flow, and reduced non-uniformity in the inlet velocity

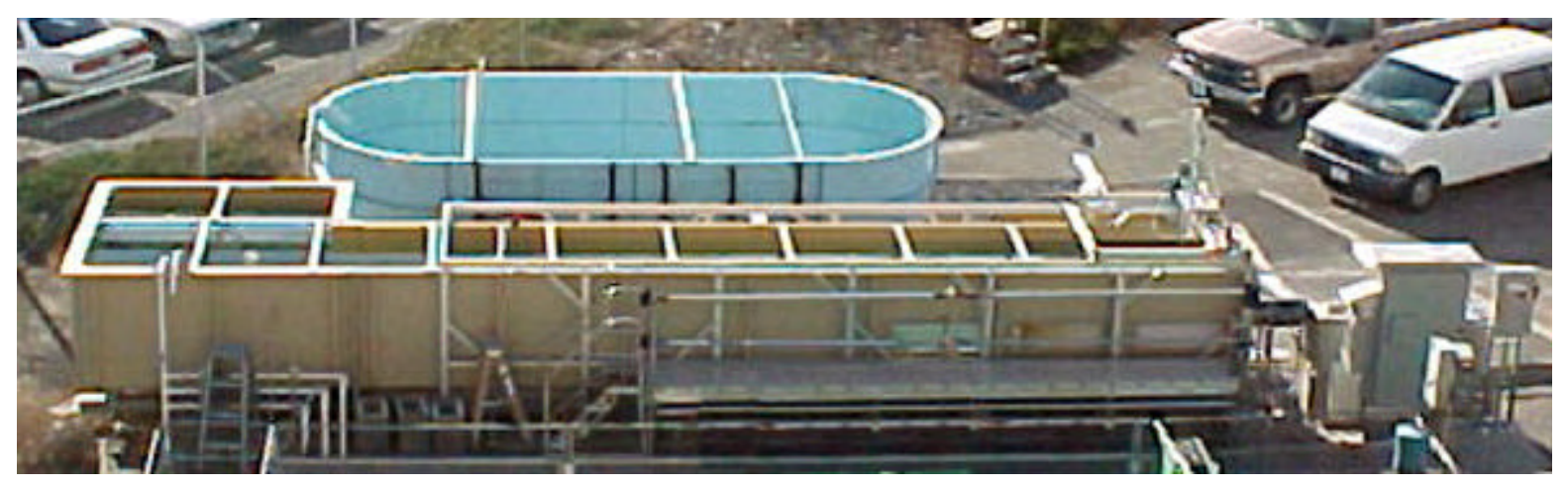

Figure 3.1. Test flume (shown in foreground). 


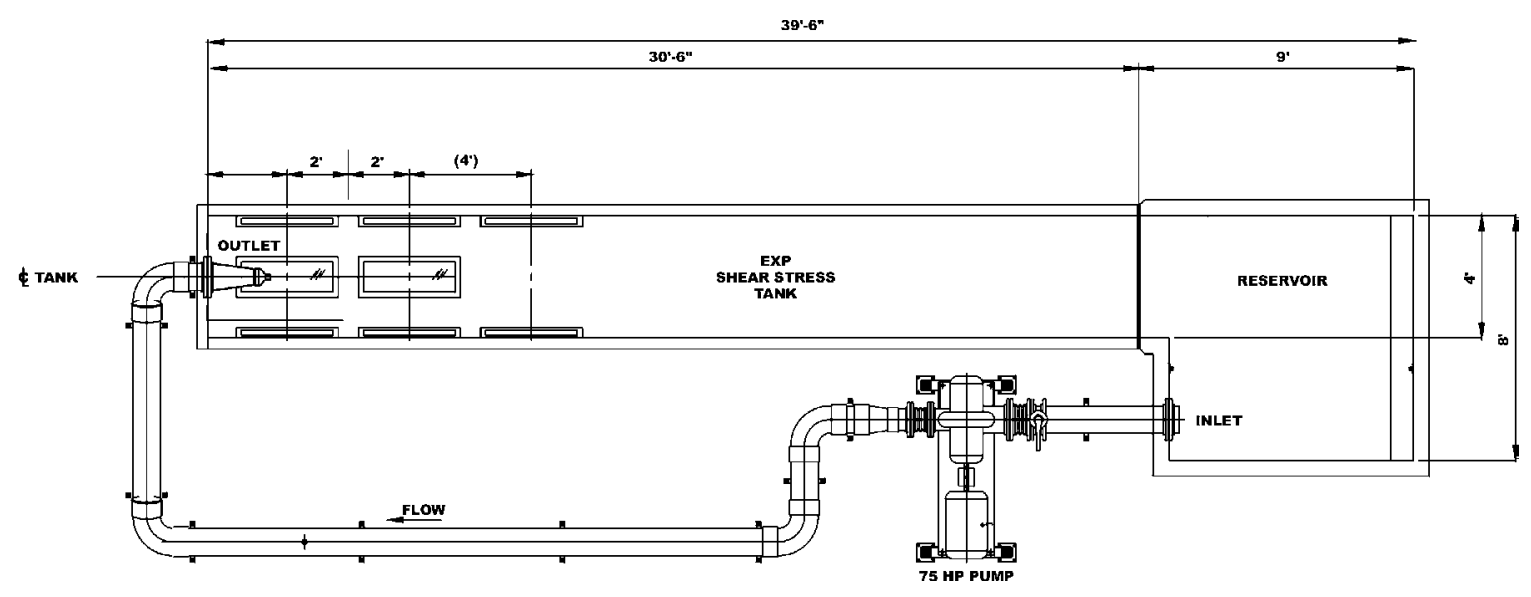

Figure 3.2. Plan view of shear test facility.

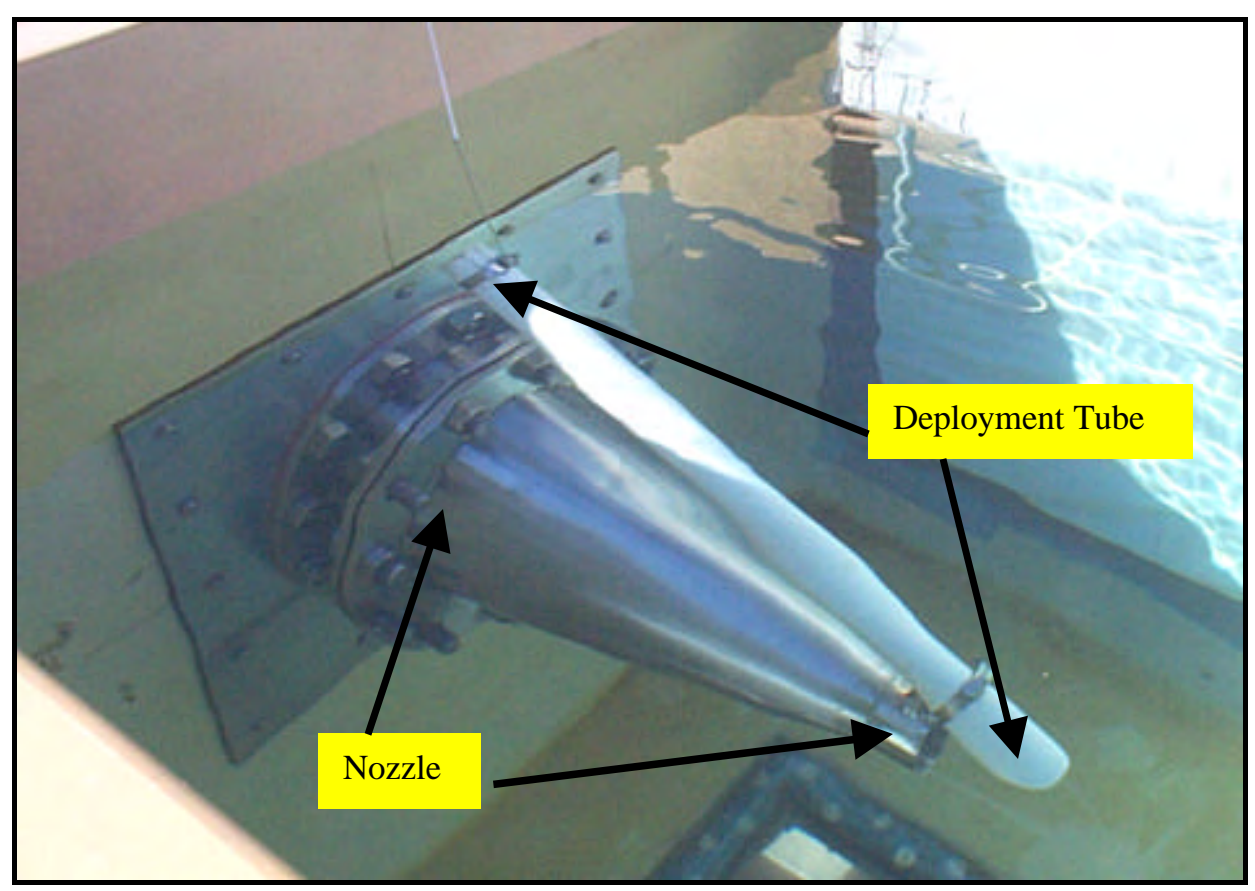

Figure 3.3. Placement of deployment tube in relation to the $6.35-\mathrm{cm}$ nozzle.

distribution. Flow conditioning devices such as honeycomb or screens to reduce inlet turbulence were not used upstream of the jet exit because fish exposure was at the edge of the jet. The jet exit was submerged under about $0.61 \mathrm{~m}(2 \mathrm{ft})$ of water during all tests. Fish were introduced immediately above the jet stream and in front of the nozzle through a Plexiglas deployment tube. 


\subsubsection{Pump}

An ITT model 150 electric pump controlled by a BALDOR Adjustable Speed Drive, ID15H460$\mathrm{EO}^{\mathrm{TM} 3}$ variable-speed motor drive was used to circulate water through the flume. The system was capable of pumping up to $9464 \mathrm{~L} / \mathrm{m}(2500 \mathrm{gpm})$ of water through a nozzle. With this volume, we created exit velocities in excess of $20 \mathrm{~m} / \mathrm{s}$ (70 fps), the velocity required to produce the shear environment desired for our tests. Water was pumped through a 25.4-cm (10-in.) PVC pipe. An in-line flow meter (Polysonics Model 2100) was used during preliminary setup to indicate flow. The motor control was adjusted to achieve the desired velocity at the exit of the nozzle. A relationship between pump volume and controller settings was developed. The relationship was confirmed and fine-tuned using Pitot tube measurements at the exit of the nozzle. A remote keypad was used to program the operating frequency $(\mathrm{Hz})$ to achieve the desired velocity at the nozzle. The pump, controller, and flume were designed to create conditions simulating the shear environment that may occur within a hydroelectric turbine.

\subsubsection{Holding Facilities}

Existing facilities at the PNNL wet lab facility were used for general rearing and acclimation. The same temperature and water type (conditioned river and well water) were used for pre- and post-test holding conditions. Test fish were held in circular tanks or troughs at test temperature for at least 7 days before testing. Post-exposure holding for delayed mortality or other effects involved use of existing ponds and troughs.

\subsection{Hydraulic Characterization of the Jet Used to Generate Shear Exposure}

Jets are a fundamental example of a free shear flow (not dominated by boundary effects) and have been the subject of numerous studies over the past century. Discussions of the basic mechanics of jets are contained in many textbooks, Daily and Harleman (1966) for example, and journal articles such as the classic paper on the subject by Albertson et al. (1950). The flow regimes in a jet are divided into the zone of flow establishment and the zone of established flow. The zone of flow establishment is characterized by a centerline velocity maximum that is equal to the jet exit velocity. For round jets, the zone of flow establishment extends approximately 6 to 7 diameters downstream of the exit. The zone of flow establishment has the highest velocity gradients and, consequently, shear environments. In the zone of flow establishment, these are located near the radial edge of the jet. In the zone of established flow, the jet centerline velocity decreases linearly with distance from the exit, and the jet continues to increase in width by entraining ambient fluid. Shear in this zone is smaller than in the initial zone of flow establishment. Fischer et al. (1979) provide additional details on the basic properties of turbulent jets.

Although the basic features of turbulent jets are well known, velocity measurements in the current test apparatus were needed to characterize the shear environment to which fish were exposed. Mean flow velocity distribution, using a Pitot tube, was the primary information used to describe the shear environment produced by the jet. Additional information to characterize the turbulent or fluctuating velocity

\footnotetext{
${ }^{3}$ Baldor Electric Company, Fort Smith, Arkansas.
} 
field was measured using an LDV. All velocity measurements were focused on the zone of flow establishment where fish were exposed to the most severe and least variable shear environment.

\subsubsection{Methods and Equipment}

Velocity measurements were acquired in the test flume for each exit velocity using a standard Pitot tube and an LDV in the test flume (see Figures 3.1-3.3). The Pitot tube provides only mean velocity information in the axial direction. In contrast, the LDV measures velocity fluctuations in three directions, and thus, provides information about quantities such as turbulence intensities and Reynolds stresses (Daily and Harleman 1966). The instruments used to measure the fluid velocity were positioned and traversed in the flume using a 3-axis step motor gantry that was installed above the test facility (Figure 3.4). This consisted of a Compumotor ${ }^{\mathrm{TM}}$ AT640 AT6400 ${ }^{4}$ step and direction controller and three ZETA $4{ }^{\mathrm{TM}}$ step-motor drives. This system was capable of positioning the instruments with submillimeter accuracy.

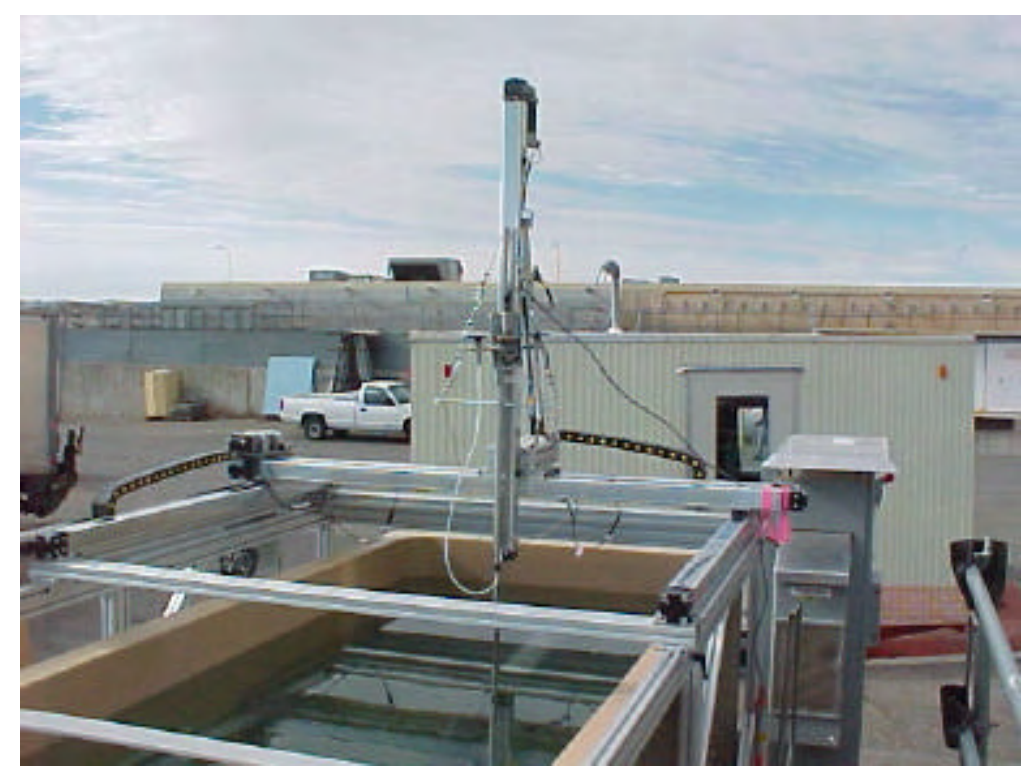

Figure 3.4. Gantry used to collect velocity measurements in the test facility.

\subsubsection{Mean-Velocity Measurements - Pitot Tube}

Mean-velocity measurements were taken using a heavy duty Pitot tube ${ }^{5}$ (Figure 3.5) that was connected to a pressure differential sensor, Viatran ${ }^{\mathrm{TM}}$ Model $274 .{ }^{6}$ The pressure sensor was connected to a Personal Daq $/ 56^{\mathrm{TM}}$ data logger, ${ }^{7}$ which was connected to a computer. The pressure sensor was factory calibrated. Eighteen samples were averaged for each location. The measurements in the zone of flow establishment were taken on a 1-mm (0.04-in.) grid that covered a radial slice that extended 1.5 diameters

\footnotetext{
${ }^{4}$ Compumotor Division of Parker Hannifin Corporation: Rohnert Park, California, USA.

${ }^{5}$ United Sensor Corporation Pitot tube, model PBC-24-G-22-KL ${ }^{\mathrm{TM}}$ : Amherst, New Hampshire, USA.

${ }^{6}$ Viatran Corporation: Grand Island, New York, USA.

${ }^{7}$ Iotech, Incorporated: Cleveland, Ohio, USA.
} 


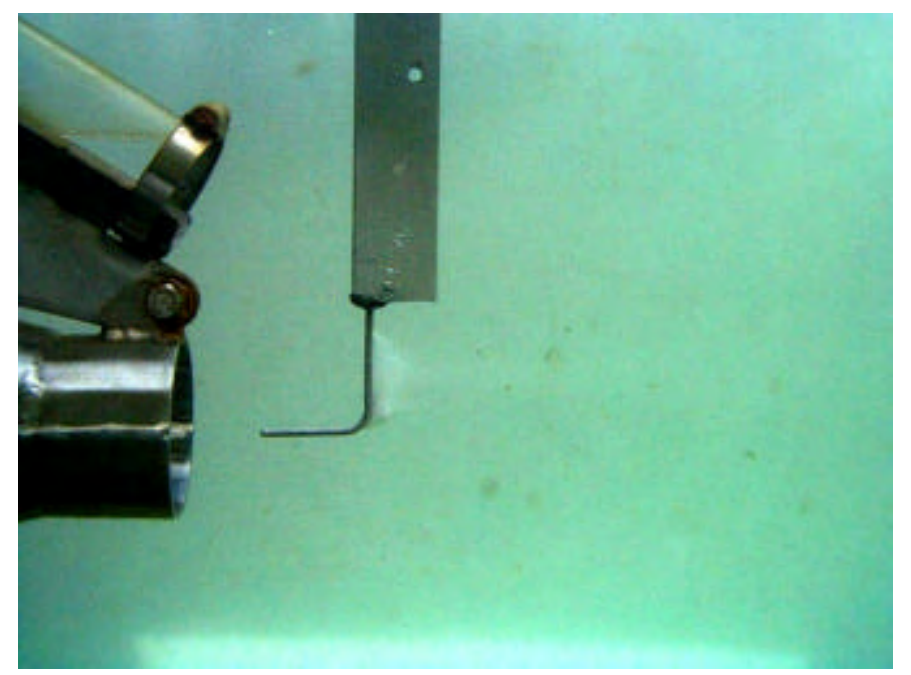

Figure 3.5. Pitot tube at $50 \mathrm{ft} / \mathrm{s}$ jet velocity. (Note: this photograph shows an early version of the fish introduction tube.)

in the radial direction and 3 diameters downstream of the jet exit. Additional details about the Pitot tube measurement grid are provided in the velocity measurements appendix.

Data collection software was written in LabView. ${ }^{\text {TM8 }}$ This program moved the traverse and recorded the data (traverse coordinates plus the pressure sensor voltage). An off-line analysis program was written in Visual Basic ${ }^{\mathrm{TM} 9}$ that performed the voltage-to-velocity calculations and output to a Tecplot ${ }^{\mathrm{TM} 10}$ readable format. Tecplot ${ }^{\mathrm{TM}}$ was used to generate contour plots of the velocity profiles.

Velocity measurements were made using the Pitot tube with and without the fish introduction tube mounted in the test facility. The separate sets of measurements showed that the tube had a negligible effect on the axial velocity, although the presence of the tube would prevent the jet from entraining fluid in that location.

\subsubsection{Velocity Measurements - Laser Doppler Velocimeter}

Velocity measurements were made using a two-component Dantec LDV. Figure 3.6 shows an underwater picture of the probe mounted vertically with the laser beams and nozzle. The probe was mounted on the same $x-y-z$ traverse as the Pitot tube (Figure 3.7). The 27-mm- (1.1-in.-) diameter LDV probe was submersible with a focal length of $198 \mathrm{~mm}(7.8 \mathrm{in}$.). The probe was connected to the 1-watt Argon laser and optics systems by a $20-\mathrm{m}$ (65.6-ft) fiber optic cable. Data collection and signal processing were performed using the standard hardware and software provided by Dantec.

\footnotetext{
${ }^{8}$ National Instruments Corporation: Austin, Texas, USA.

${ }^{9}$ Microsoft Corporation: Redmond, Washington, USA.

${ }^{10}$ Amtec Engineering, Incorporated: Bellevue, Washington, USA.
} 


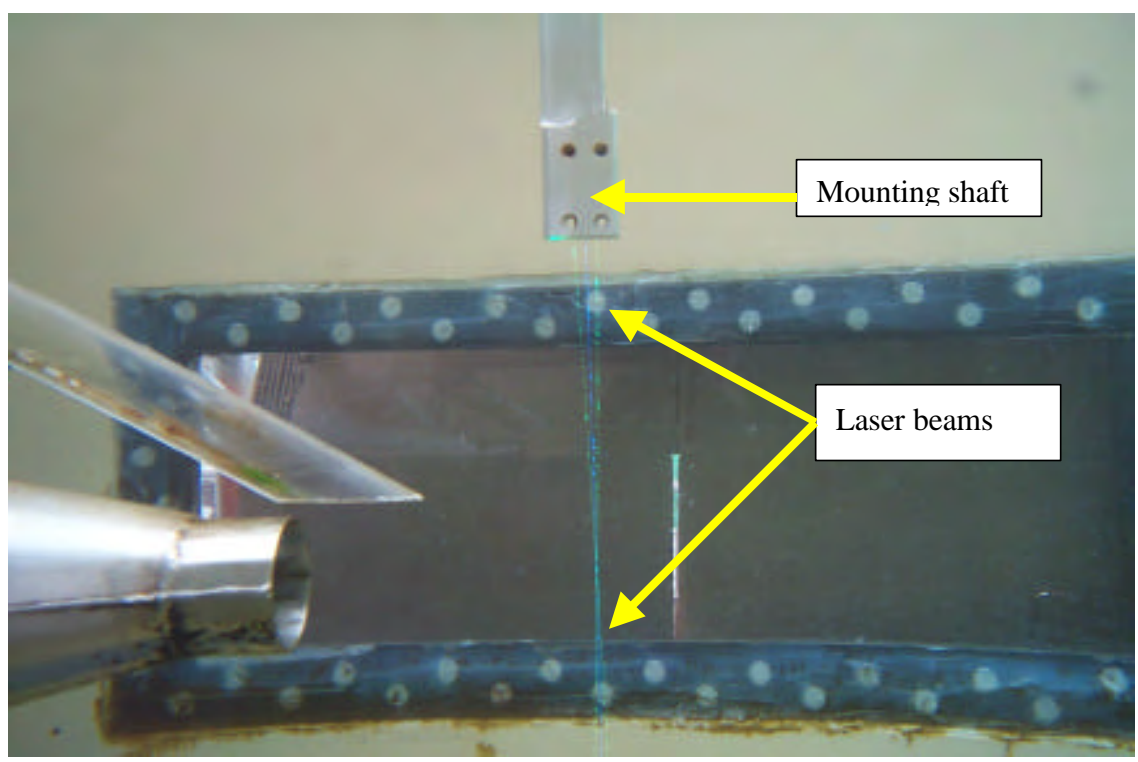

Figure 3.6. Photograph of nozzle, mounting shaft, and laser beams.

Because the LDV could measure only two velocity components at a time, it was necessary to collect data with two probe orientations to obtain three-dimensional $(\mathrm{u}, \mathrm{v}, \mathrm{w})$ data. The probe was first positioned horizontally to obtain the downstream or axial velocities (u) in the $\mathrm{z}$ direction and the vertical radial (w) velocities in the y direction (Figure 3.7 [top]). Once these velocities were measured for each exit velocity, the probe was reoriented vertically to measure the axial velocity (u) and the lateral velocity (v) in the x direction (Figure 3.7 [bottom]). Note that the lateral (v) velocity is not a radial component.

For each LDV probe orientation, two-dimensional velocity data were collected on a vertical radian from the center of the jet out to 1 diameter (or 0.5 diameter beyond the edge of jet). The sample spacing used was $1 \mathrm{~mm}$, and at each point, velocity measurements were made until either 2000 samples were collected or a total time of $30 \mathrm{~s}$ elapsed, whichever occurred first. If 2000 measurements were not recorded within $30 \mathrm{~s}$, as was the case for near-zero velocity regions, the LDV would then move to the next point. The 30-s cut-off value was selected to allow measurements over the entire sampling volume to be completed in a reasonable time.

\subsection{Test Fish}

Species selected for testing included rainbow trout, Oncorhynchus mykiss, spring and fall chinook salmon, O. tshawytscha, American shad, Alosa sapidissima, and steelhead, O. mykiss. Fall chinook stocks originated from Priest Rapids Hatchery. Spring chinook stocks were obtained from Leavenworth National Fish Hatchery. Steelhead (Skamania strain) were obtained from Beaver Creek Hatchery. American shad were obtained from the naturally emigrating run at McNary Dam, and rainbow trout were raised at the PNNL facility. Fish size ranged from 8.5 to $21 \mathrm{~cm}$ (Table 3.1). Test fish were all in good-toexcellent condition (i.e., minimal scale loss) and were selected to get a broad representation of the natural outmigrating stocks present in the Columbia River Basin. An effort was made to test the fish during their smoltification life stage, with the exception of hatchery-reared rainbow trout. 


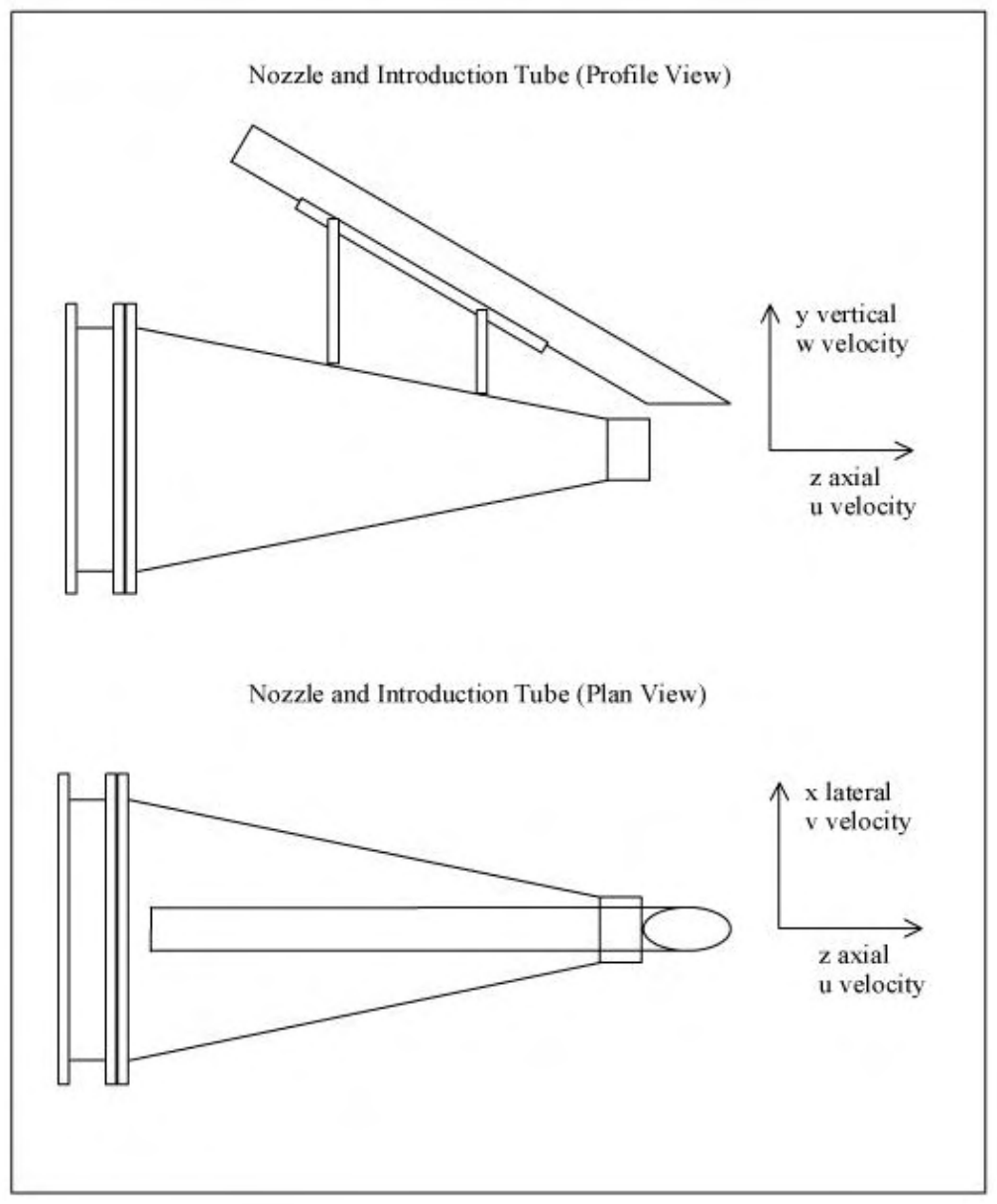

Figure 3.7. Schematic of nozzle showing coordinate system.

Table 3.1. Fish species used for tests.

\begin{tabular}{|l|l|c|l||}
\hline \multicolumn{1}{|c|}{ Species } & \multicolumn{1}{c|}{ Life Stage } & \multicolumn{1}{c|}{$\begin{array}{c}\text { Fork Length } \\
\text { (mean, cm) }\end{array}$} & \multicolumn{1}{|c|}{$\begin{array}{c}\text { Orientation to Water } \\
\text { Jet }\end{array}$} \\
\hline \hline Fall chinook & smolt & 14 & headfirst, tailfirst \\
\hline Fall chinook & pre smolt & 8.5 & headfirst \\
\hline Spring chinook & smolt & 14.5 & headfirst, tailfirst \\
\hline Steelhead & smolt & 21.5 & headfirst, tailfirst \\
\hline Rainbow trout & yearling & 15.5 & headfirst \\
\hline American shad & yearling & 10 & headfirst \\
\hline
\end{tabular}




\subsubsection{Handling and Maintenance of Test Fish}

\section{Slow Fish to Fast Water}

A holding/acclimation trough was installed near the test facility. Test stocks were maintained at low densities and with a high water turnover rate to maintain optimal water quality conditions during holding and acclimation periods. Test fish were loaded into the exposure system without removing them from water. They were randomly captured from the holding trough using a small section of clear tubing (cartridge) containing a small volume of water (Figure 3.8). Each fish was then transferred to the deployment tube where it would swim down the tube and exit into the flow field of the nozzle (headfirst deployment). The fish readily passed down the introduction tube and into the flow field within a few seconds. The same procedure was used for the tailfirst test series. Freeze branding with liquid nitrogen was used to differentiate control and test fish in the predation tests.

Once a fish was loaded into the cartridge, the pump was activated and allowed to reach the required test velocity condition. During this time $(\sim 5 \mathrm{~s})$, the fish was resting in the cartridge. The exposure began when the fish was allowed to swim from the cartridge into the deployment tube and into the shear environment (Figure 3.9). The pump speed was randomly determined for each test group series.

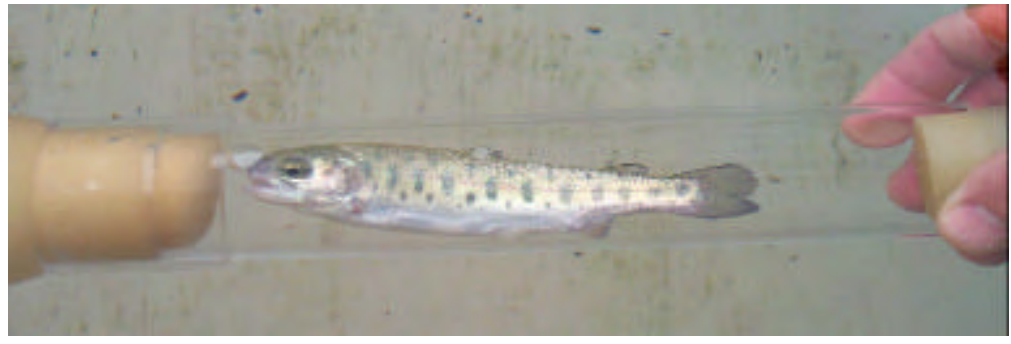

Figure 3.8. Transfer cartridge used to capture test fish before being subjected to the shear environment.

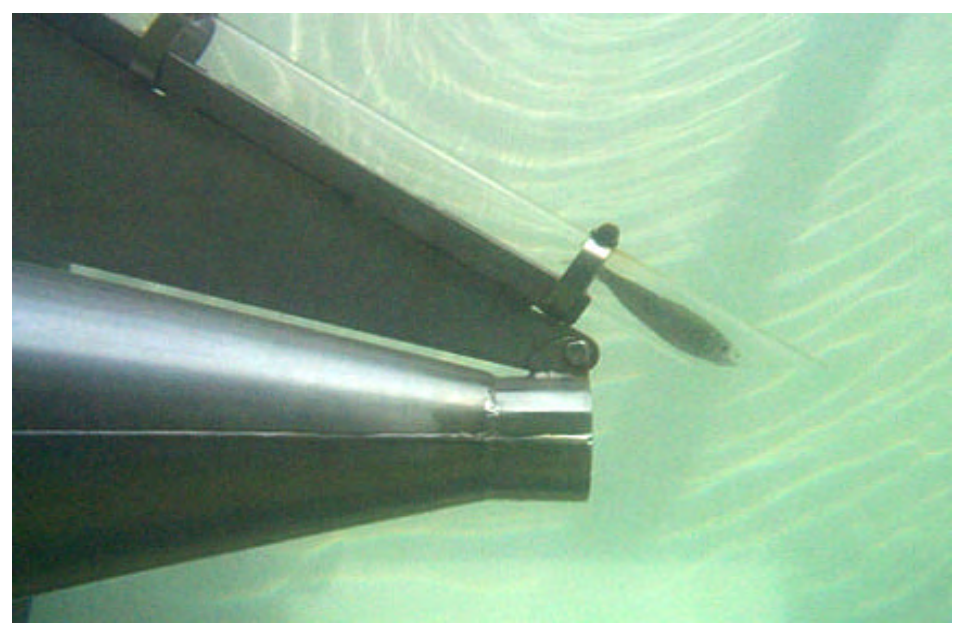

Figure 3.9. Fish release method just before entering the shear environment. 
After each exposure, the system was shut down (to avoid potential injury from multiple exposures to the shear environment), and the fish was recovered from the flume with dip nets. Recovery was also aided by the use of a brail or crowding fence to capture the fish. The fish was then placed back in the clear cartridge, and its external condition was evaluated for injuries.

For every series of tests, a control group comprising 10 fish was introduced into the deployment tube, allowed to swim out, and then recaptured with dip nets with no exposure to the shear environment (pump off). This group was used as reference for monitoring injuries of exposed fish.

\section{Fast Fish to Slow Water}

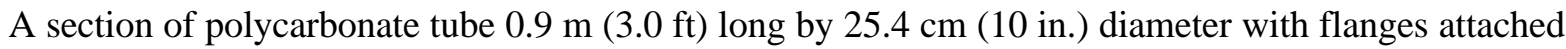
to both ends was attached to the inflow end of the tank. The stainless-steel nozzle was then attached to the downstream end of the tube insert. At the top center of the tube, a 5-cm (2-in.) diameter x 51-cm(20-in.-) long clear pipe was plumbed in to facilitate fish deployment (Figure 3.10). A perforated barrier was also fastened to the inside of the tube to prevent fish from swimming up into the inflow pipe. Test fish were loaded into the apparatus by mating the cartridge filled with water and test fish to the 5-cm diameter pipe. Once the fish swam into the clear tube, the lower ball valve was closed, and the pump was turned on. Depending on the pump speed, test fish could be observed swimming in the chamber for a short duration before becoming fatigued and exiting the nozzle terminus (Figure 3.11). Nearly all the test fish passed through the nozzle tailfirst.

Based on measurements taken with a Pitot tube, the time needed for the pump to achieve a constant velocity at the nozzle terminus was $2 \mathrm{~s}$. The high-speed video system was used to document the fish orientation upon exiting the nozzle and provide a permanent record of fish behavior as fish left the shear

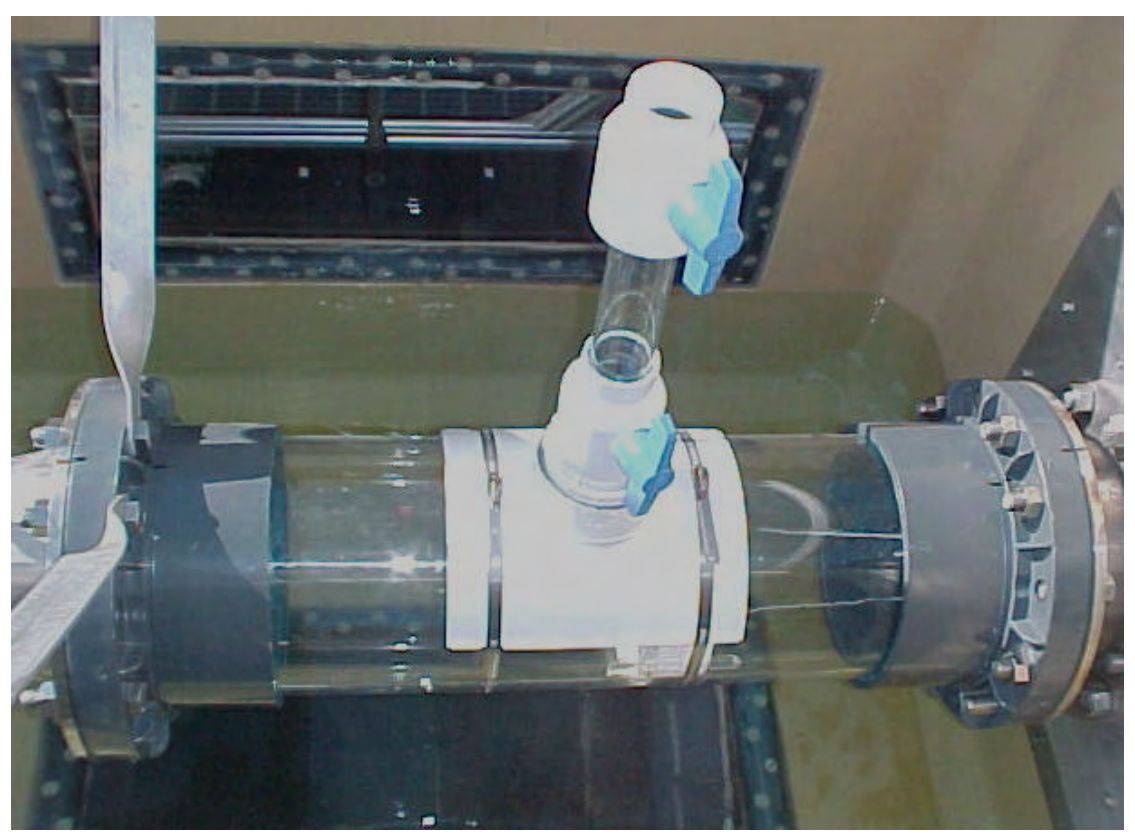

Figure 3.10. Test apparatus used to deploy fish during the fast-fish-to-slow-water tests. 


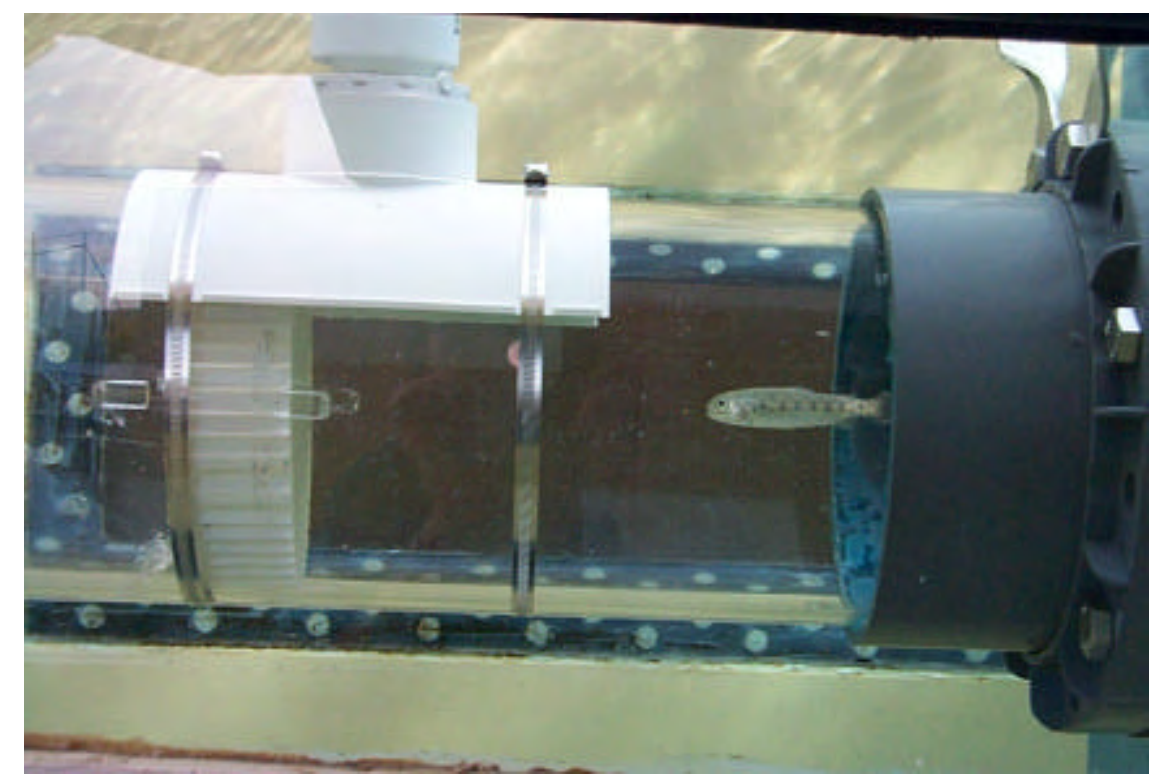

Figure 3.11. Rainbow trout before entering nozzle during a fast-fish-to-slow-water test.

environment. As in the slow-to-fast-water scenario, the pump was deactivated, the fish netted, and injuries were recorded. Rainbow trout $(12 \mathrm{~cm}, 4.7 \mathrm{in}$.) were used for all fast-fish-to-slow-water tests. Three test series were run at strain rates of $688,852,1008$, and $1150 \mathrm{~cm} / \mathrm{s} / \mathrm{cm}, \Delta y=1.8 \mathrm{~cm}^{11}$. Based on range-finding tests, we chose to expose a test group to an exit velocity of $1150 \mathrm{~cm} / \mathrm{s} / \mathrm{cm}, \Delta y=1.8 \mathrm{~cm}$. This strain rate was calculated based on the extrapolation of Pitot tube measurement at lower strain rates. The number of fish used for each velocity was 20 at $688 \mathrm{~cm} / \mathrm{s} / \mathrm{cm}, \Delta y=1.8 \mathrm{~cm}$ and 40 fish for the remaining rates of strain. Each test group was held in separate cages $48 \mathrm{~h}$ after exposure to determine delayed mortality.

\subsubsection{Post-Test Holding}

After examination, each test group (including control fish) was placed in small net pens located in a concrete raceway located adjacent to the flume. The raceway was supplied with well water maintained at the test temperature. Test fish were held for $48 \mathrm{~h}$ to monitor delayed mortality or other effects indicative of stress or injury (dark discoloration, lethargy, fungal/disease infection, and osmoregulation problems).

\subsection{Experimental Procedures}

The velocities selected for testing were designed to generate a no-observed-effect level (NOEL) or lowest-observed-effect level (LOEL) curve for injury, direct mortality (both immediate and delayed), and indirect mortality due to predation. Based on the results of range-finding tests, and depending on the response variable to be measured, we determined the number of test organisms, including controls,

\footnotetext{
${ }^{11}$ See Footnote 1 in the Summary.
} 
required for subsequent testing and the range of velocities to be tested. The actual intervals between exit velocities tested were based on the injury-response pattern and the precision (i.e., width of the confidence interval) required for analysis.

Biological response curves generated for each test species included effects due to the two modes of exposure (slow fish to fast water and fast fish to slow water) and specific orientation (headfirst vs. tailfirst). These response curves accounted for both direct and indirect mortality. Statistical tests for evaluating the lethal and sublethal effects on fish from being subjected to a shear environment were determined based on best methods needed to test our hypothesis.

An analysis was done to determine if there was a significant difference between the control and exposed fish groups (treatment factor) and to see if the run number or side had any effect on the experiment. Analysis of variance (ANOVA) was performed using the underlying binomial distribution assumption because of the response variable being binomial (either ok or injured). For both slow-fish-tofast-water and fast-fish-to-slow-water tests, the metrics of interest were: 1) the percentage of fish with a minor injury or worse; 2) the percentage of fish with a major injury or worse; and 3) the percentage of fish that died. Each of the three percentages was analyzed separately.

For the tests in which a control group was performed, the statistical test used was a chi-square proportion test (Bernard and Malone 1988). The slowest velocity treatment percentages were compared to the control for a difference. If no significant difference was found, then those treatment percentages were pooled with the control and then compared to the next treatment velocity. This analysis and pooling continued until a significance was found for a specific treatment velocity. The control pooled with the non-significant velocity runs was compared with each of the remaining velocities. P-values were calculated from a chi-square distribution.

For the tests in which no control group was performed, a binomial proportion test was performed (Bernard and Malone 1988). The smallest velocity treatment percentages were compared to a hypothesized value of $2 \%(0 \%$ will not work because in a binomial distribution it would result in a variance of 0 ; therefore, a small percentage was chosen as the hypothesized value). If this first comparison was nonsignificant, then the next velocity's treatment percentages were compared to the smallest velocity or $2 \%$, whichever was larger. If the first comparison was significant, then each of the next velocity treatments were compared to the $2 \%$ hypothesized value. P-values were calculated from a binomial distribution.

At any given jet velocity, we expected to see different injury and mortality rates for the headfirst vs. the tailfirst introductions. Because of the fish's streamlining, a water jet directed backward from the fish's head (tailfirst introduction) would be expected to be less damaging than a jet directed forward from the tail (headfirst introduction). For example, the fish's scales imbricate (overlap) in a backward direction, so that a jet directed forward would likely pry the scales off. Also, a water jet directed backward from the head would simply press the operculum down against the head. In contrast, a jet directed forward would lift the operculum up and push it forward, perhaps creating a crease or tearing the isthmus where the two opercula are joined on the dorsal side of the fish.

Similarly, the distinction between the slow-fish-to-fast-water tests and the fast-fish-slow-to-water tests is an important one, because the two procedures created fundamentally different exposures to a shear 
environment. In the slow-fish-to-fast-water test, fish moved slowly down the introduction tube and then entered the shear environment created between the jet and the relatively static water in the flume. Within a fraction of a second, the fish was rapidly accelerated and exposed to a shear environment, typically on only a small portion of its body.

On the other hand, the fish exposed to the fast-fish-to-slow-water test potentially had a very different experience. In this procedure, a fish in the pipe upstream of the nozzle was gradually accelerated to the nozzle exit velocity. Eventually, the fish exited the nozzle and experienced the shear environment associated with the jet spreading out in the mixing zone of the flume. Unlike the slow-fish-to-fast-water procedure, however, the fish was less likely to experience the shear environment associated with the boundary between two water masses of very different velocities. The fish's entire body could be flexed, twisted, or compressed in the mixing zone, potentially resulting in external creases or internal injuries. Within a turbine, this type of exposure could occur in much of the bulk flow, but especially in the draft tube and tailrace where fish moving downstream with the water mass encounter a shear environment.

As a consequence of these fundamentally different modes of exposure to fluid forces, our analyses of the two approaches had a different focus. Fish exposed to the shear environment in the slow-fish-to-fastwater test may have been injured as a result of a very localized, but severe forces. For example, contact with the shear environment may have injured or removed an eye or torn an operculum, while the rest of the body showed no obvious injuries. In this case, development of criteria for shear environments focused on calculating an index that could be related to a specific biological response. On the other hand, a fish in the fast-fish-to-slow-water tests had fewer localized injuries.

\subsubsection{Characterization of Direct Injury and Mortality}

Biological responses determined included the type and extent of injuries (tissue damage) direct mortality (initial and delayed), and indirect mortality (increased susceptibility to predation). Evaluation of external injuries was the primary method for monitoring tissue damage and for assessing cause of direct mortality.

The occurrence and severity of injuries (biological responses) were monitored for each fish, including but not limited to decapitation, evisceration, eye damage, descaling, desliming, gill/opercular damage, split fins, bruising/discoloration, and spinal fracture. All injuries resulting in direct mortality were noted. Most injuries were evaluated with a yes/no response; however, evaluation of some injuries required use of a graduated scale for comparison. Minor injuries were those that were visible but not life-threatening and tended to heal and disappear over the post-exposure observation period. Small bruises $(\leq 0.5 \mathrm{~cm}$ in diameter) with minor discoloration (most commonly observed at the dorsal insertion of the operculum) were given a minor injury rating because fish quickly recovered from such injuries with no apparent ill effects. In contrast, any injury that resulted in prolonged loss of equilibrium and the more severe injuries that were life-threatening or persisted throughout the post-exposure observation were rated as major. For example, a large bruise ( $\geq 0.5 \mathrm{~cm}$ in diameter), damage to the spinal column, cuts with visible bleeding, injured eyeballs (bulged, hemorrhaged, or missing), gill damage (inverted gill arches, or tears at the insertions of the gill arches severe enough to result in bleeding), and descaling were placed in a major injury category. Evaluation of descaling was based on methods developed for monitoring descaling at hydroelectric dams (i.e., each side of fish is divided into five zones). If descaling occurred on $\sim 40 \%$ of the fish's body, in two zones on the same side, the fish was considered to be descaled (Basham et al. 1982). 


\subsubsection{Indirect Mortality (Predation) Tests}

Increased susceptibility to predation can occur if fish are stunned or disoriented and temporarily lose the ability to detect and avoid predators. Predation tests were conducted with juvenile rainbow trout at the NOEL and at one experimental condition higher than this value (i.e., LOEL). Predators consisted of 2-year-old rainbow trout conditioned to actively feed on smolt-size fish. Tests were conducted using a modification of the approach described by Coutant (1970). A test replicate consisted of equal numbers (20 each) of control and exposed fish introduced into the shear tank. Controls were differentiated from test fish by a freeze brand on the right or left side of the fish. Control fish were introduced into the flume though a separate tube that exited approximately $1 \mathrm{~m}(3.3 \mathrm{ft})$ downstream of the nozzle on the edge of the flow field. Ten replicates were used for both test series.

A population of 18 to 26 predators was confined at one end of the test facility with a crowder during the treatment and control fish releases. After all 40 test fish were released, the pump was stopped, and a crowder was used to evenly mix the two release groups. After mixing was complete $(\sim 10 \mathrm{~s})$, both crowders were removed and the predators were set free to pursue the prey. In addition, the standpipe was pulled so that the water level was lowered to a depth of $1 \mathrm{~m}$. This reduced the possibility of the predators jumping out of the tank while pursuing the prey. The predators were allowed to pursue the prey fish for $15 \mathrm{~min}$ or when approximately $50 \%$ of the fish were eaten, whatever came first. All survivors were separated from the predators using crowders, removed, and identified as treatment or control. We also noted if the survivors had any external marks indicating a "hit" by a predator.

\subsubsection{High-Speed Video System}

Video images of exposed fish were captured using two identical high-speed cameras (Redlake Imaging MotionScope $\left.{ }^{\mathrm{TM}} 1000 \mathrm{~S}\right)$, positioned to view fish as they exited the tube from a side (x-y) and bottom view (y-z or $\mathrm{x}-\mathrm{z}$ plane). Cameras were situated near the viewing panels and connected to processors located in a nearby office trailer. Cameras recorded fish orientation and location from the moment a fish descended the introduction tube, came into contact with the shear environment, and was swept out of the immediate shear environment ( $0.5 \mathrm{~m}[1.6 \mathrm{ft}])$. An entire exposure sequence lasted only a fraction of a second. Cameras recorded each event simultaneously at 500 frames per second, which provided an approximate 2-s buffer of stored memory. A tape reviewer recorded each event to videotape at least two speeds (10 and 30 frames per second) so that specific injuries could be verified. The field of view for each system was approximately $44.4 \mathrm{~cm}$ (17.5 in.) vertical x $45 \mathrm{~cm}$ (17.7 in.) horizontal for most tests. A calibration tape was placed along the axis of the nozzle and recorded with both cameras at the beginning of each test day. The calibration data were used later in post processing to determine fish position and acceleration. All recordings were made on a Sony model EVC $200 \mathrm{Hi} 8$-mm tape recorder attached to a Robot model MV50 four-channel mutiplexer. A video overlay board was used to record the test fish and exit velocity for each test series.

\subsubsection{Recording the Paths of Fish in the Jet Plume}

An imaging software program (Optimas ${ }^{\mathrm{TM}}$ ) was used to digitize the images, plot trajectories, and estimate fish acceleration and velocities. The protocol for the estimation of fish acceleration was based on developing specific macros, which advanced the tape at a specific interval, digitizing the image, and 
then measuring the distance traveled from a known starting point. A fixed location on the fish (usually the eye) was used to determine distance moved. The three variables analyzed were 1) distance vs. time, 2) velocity vs. time, and 3 ) acceleration vs. time.

In addition, the fish trajectories were plotted to determine the point of entry and duration that the fish was exposed to the shear environment. Other physical characteristics such as rotation, torsion, and bending were also noted by reviewing the tape recordings. An example of a fish path through the shear layer is shown in Figure 3.12. Sample video files (mpg format) can be found in Appendix C. The video files include a representation of each species tested and show a progression of the NOEL to the velocities where major injuries occurred.

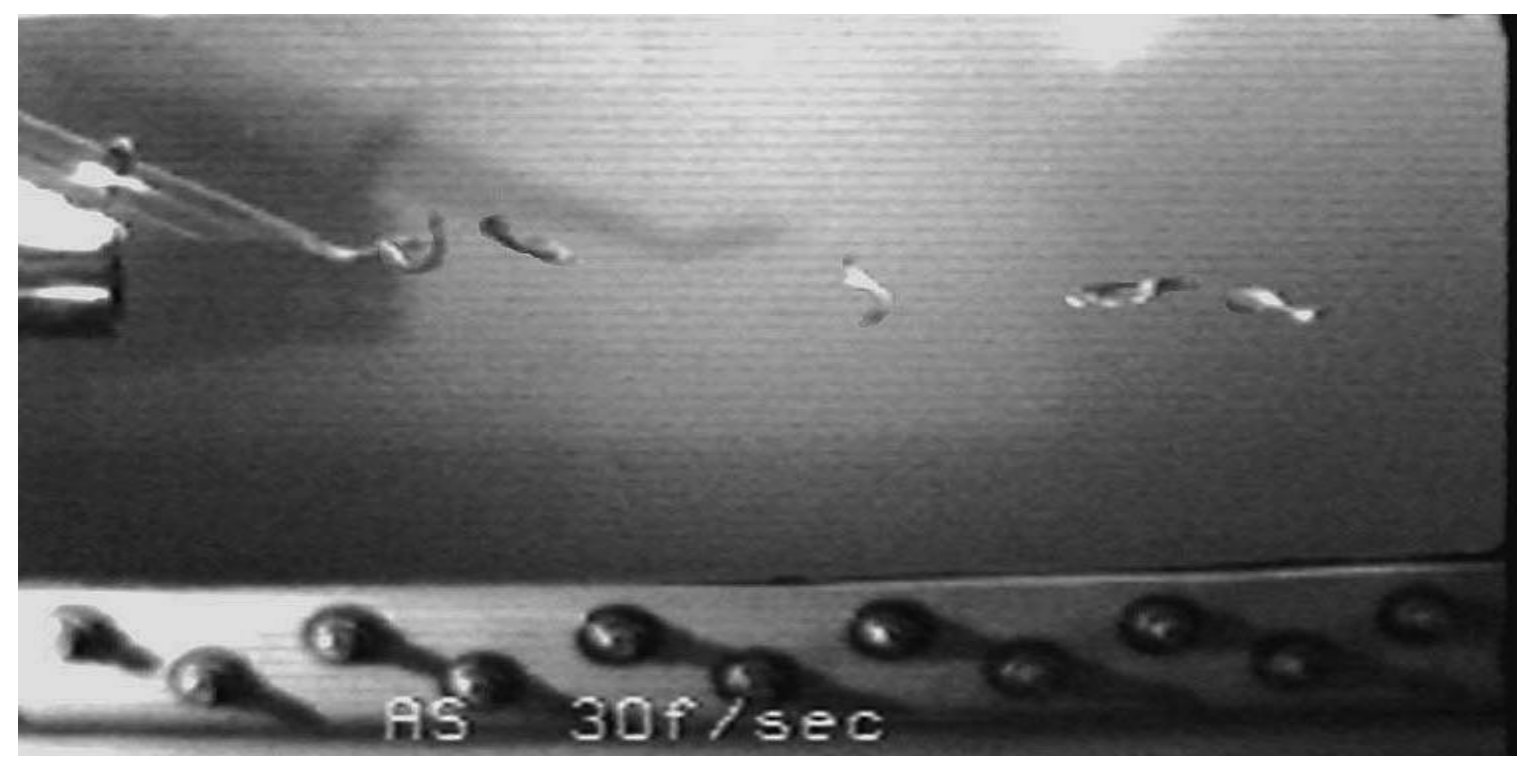

Figure 3.12. Digitized images of American shad showing their position and orientation when exposed to flow field. 


\subsection{Results}

This section presents results for the velocity measurements taken in the jet and used to compute the strain rate index (Section 4.1) and the observations of biological response for the test fish subjected to a shear environment (Section 4.2).

\subsection{Mean-Flow Characteristics}

Velocity field measurements were made for a series of jet exit velocities of 3.0, 6.1, 9.1, 12.2, 15.2, $18.3,21.3 \mathrm{~m} / \mathrm{s}(10,20,30,40,50,60$, and $70 \mathrm{ft} / \mathrm{s})$. This range corresponds to a range of Reynolds numbers of $1.48 \times 10^{5}$ to $8.87 \times 10^{5}$. These are well above the minimum of 4000 to achieve fully developed turbulence according to Fischer et al. (1979). For comparison, the exit Reynolds number in the jet experiments reported by Sami et al. (1967) was $2.2 \times 10^{5}$.

The mean-flow velocity measurements obtained using the Pitot tube were used to describe the jet centerline velocity and fluid strain rate. The nondimensional centerline jet velocity measured in this study is compared to several previous measurements that were summarized by Fischer et al. (1979) (Figure 4.1). The decay (decrease) of the jet-centerline velocity compares well to other works. The centerline-velocity (u) nondimensionalized by the exit velocity (u exit) is a function of the downstream distance from the jetexit ( $\mathrm{z}$, as defined in Figure 3.7) nondimensionalized by the square root of the nozzle exit area as follows:

$$
\begin{array}{ll}
\text { PNNL Jet: } & \frac{u}{u_{\text {exit }}}=6.42 \frac{A^{1 / 2}}{Z} \\
\text { Daily and Harleman (1966): } & \frac{u}{u_{\text {exit }}}=6.4 \frac{A^{1 / 2}}{Z} \\
\text { Chen and Rodi (1980): } & \frac{u}{u_{\text {exit }}}=7.0 \frac{A^{1 / 2}}{Z}
\end{array}
$$

where $\mathrm{A}$ is the cross-sectional area of the nozzle exit, and $\mathrm{Z}$ is the distance downstream from the jet exit.

The decay of the centerline velocity in the PNNL jet is within the range reported in the literature. Typical velocity profiles across the jet are presented in the next section in conjunction with the LDV turbulence measurements.

\subsection{Estimation of Exposure Strain Rate}

The initial mean-flow data showed that the strain rate and turbulence stresses increased closer to the jet exit. This observation and the design of the experimental apparatus suggested that by moving the deployment tube to a position as close to the nozzle as possible, the strain rate exposure injuries would be observed at lower exit velocities. That expectation, surprisingly, was not met. The second set of biological data from the near-tube deployment was not statistically different from the far-tube deployment. These results led to a reexamination of the hydraulic variables used to characterize exposure and injury. 


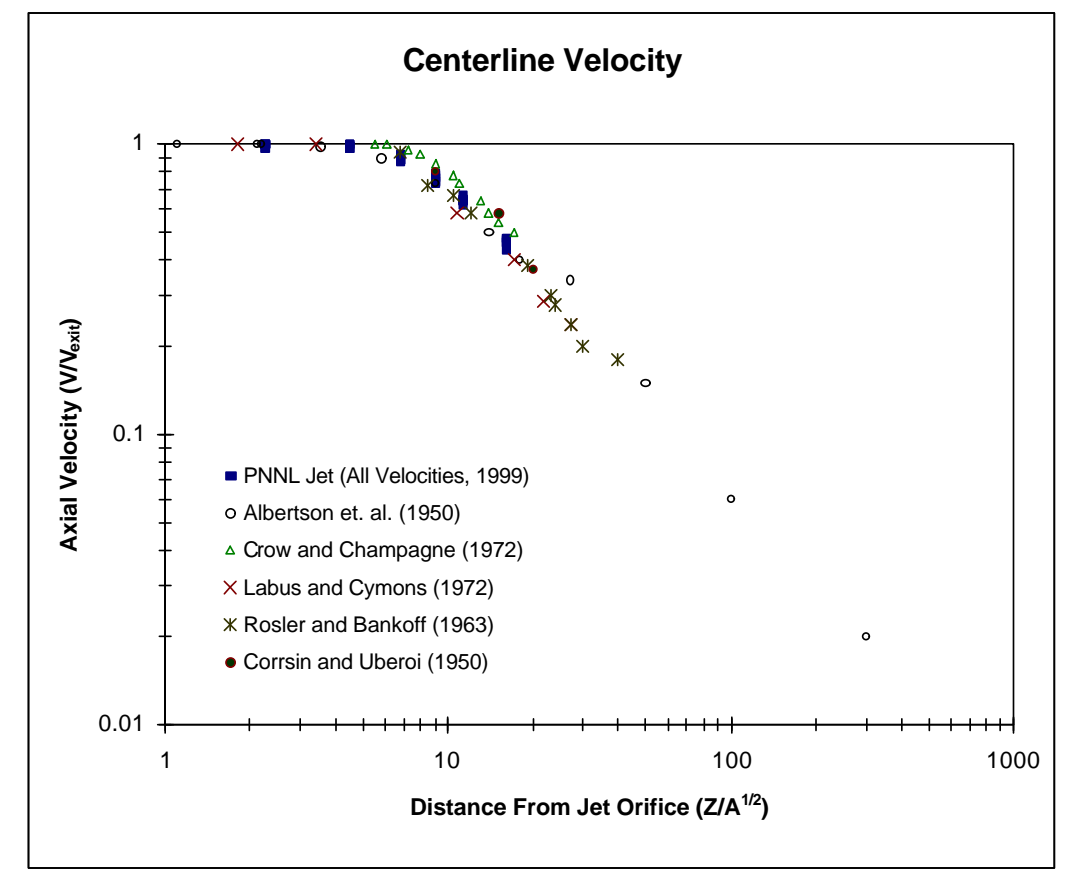

Figure 4.1. Comparison of nondimensional centerline jet velocity data with previous investigations reported in Fischer et al. (1979).

Initially, the strain rate calculations were done at the spatial resolution of the measurements as they were taken, i.e., 1-mm (0.039 in.). Equation (7) shows the finite-difference form of the strain rate (Equation 1). Thus, initially $\Delta \mathrm{y}$ was equal to $1 \mathrm{~mm}(0.039 \mathrm{in}$.).

$$
\mathrm{e}=\frac{\Delta \overline{\mathrm{u}}}{\Delta \mathrm{y}}
$$

A second set of strain rate data was calculated from the original velocity measurements, but this time using a $\Delta y=1.8 \mathrm{~cm}(0.7 \mathrm{in}$.). This value was the minimum width of the salmonids tested and was determined to be an appropriate scale for expressing the strain rate that a fish might experience as a result of the shear exposure. This is the exposure strain rate using the length scale of the typical fish tested. It is not, and not expected to be, equivalent to the local fluid strain rate computed at the finer scale resolution of the velocity measurements. An additional assumption in computing the exposure strain rate was that the velocity within the deployment tube was nearly zero (this could not be measured directly with the Pitot tube). The exposure strain rate showed almost no variation over the distance between the two deployment tube locations (Figure 4.2). The strain rate that was computed using a $\Delta y=1.8 \mathrm{~cm}(0.7 \mathrm{in}$.) is called the exposure strain rate in the ensuing discussion of the biological results.

Although the calculated rate of strain at a $\Delta y=1 \mathrm{~mm}$ differed between the "near" and "far" introduction locations, the fish appeared to be affected by the rate of strain at a larger spatial scale. When the rate of strain was calculated at a $\Delta y=18 \mathrm{~mm}$ there was little difference in the rate of strain (at this 


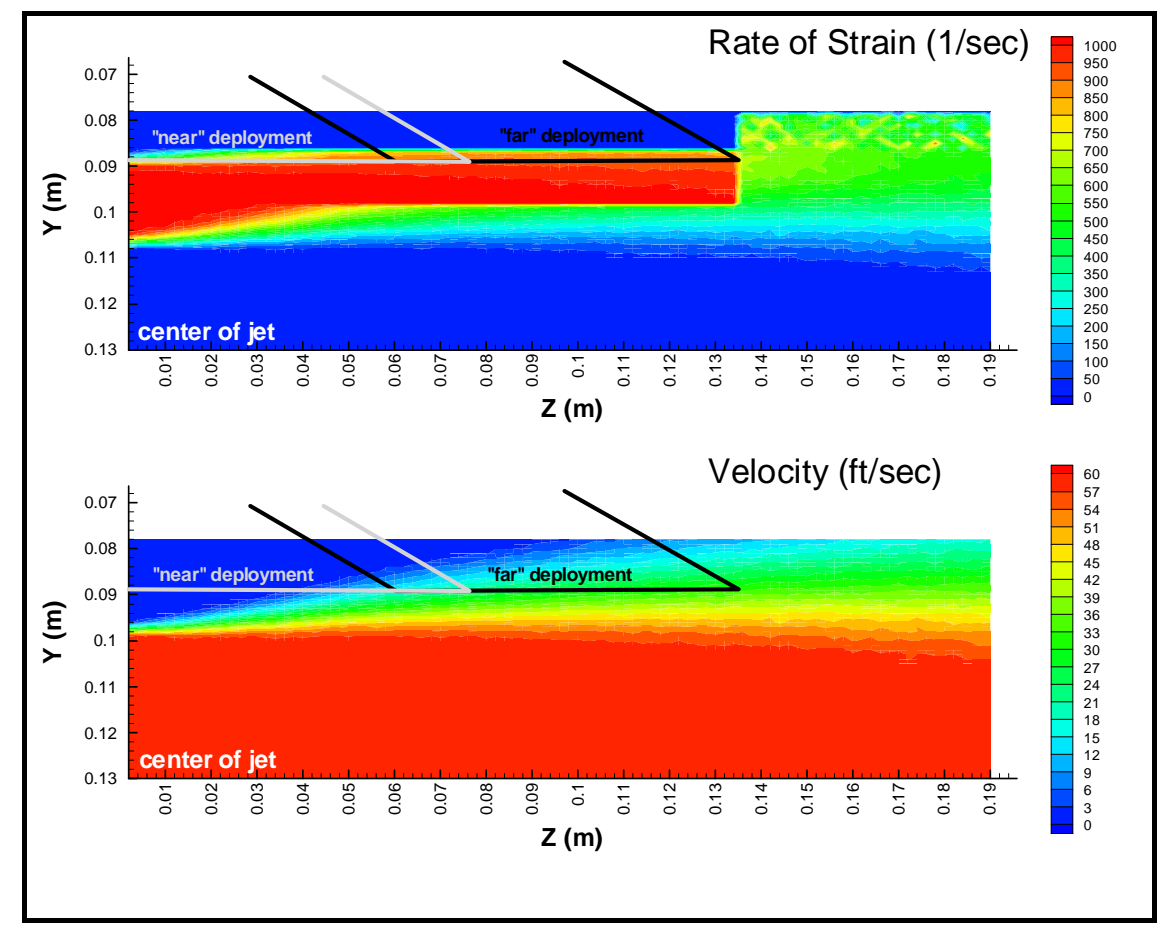

Figure 4.2. Diagram of shear layers as measured at a velocity of $60 \mathrm{ft} / \mathrm{s}$ (resulting in a computed strain rate of $1008 \mathrm{~cm} / \mathrm{s} / \mathrm{cm}, \Delta \mathrm{y}=1.8 \mathrm{~cm}$ ) showing both near and far location of deployment tube.

scale) experienced by the fish in the "near" and "far" introduction locations (see Figure 4.2). In addition, there were no significant differences in the injury and mortality rates between these two deployment tube locations.

\subsection{Turbulence Characteristics}

Figure 4.3 shows two-dimensional plots of the $\mathrm{U}, \mathrm{V}$, and $\mathrm{W}$ velocities, where the axes are in millimeters, and the center of the jet is located at $(0,0)$. Note that $\mathrm{V}$ and $\mathrm{W}$ are highest at the nozzle edge.

The other variables representing turbulence properties (turbulence intensities or root mean square (RMS), Reynolds Stress, turbulent kinetic energy (TKE), and shear) are also highest at the nozzle edge at these downstream locations that are within the zone of flow establishment. It is at the nozzle's edge where test fish were subjected to the shear environment (Figures 3.3 and 3.9).

Figures 4.4-4.7 further illustrate the mean flow and turbulence characteristics. The plots show a profile of each hydraulic variable with respect to normalized radial distance from the center of the jet $(y / r)$ at various normalized (by the nozzle diameter, $\mathrm{d}$ ) axial distances from the nozzle outlet. The normalized abscissa (y/r) in each plot is computed by dividing the radial distance (y) by the jet exit radius(r). Thus, the edge of the jet is located at $y / r=1$ at the outlet. The fish are subjected to the shear environment at 

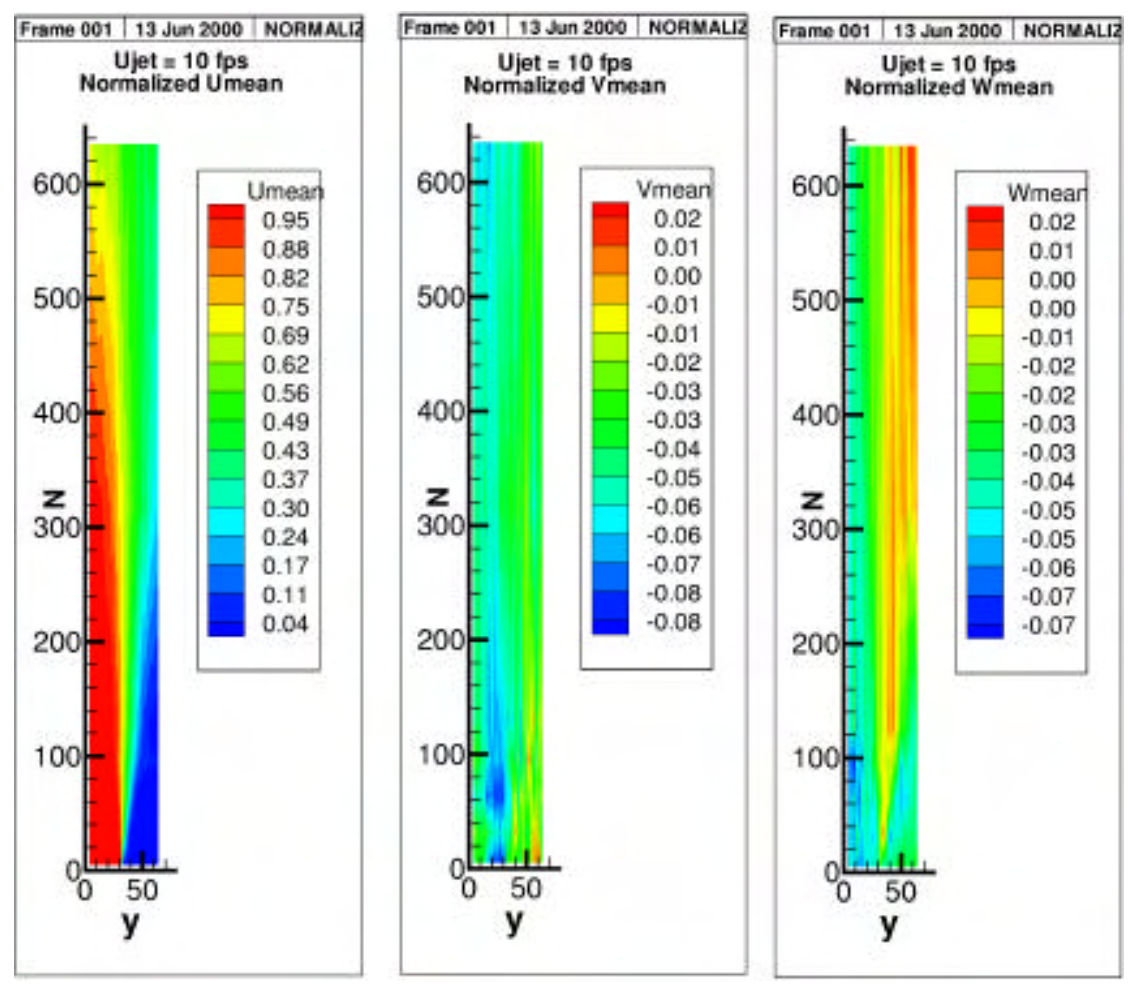

Figure 4.3. Two-dimensional plots of $\mathrm{U}, \mathrm{V}$, and $\mathrm{W}$.

approximately $y / r=1$. The ordinate axis variables are also normalized to the magnitude of the centerline exit jet velocity (ujet), with the exception of TKE, laminar shear (LAMSHEAR), and turbulent shear (TURBSHEAR). The plots indicate that:

- U drops off rapidly at the nozzle edge ( $\mathrm{y} / \mathrm{r}=1)$ (Figure 4.4).

- $\mathrm{V}$ and $\mathrm{W}$ tend to increase with distance from the jet center (Figure 4.4).

- turbulence measures are maximum just beyond the jet edge (y/r>1) (Figure 4.5).

As shown in Figures 4.4 and 4.6, depending on the exact location where the fish intersected the jet, it would be exposed to variable turbulence conditions even though the computed exposure strain rate was more nearly constant. The computed exposure strain rate experienced by the fish could vary by about 3-6\% based on using the axial velocity turbulence intensities (root mean square values) as a measure of the variability of the turbulent velocity field of the jet.

\subsection{Biological Responses}

The biological response results are presented for:

- direct injury and mortality to the test fish whether the fish were inside of (fast-fish-to-slow-water) or outside of (slow-fish-to-fast-water) the jet and by orientation (headfirst or tailfirst)

- indirect mortality for fish subjected to predators following sublethal conditions. 

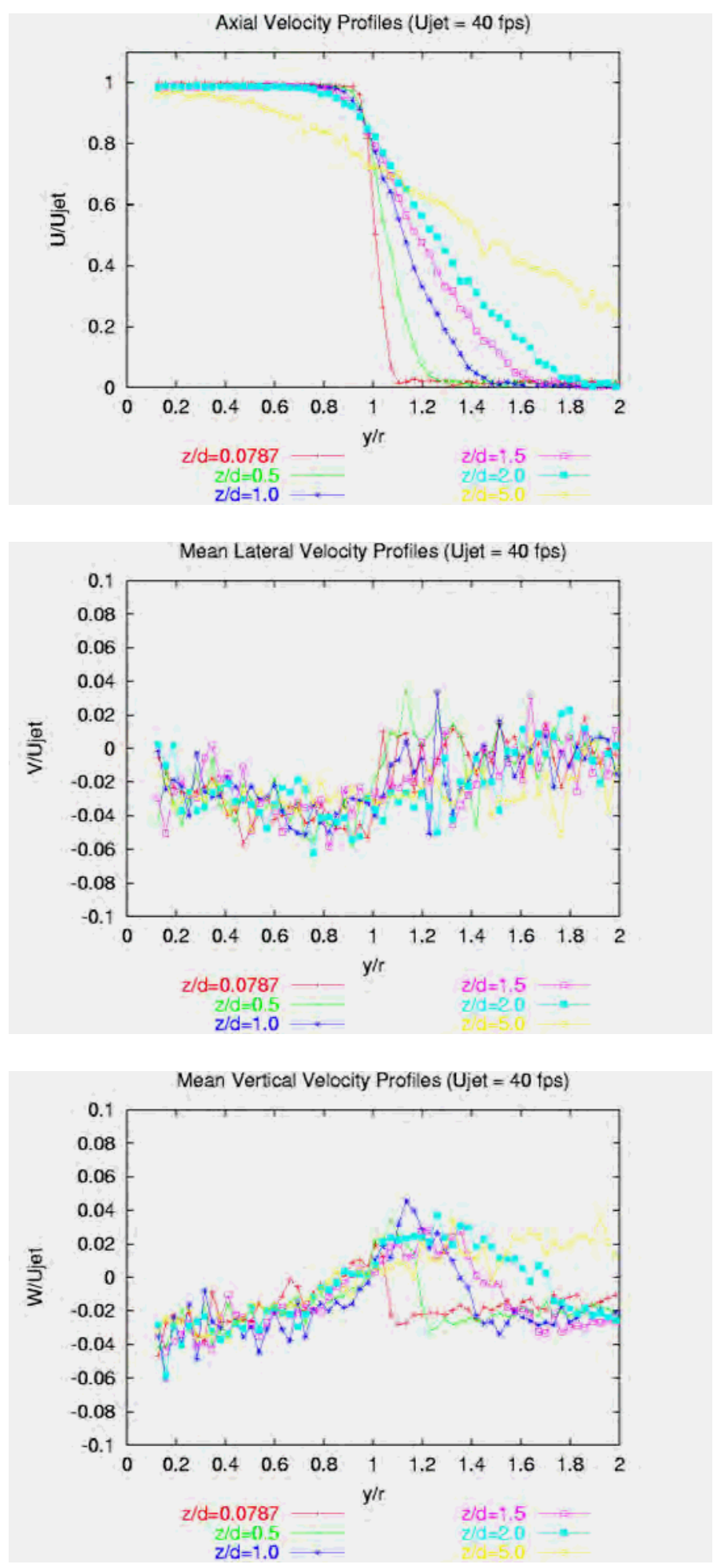

Figure 4.4. Profiles of normalized velocity vectors at jet speed $U=40 \mathrm{fps}$. 

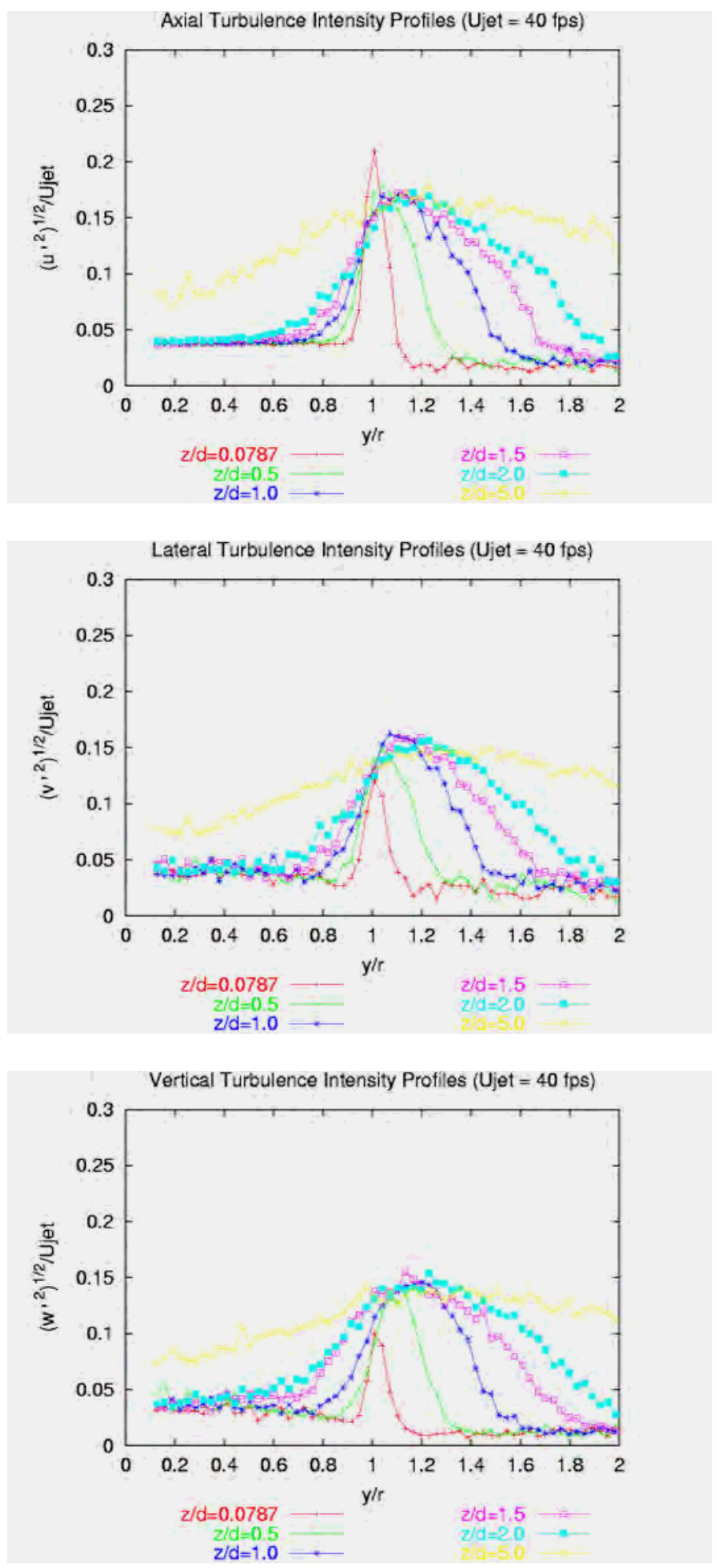

Figure 4.5. Profiles of normalized turbulence intensities at jet speed $U=40 \mathrm{fps}$. 

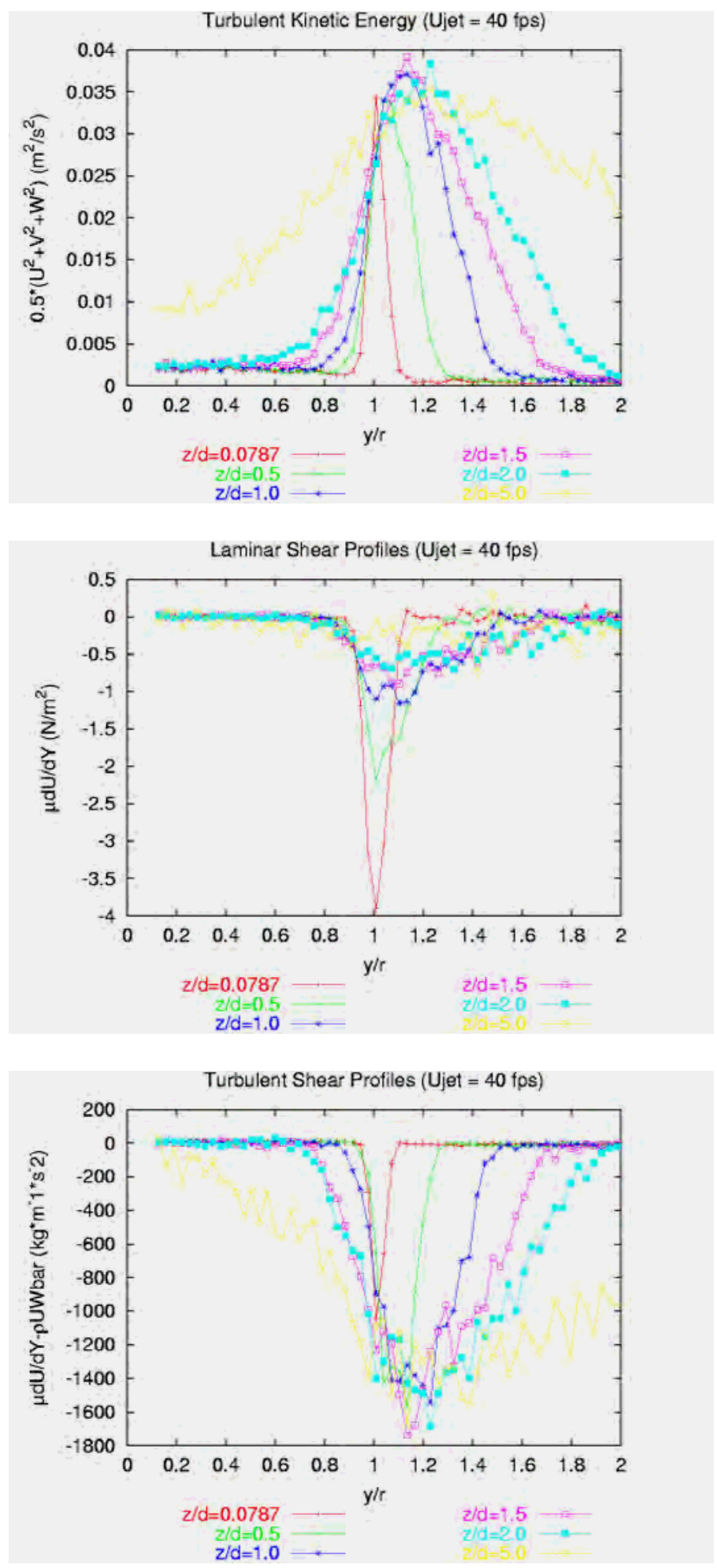

Figure 4.6. Profiles of TKE, LAMSHEAR, and TURBSHEAR at jet speed $U=40 \mathrm{fps}$. 

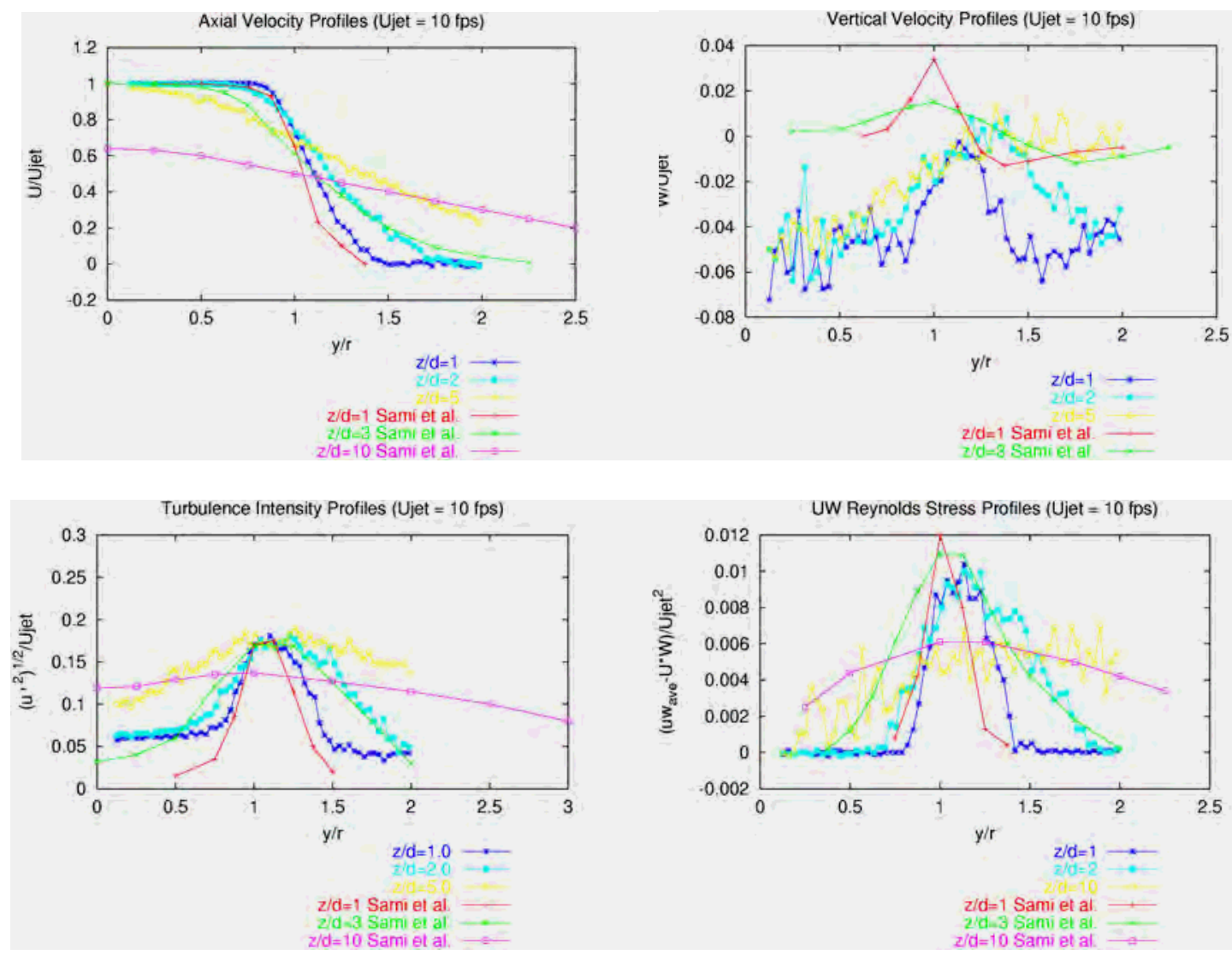

Figure 4.7. Profiles of normalized axial (u) and vertical (w) velocities, turbulence fluctuations, and Reynolds stresses for jet speed $U=10$ fps plotted with data from Sami et al. (1967).

\subsubsection{Direct Injury and Mortality}

\section{Slow-Fish-to-Fast-Water/Headfirst Orientation}

The effects of a headfirst entry into a shear environment of six different intensities were determined for two different age/size groups of fall chinook salmon, spring chinook salmon smolts, juvenile rainbow trout, steelhead smolts, and juvenile American shad. Injuries typically involved bent or bruised opercula (Figure 4.8) and damaged or missing eyes (Figure 4.9). Some fish survived the 48-h observation period even with major injuries. (See Appendix B.) Salmonids generally showed increased resistance to injury with increased size. American shad were particularly vulnerable to the effects of shear stress. A species/stock-specific description of test results is presented in the following subsections.

Initial tests were conducted with the fish deployment located 1.5 jet nozzle diameters $(9.5 \mathrm{~cm}$, $3.75 \mathrm{in}$.) downstream of the jet opening, while fish were deployed adjacent to the jet nozzle in subsequent tests (Table 4.1). Data for the report were combined (i.e., the far and near data sets were combined for 


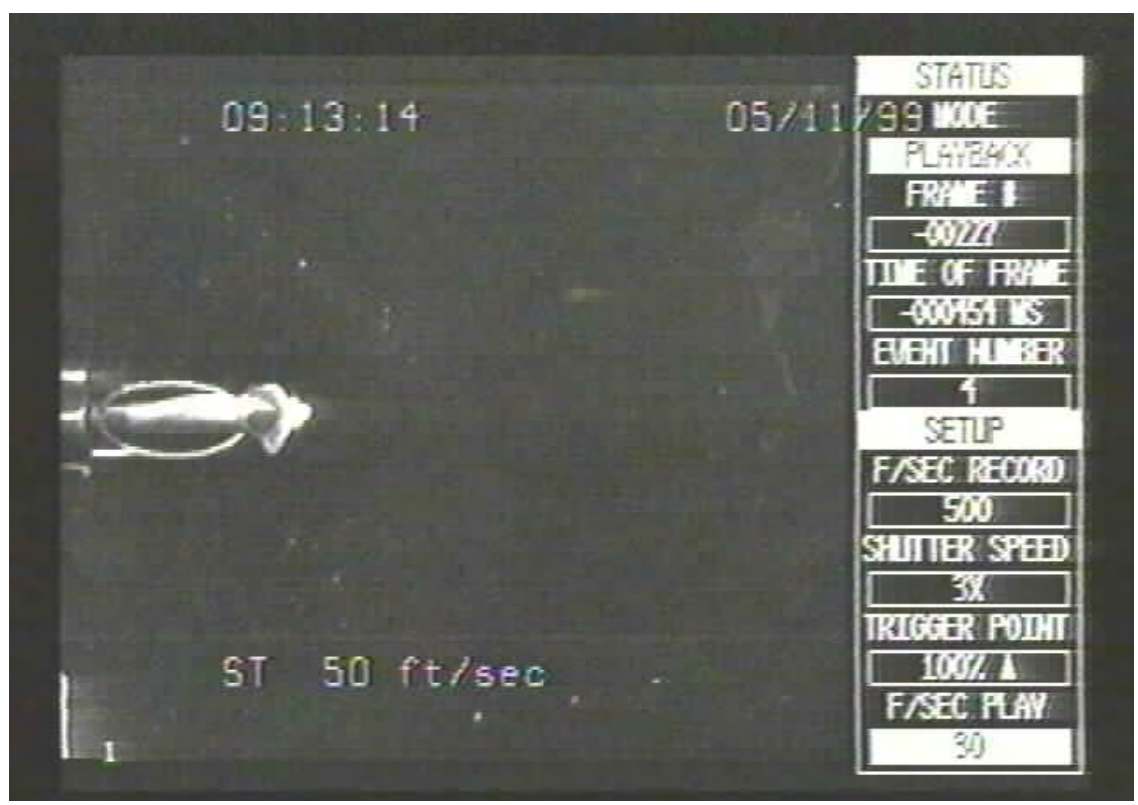

Figure 4.8. Steelhead smolt (bottom view) introduced headfirst to a jet with a strain rate of $852 \mathrm{~cm} / \mathrm{s} / \mathrm{cm}$, $\Delta y=1.8 \mathrm{~cm}$. Note the expansion and bending of the opercula.

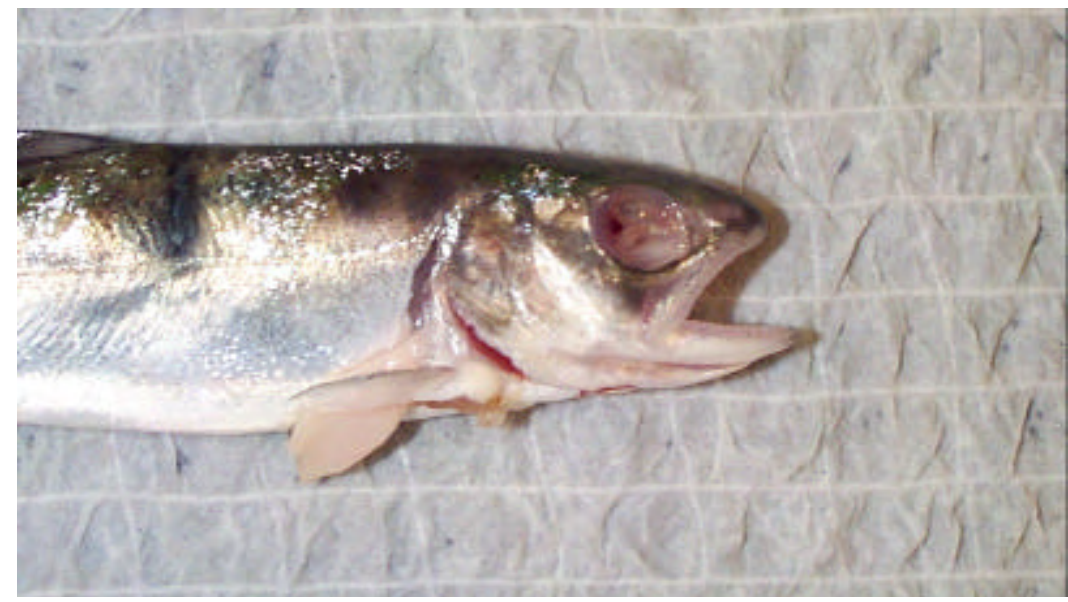

Figure 4.9. Juvenile fall chinook salmon injuries resulting from headfirst exposure to a jet with a strain rate of $1008 \mathrm{~cm} / \mathrm{s} / \mathrm{cm}, \Delta y=1.8 \mathrm{~cm}$. Note missing eye and bent opercle.

age-1 fall chinook salmon) because near and far results did not differ significantly. All American shad and rainbow trout tests were conducted with fish introduced at 1.5 jet nozzle diameters downstream of the nozzle. All spring chinook salmon, steelhead, and age- 0 fall chinook salmon tests were conducted at the near nozzle deployment. 
Table 4.1. Comparison of injuries to fall chinook salmon (age-1) from two deployment distances from the jet that produced shear stress in the test facility. The distances from the jet were 1.5 jet nozzle diameters $(9.5 \mathrm{~cm}, 3.75 \mathrm{in}$.) downstream of the nozzle opening (far) and adjacent to the nozzle opening (near). The proportion of fish injured and sample size $(\mathrm{N})$ are shown for each strain rate $(\mathrm{cm} / \mathrm{s} / \mathrm{cm}, \Delta \mathrm{y}=1.8 \mathrm{~cm})$ tested at the two deployment distances. Injury categories are minor injury or worse (minor), major injury or worse (major), and death. Enumeration of major injuries do not include minor injuries.

\begin{tabular}{|c|c|c|c|c|c|c|c|c|}
\hline \multirow[b]{3}{*}{ Rate of Strain } & \multicolumn{4}{|c|}{ Far } & \multicolumn{4}{|c|}{ Near } \\
\hline & \multicolumn{4}{|c|}{ Injury } & \multicolumn{4}{|c|}{ Injury } \\
\hline & Minor & Major & Dead & $\mathbf{N}$ & Minor & Major & Dead & $\mathbf{N}$ \\
\hline 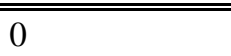 & 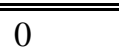 & 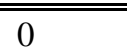 & 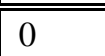 & 10 & $\mathrm{ND}^{(\mathrm{a})}$ & $\mathrm{ND}^{(\mathrm{a})}$ & $\mathrm{ND}^{(\mathrm{a})}$ & 0 \\
\hline 168 & 0 & 0 & 0 & 10 & $\mathrm{ND}^{(\mathrm{a})}$ & $\mathrm{ND}^{(\mathrm{a})}$ & $\mathrm{ND}^{(\mathrm{a})}$ & 0 \\
\hline 341 & 0 & 0 & 0 & 10 & $\mathrm{ND}^{(\mathrm{a})}$ & $\mathrm{ND}^{(\mathrm{a})}$ & $\mathrm{ND}^{(\mathrm{a})}$ & 0 \\
\hline 517 & 0.10 & 0 & 0 & 50 & 0.12 & 0.00 & 0 & 50 \\
\hline 688 & 0.42 & 0.06 & 0.02 & 50 & 0.52 & 0.12 & 0.06 & 50 \\
\hline 852 & 0.60 & 0.20 & 0.07 & 30 & 0.90 & 0.30 & 0.03 & 30 \\
\hline 1008 & 1.00 & 0.80 & 0.40 & 10 & $\mathrm{ND}^{(\mathrm{a})}$ & $\mathrm{ND}^{(\mathrm{a})}$ & $\mathrm{ND}^{(\mathrm{a})}$ & 0 \\
\hline
\end{tabular}

\section{High-Speed Videography}

Separate plots were constructed for each species exposed to the shear layer for headfirst exposures. Appendix C (acceleration plots) presents a subset of the strain rates to which each species was exposed. In addition to distance vs. time, velocity vs. time, and acceleration vs. time, Excel spreadsheets are included that show fish trajectories as they encountered the shear environment. Comparing fish with similar injuries and noting any characteristics that would be ubiquitous throughout the plots, it was anticipated that these characteristics would indicate conditions that could cause specific injuries. Observation of these three plots for each respective fish did not yield any noticeable trends that would indicate a certain value or behavior of acceleration that would be useful in determining the causes of injury. It was found that the injuries had a random occurrence. No specific pattern could be correlated to the observed injuries with trends in the plots.

To verify this assumption, videos in which a major injury had occurred (i.e., dislodged eye) were analyzed for spring and age- 0 fall chinook salmon. The time this event occurred was referenced to the velocity and acceleration plots to determine if any special feature or common characteristic could be found. Additional plots were made for the age- 0 fall chinook and spring chinook in hopes of confirming or denying the random nature of injuries. Again no recognizable pattern could be found to disprove the random nature of injuries. Observation of the data did not yield a value that would indicate a level of acceleration where injuries occurred. In addition, the acceleration values varied between the age- 0 fall chinook ( $8.5 \mathrm{~cm}, 3.3 \mathrm{in}$.) and spring chinook salmon $(14.5 \mathrm{~cm}, 5.7 \mathrm{in}$.). A general estimate for the critical acceleration at a rate of strain of $852 \mathrm{~cm} / \mathrm{s} / \mathrm{cm}, \Delta y=1.8 \mathrm{~cm}$ was $466 \mathrm{~m} / \mathrm{s}^{2}\left(1529 \mathrm{ft} / \mathrm{s}^{2}\right)$ for age- 0 fall chinook and $260 \mathrm{~m} / \mathrm{s}^{2}\left(853 \mathrm{ft} / \mathrm{s}^{2}\right)$ for spring chinook salmon. (See Appendix C.) 


\section{Species-Specific Results (Fall Chinook Salmon)}

Juvenile fall chinook salmon were relatively susceptible to direct injury or mortality from headfirst exposure to the higher rates of strain tested. A total of 180 age- 0 and 300 age- 1 fall chinook salmon were exposed to six different rates of strain. Both age- 0 (mean $\mathrm{FL}=8.5 \mathrm{~cm}$ ) and age- 1 (mean $\mathrm{FL}=14 \mathrm{~cm}$ ) fall chinook salmon suffered a significant incidence of minor injuries at strain rate of $688 \mathrm{~cm} / \mathrm{s} / \mathrm{cm}$ $(\Delta y=1.8 \mathrm{~cm})$ (Figures 4.10 and 4.11). Major injuries and death occurred in test groups of age-0 fall chinook salmon exposed to the highest strain rate tested $(1008 \mathrm{~cm} / \mathrm{s} / \mathrm{cm}, \Delta y=1.8 \mathrm{~cm})$. Interestingly, the larger age-1 fall chinook salmon showed major injuries and death at a lower strain rate $(688 \mathrm{~cm} / \mathrm{s} / \mathrm{cm}$, $\Delta y=1.8 \mathrm{~cm})$. Control fish were not injured in any of the tests.

Chi-square tests of data for age-0 fall chinook salmon introduced headfirst showed that the highest strain rate without any significant minor injury (or worse) was $517 \mathrm{~cm} / \mathrm{s} / \mathrm{cm}(\Delta y=1.8 \mathrm{~cm})$. The highest strain rate without any significant major injury (or worse) was $852 \mathrm{~cm} / \mathrm{s} / \mathrm{cm} \Delta \mathrm{y}=1.8 \mathrm{~cm}$ ) (Table 4.2).

Chi-square tests of data for age-1 fall chinook salmon introduced headfirst indicate the highest strain rate without any significant minor injury (or worse) was $517 \mathrm{~cm} / \mathrm{s} / \mathrm{cm}(\Delta y=1.8 \mathrm{~cm})$. The highest strain rate without any significant major injury (or worse) was also $517 \mathrm{~cm} / \mathrm{s} / \mathrm{cm}(\Delta y=1.8 \mathrm{~cm})$, and the highest strain rate without any significant proportion of death was $852 \mathrm{~cm} / \mathrm{s} / \mathrm{cm}(\Delta \mathrm{y}=1.8 \mathrm{~cm})$ (Table 4.3).

\section{Species-Specific Results (Spring Chinook Salmon)}

Spring chinook salmon showed similar resistance to the direct effects of strain as the other salmonid species/stocks tested. A significant proportion of minor injuries or worse was detected when spring chinook salmon smolts were introduced into a jet with an estimated strain rate of $688 \mathrm{~cm} / \mathrm{s} / \mathrm{cm}$ $(\Delta \mathrm{y}=1.8 \mathrm{~cm})$ (Figure 4.12).

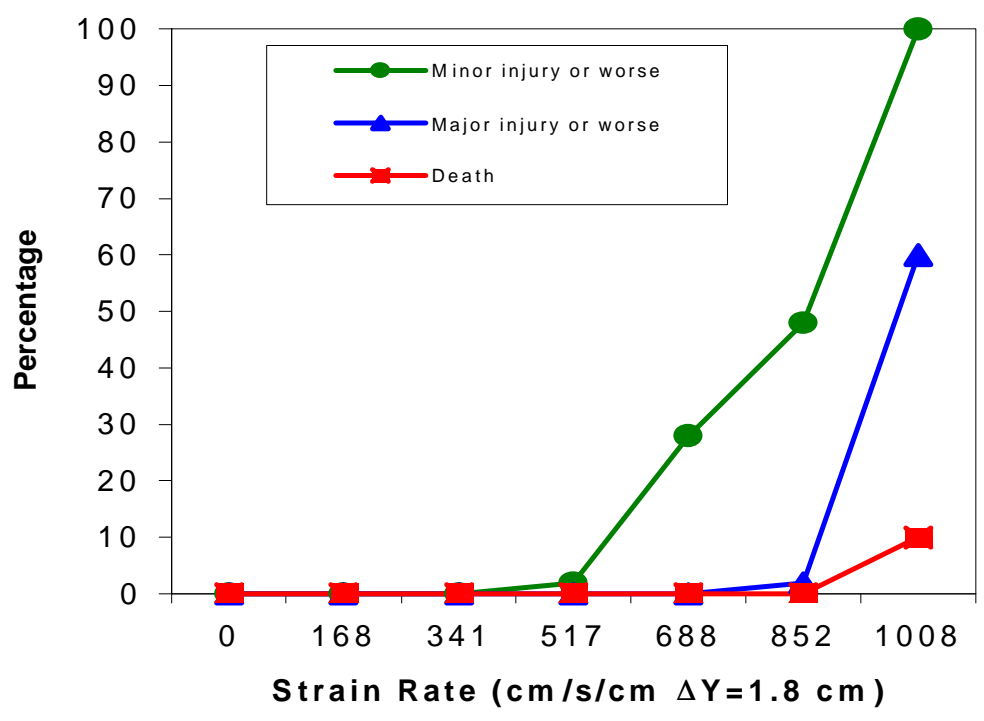

Figure 4.10. Percentage of age- 0 fall chinook salmon (mean $F L=8.5 \mathrm{~cm}$ ) injured or killed during headfirst exposure to a jet with different strain rates $(\mathrm{cm} / \mathrm{s} / \mathrm{cm}, \Delta y=1.8 \mathrm{~cm})(\mathrm{N}=190)$. 


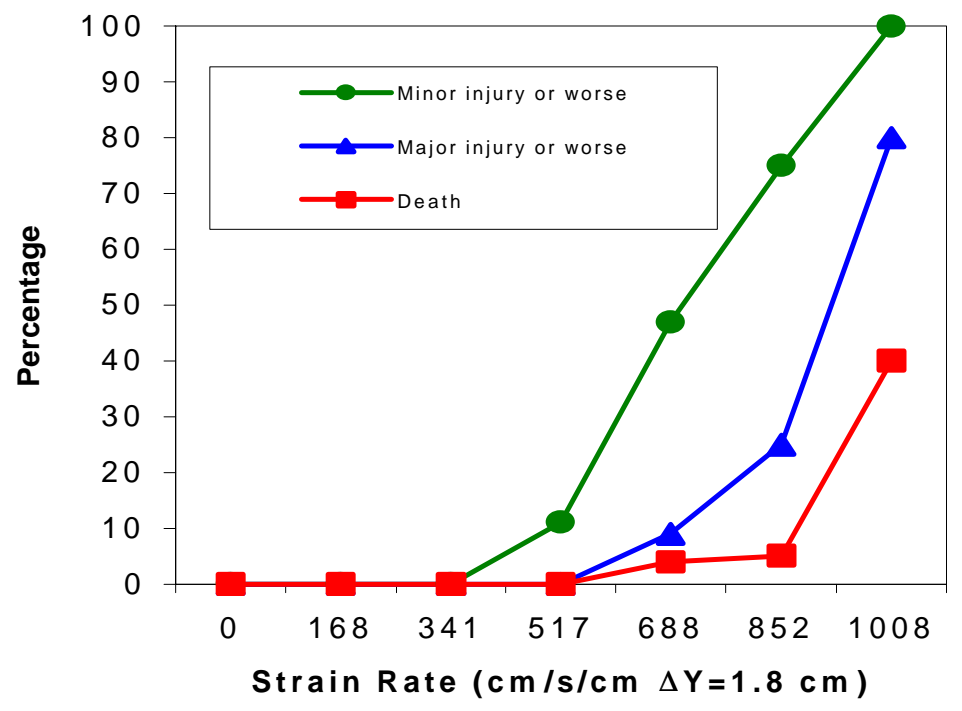

Figure 4.11. Percentage of age- 1 fall chinook salmon (mean $F L=14 \mathrm{~cm}$ ) injured or killed during headfirst exposure to a jet with different strain rates $(\mathrm{N}=300)$.

Table 4.2. Proportions and P-values (in parentheses) for Chi-square proportion tests performed on the effects of headfirst strain rate exposure on injury and death in age- 0 fall chinook salmon. Shaded cells denote the LOEL for strain rate on injury.

\begin{tabular}{||c|c|c|c|c|c|c||}
\hline \multirow{2}{*}{ Injury Level } & \multicolumn{7}{|c||}{ Strain Rate $(\mathbf{c m} / \mathbf{s} / \mathbf{c m}, \Delta \mathbf{y}=\mathbf{1 . 8} \mathbf{~ c m})$} \\
\cline { 2 - 7 } & $\mathbf{1 6 8}$ & $\mathbf{3 4 1}$ & $\mathbf{5 1 7}$ & $\mathbf{6 8 8}$ & $\mathbf{8 5 2}$ & $\mathbf{1 0 0 8}$ \\
\hline \hline Minor injury or worse & 0.00 & 0.00 & 0.02 & 0.28 & 0.48 & 1.00 \\
& $(1.00)$ & $(1.00)$ & $(1.00)$ & $(<0.001)$ & $(<0.001)$ & $(<0.001)$ \\
\hline Major injury or worse & 0.00 & 0.00 & 0.00 & 0.00 & 0.02 & 0.60 \\
& $(1.00)$ & $(1.00)$ & $(1.00)$ & $(1.00)$ & $(1.00)$ & $(<0.001)$ \\
\hline Death & 0.00 & 0.00 & 0.00 & 0.00 & 0.00 & 0.10 \\
& $(1.00)$ & $(1.00)$ & $(1.00)$ & $(1.00)$ & $(1.00)$ & $(0.586)$ \\
\hline
\end{tabular}

Table 4.3. Proportions and P-values (in parentheses) for Chi-square proportion tests performed on the effects of headfirst strain rate exposure on injury and death in age- 1 fall chinook salmon. Shaded cells denote the LOEL for strain rate on injury.

\begin{tabular}{||l|c|c|c|c|c|c||}
\hline \multirow{2}{*}{ Injury Level } & \multicolumn{7}{|c||}{ Strain Rate $(\mathbf{c m} / \mathbf{s} / \mathbf{c m}, \mathbf{\Delta y}=\mathbf{1 . 8} \mathbf{~ c m})$} \\
\cline { 2 - 7 } & $\mathbf{1 6 8}$ & $\mathbf{3 4 1}$ & $\mathbf{5 1 7}$ & $\mathbf{6 8 8}$ & $\mathbf{8 5 2}$ & $\mathbf{1 0 0 8}$ \\
\hline \hline Minor injury or worse & 0.00 & 0.00 & 0.11 & 0.47 & 0.75 & 1.00 \\
& $(1.00)$ & $(1.00)$ & $(0.20)$ & $(<0.001)$ & $(<0.001)$ & $(<0.001)$ \\
\hline Major injury or worse & 0.00 & 0.00 & 0.00 & 0.09 & 0.25 & 0.80 \\
& $(1.00)$ & $(1.00)$ & $(1.00)$ & $(0.002)$ & $(<0.001)$ & $(<0.001)$ \\
\hline Death & 0.00 & 0.00 & 0.00 & 0.04 & 0.05 & 0.40 \\
& $(1.00)$ & $(1.00)$ & $(1.00)$ & $(0.14)$ & $(0.12)$ & $(<0.001)$ \\
\hline \hline
\end{tabular}




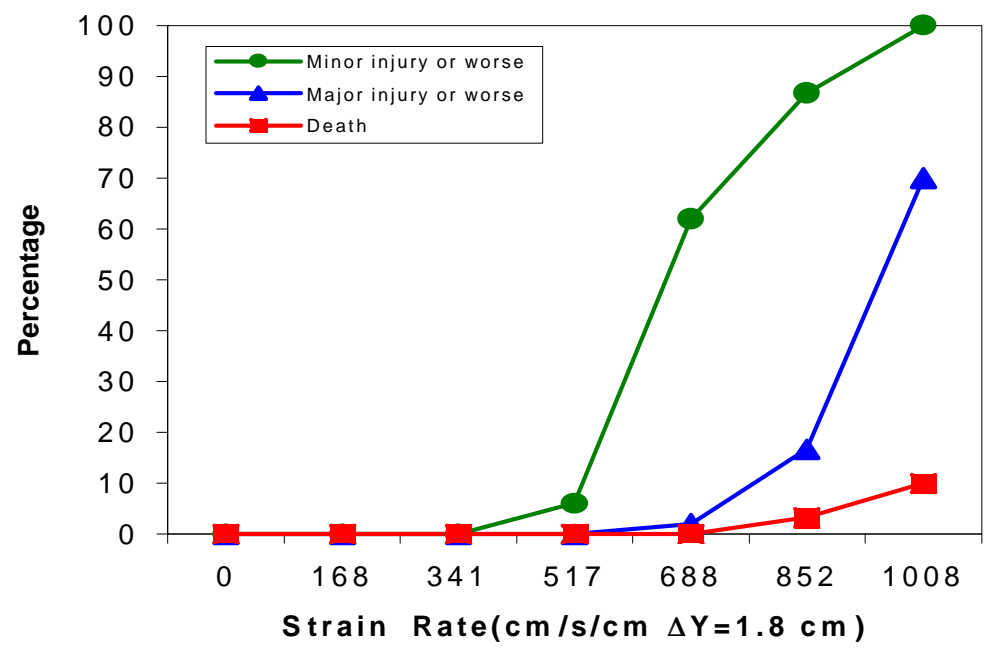

Figure 4.12. Percentage of spring chinook salmon smolts (mean $\mathrm{FL}=14.5 \mathrm{~cm}$ ) injured or killed during headfirst exposure to different strain rates $(\mathrm{N}=170)$.

Chi-square tests of data for spring chinook salmon smolt that were introduced headfirst indicate the highest strain rate without any significant minor injury (or worse) was $517 \mathrm{~cm} / \mathrm{s} / \mathrm{cm}(\Delta y=1.8 \mathrm{~cm})$. The highest strain rate without any significant major injury (or worse) was $688 \mathrm{~cm} / \mathrm{s} / \mathrm{cm}(\Delta y=1.8 \mathrm{~cm})$. There was no significant mortality at even the highest strain rate tested $(10 \%$ of test fish exposed to a strain rate of $1008 \mathrm{~cm} / \mathrm{s} / \mathrm{cm}(\Delta \mathrm{y}=1.8 \mathrm{~cm})$ died, but this was not significantly different from zero [Table 4.4]).

Table 4.4. Proportions and $\mathrm{P}$-values (in parentheses) for Chi-square proportion tests performed on the effects of headfirst strain rate exposure on injury and death in spring chinook salmon smolts. Shaded cells denote the LOEL for strain rate on injury.

\begin{tabular}{||l|c|c|c|c|c|c||}
\hline \multirow{2}{*}{\multicolumn{1}{|c|}{ Injury Level }} & \multicolumn{7}{|c||}{ Strain Rate $(\mathbf{c m} / \mathbf{s} / \mathbf{c m}, \Delta \mathbf{y}=\mathbf{1 . 8} \mathbf{~ c m})$} \\
\cline { 2 - 7 } & $\mathbf{1 6 8}$ & $\mathbf{3 4 1}$ & $\mathbf{5 1 7}$ & $\mathbf{6 8 8}$ & $\mathbf{8 5 2}$ & $\mathbf{1 0 0 8}$ \\
\hline \hline Minor injury or worse & 0.00 & 0.00 & 0.06 & 0.58 & 0.87 & 1.00 \\
& $(1.00)$ & $(1.00)$ & $(0.78)$ & $(<0.001)$ & $(<0.001)$ & $(<0.001)$ \\
\hline Major injury or worse & 0.00 & 0.00 & 0.00 & 0.04 & 0.17 & 0.40 \\
& $(1.00)$ & $(1.00)$ & $(1.00)$ & $(0.90)$ & $(0.01)$ & $(<0.001)$ \\
\hline Death & 0.00 & 0.00 & 0.00 & 0.00 & 0.03 & 0.10 \\
& $(1.00)$ & $(1.00)$ & $(1.00)$ & $(1.00)$ & $(0.66)$ & $(0.64)$ \\
\hline \hline
\end{tabular}

\section{Species-Specific Results (Rainbow Trout)}

Juvenile rainbow trout were slightly more resistant to injury from exposure to strain rate than chinook salmon. No major injuries were detected in test fish exposed to strain rates less than $852 \mathrm{~cm} / \mathrm{s} / \mathrm{cm}$ $(\Delta y=1.8 \mathrm{~cm}$ [Table 4.5, Figure 4.13]). 
Chi-square tests of data for juvenile rainbow trout introduced headfirst indicate the highest strain rate without any significant minor injury (or worse) was $688 \mathrm{~cm} / \mathrm{s} / \mathrm{cm}(\Delta y=1.8 \mathrm{~cm}$, [Table 4.5]). Compared to controls, there were no significant increases in major injuries or mortality at even the highest strain rate tested (Table 4.5).

Table 4.5. Proportions and P-values (in parentheses) for Chi-square proportion tests performed on the effects of headfirst strain rate exposure on injury and death in juvenile rainbow trout. Shaded cells denote the LOEL for strain rate on injury.

\begin{tabular}{||c|c|c|c|c|c|c||}
\hline \multirow{2}{*}{ Injury Level } & \multicolumn{7}{|c|}{ Strain rate $(\mathbf{c m} / \mathbf{s} / \mathbf{c m}, \mathbf{\Delta y = 1 . 8} \mathbf{~ c m})$} \\
\cline { 2 - 7 } & $\mathbf{1 6 8}$ & $\mathbf{3 4 1}$ & $\mathbf{5 1 7}$ & $\mathbf{6 8 8}$ & $\mathbf{8 5 2}$ & $\mathbf{1 0 0 8}$ \\
\hline \hline Minor injury or worse & 0.10 & 0.00 & 0.00 & 0.06 & 0.28 & 0.33 \\
& $(0.77)$ & $(1.00)$ & $(1.00)$ & $(0.67)$ & $(<0.001)$ & $(<0.001)$ \\
\hline Major injury or worse & 0.00 & 0.00 & 0.00 & 0.00 & 0.06 & 0.07 \\
& $(1.00)$ & $(1.00)$ & $(1.00)$ & $(1.00)$ & $(0.45)$ & $(0.76)$ \\
\hline Death & 0.00 & 0.00 & 0.00 & 0.00 & 0.00 & 0.00 \\
& $(1.00)$ & $(1.00)$ & $(1.00)$ & $(1.00)$ & $(1.00)$ & $(1.00)$ \\
\hline
\end{tabular}

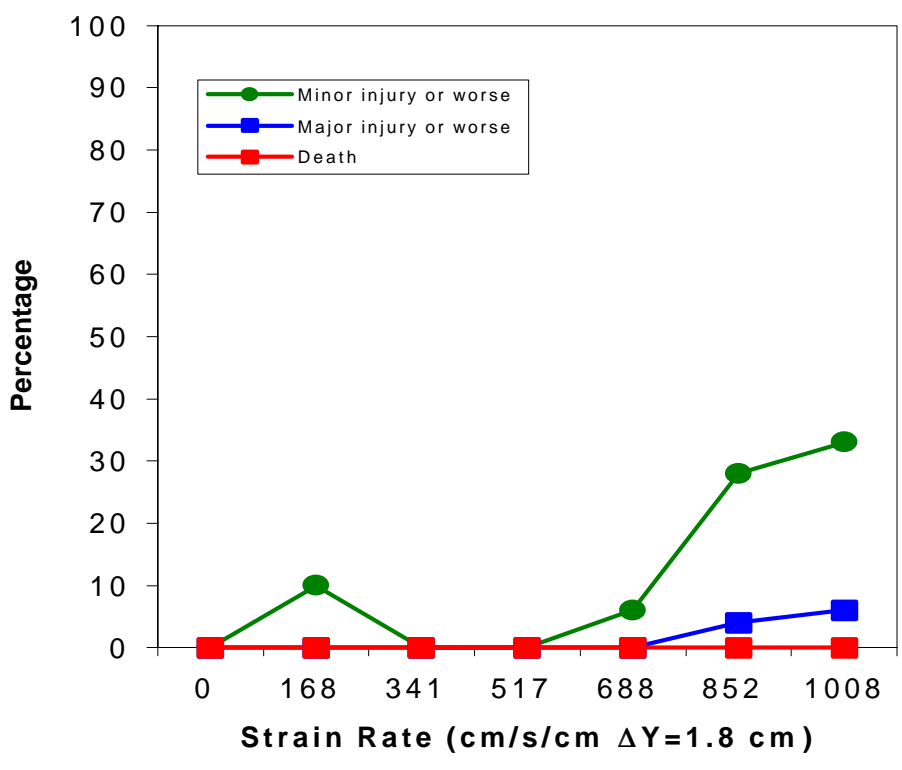

Figure 4.13. Percentage of juvenile rainbow trout (mean $F L=15.5 \mathrm{~cm}$ ) injured or killed during headfirst exposure to different strain rates $(\mathrm{N}=170)$.

\section{Species-Specific Results (Steelhead)}

Steelhead were relatively resistant to injury from exposure to the strain rates we tested. Steelhead received minor injuries as a result of headfirst exposure to a strain rate of $688 \mathrm{~cm} / \mathrm{s} / \mathrm{cm}(\Delta y=1.8 \mathrm{~cm})$ [Table 4.6 and Figure 4.14]). 
The proportion of steelhead sustaining major injuries (7\%) was not significantly different from zero (Table 4.6). No steelhead died as a result of exposure to even the highest strain rate $(1008 \mathrm{~cm} / \mathrm{s} / \mathrm{cm}$ $[\ddot{\mathrm{A}} \mathrm{y}=1.8 \mathrm{~cm}])$.

Table 4.6. Proportions and P-values (in parentheses) for Chi-square proportion tests performed on the effects of headfirst strain rate exposure on injury and death in steelhead smolts. Shaded cells denote the LOEL for strain rate on injury.

\begin{tabular}{||l|c|c|c|c|c|c||}
\hline \multirow{3}{*}{ Injury Level } & \multicolumn{7}{|c||}{ Strain Rate $(\mathbf{c m} / \mathbf{s} / \mathbf{c m}, \mathbf{\Delta}=\mathbf{1 . 8} \mathbf{~ c m})$} \\
\cline { 2 - 7 } & $\mathbf{1 6 8}$ & $\mathbf{3 4 1}$ & $\mathbf{5 1 7}$ & $\mathbf{6 8 8}$ & $\mathbf{8 5 2}$ & $\mathbf{1 0 0 8}$ \\
\hline \hline Minor injury or & 0.20 & 0.00 & 0.00 & 0.18 & 0.67 & 1.00 \\
worse & $(1.00)$ & $(1.00)$ & $(1.00)$ & $(0.004)$ & $(<0.001)$ & $(<0.001)$ \\
\hline Major injury or & 0.00 & 0.00 & 0.00 & 0.00 & 0.07 & 0.00 \\
worse & $(1.00)$ & $(1.00)$ & $(1.00)$ & $(1.00)$ & $(0.44)$ & $(0.87)$ \\
\hline Death & 0.00 & 0.00 & 0.00 & 0.00 & 0.00 & 0.00 \\
& $(1.00)$ & $(1.00)$ & $(1.00)$ & $(1.00)$ & $(1.00)$ & $(1.00)$ \\
\hline \hline
\end{tabular}

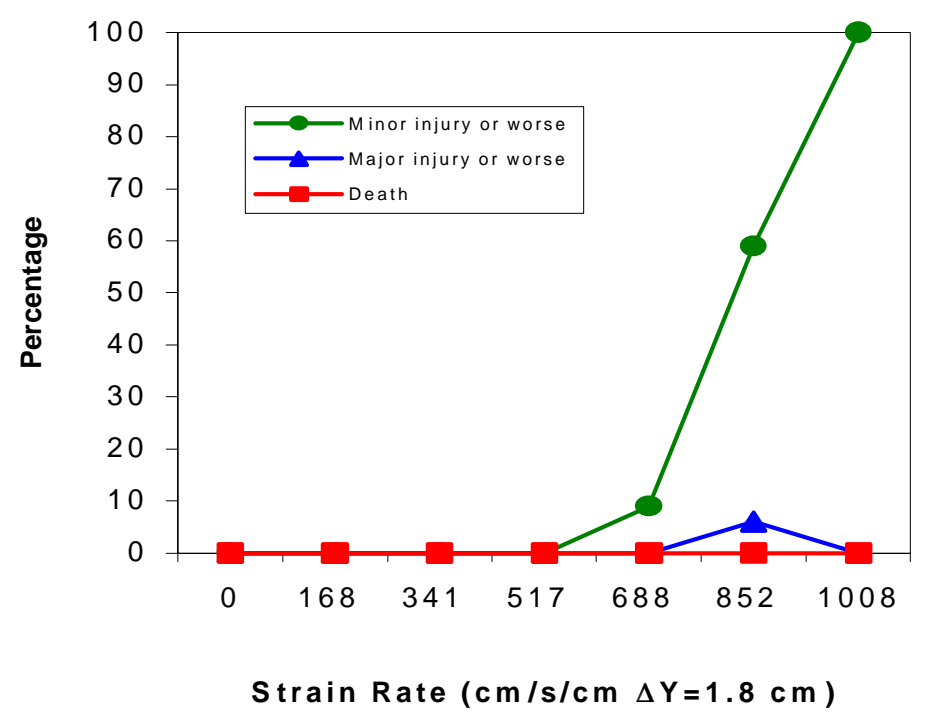

Figure 4.14. Percentage of steelhead smolts (mean $\mathrm{FL}=21.5 \mathrm{~cm}$ ) injured or killed during headfirst exposure to different strains rates $(\mathrm{N}=170)$.

\section{Species-Specific Results (American Shad)}

Of all the species of fish tested, American shad were most sensitive to the effects of exposure to shear stress. Shad were also very sensitive to the effects of handling, as evidenced by a $20 \%$ mortality rate in control fish within the first 48-h post-handling (Table 4.7, Figure 4.15). 
Table 4.7 shows that a strain rate of $517 \mathrm{~cm} / \mathrm{s} / \mathrm{cm}(\Delta y=1.8 \mathrm{~cm})$ resulted in significant injury and mortality in American shad. All the American shad exposed to the highest strain rate tested $(1008 \mathrm{~cm} / \mathrm{s} / \mathrm{cm}[\Delta \mathrm{y}=1.8 \mathrm{~cm}])$, died within $48 \mathrm{~h}$ of exposure.

Table 4.7. Proportions and P-values (in parentheses) for Chi-square proportion tests performed on the effects of headfirst strain rate exposure on injury and death in American shad. Shaded cells denote the LOEL for strain rate on injury.

\begin{tabular}{||l|c|c|c|c|c|c|c||}
\hline \multirow{2}{*}{ Injury Level } & \multicolumn{7}{|c||}{ Strain rate $\mathbf{( c m / s / c m , ~} \mathbf{y}=\mathbf{1 . 8} \mathbf{~ c m})$} \\
\cline { 2 - 8 } & $\mathbf{0}$ & $\mathbf{1 6 8}$ & $\mathbf{3 4 1}$ & $\mathbf{5 1 7}$ & $\mathbf{6 8 8}$ & $\mathbf{8 5 2}$ & $\mathbf{1 0 0 8}$ \\
\hline \hline Minor injury & 0.20 & 0.10 & 0.23 & 0.27 & 0.80 & 0.97 & 1.00 \\
or worse & $(0.89)$ & $(0.39)$ & $(0.24)$ & $(<0.001)$ & $(<0.001)$ & $(<0.001)$ & $(<0.001)$ \\
\hline Major injury & 0.20 & 0.10 & 0.13 & 0.13 & 0.50 & 0.93 & 1.00 \\
or worse & $(0.89)$ & $(0.88)$ & $(0.88)$ & $(<0.001)$ & $(<0.001)$ & $(<0.001)$ & $(<0.001)$ \\
\hline Death & 0.20 & 0.10 & 0.10 & 0.10 & 0.43 & 0.87 & 1.00 \\
& $(0.89)$ & $(0.96)$ & $(0.96)$ & $(0.003)$ & $(<0.001)$ & $(<0.001)$ & $(<0.001)$ \\
\hline
\end{tabular}

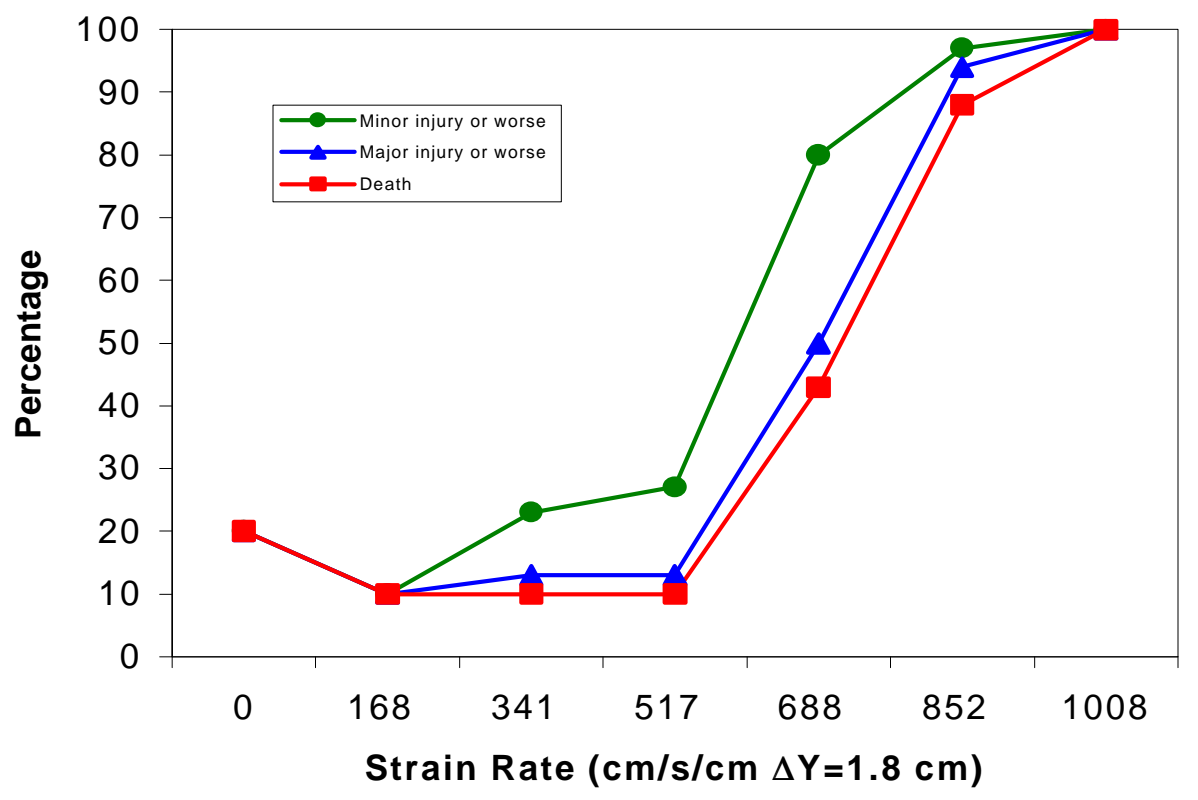

Figure 4.15. Percentage of American shad (mean $F L=10 \mathrm{~cm}$ ) injured or killed during headfirst exposure to different strain rates $(\mathrm{N}=150)$.

\section{Slow-Fish-to-Fast-Water/Tailfirst Orientation}

Fall and spring chinook salmon and steelhead were also exposed to a shear environment by a tailfirst orientation. Fish that were introduced tailfirst into the shear environment generally sustained lower injury rates than those introduced headfirst. Species/stock-specific results are presented below. 


\section{Fall Chinook Salmon}

Fall chinook salmon introduced into the highest strain rates suffered primarily minor injuries (Figure 4.16). The highest level of strain rate that did not result in a significant proportion of minor injuries was $852 \mathrm{~cm} / \mathrm{s} / \mathrm{cm}(\Delta \mathrm{y}=1.8 \mathrm{~cm})$ (Table 4.8$)$. We did not detect significant proportions of major injuries or mortalities in fall chinook salmon exposed to the three higher strain rates tested (i.e., $>688 \mathrm{~cm} / \mathrm{s} / \mathrm{cm})$.

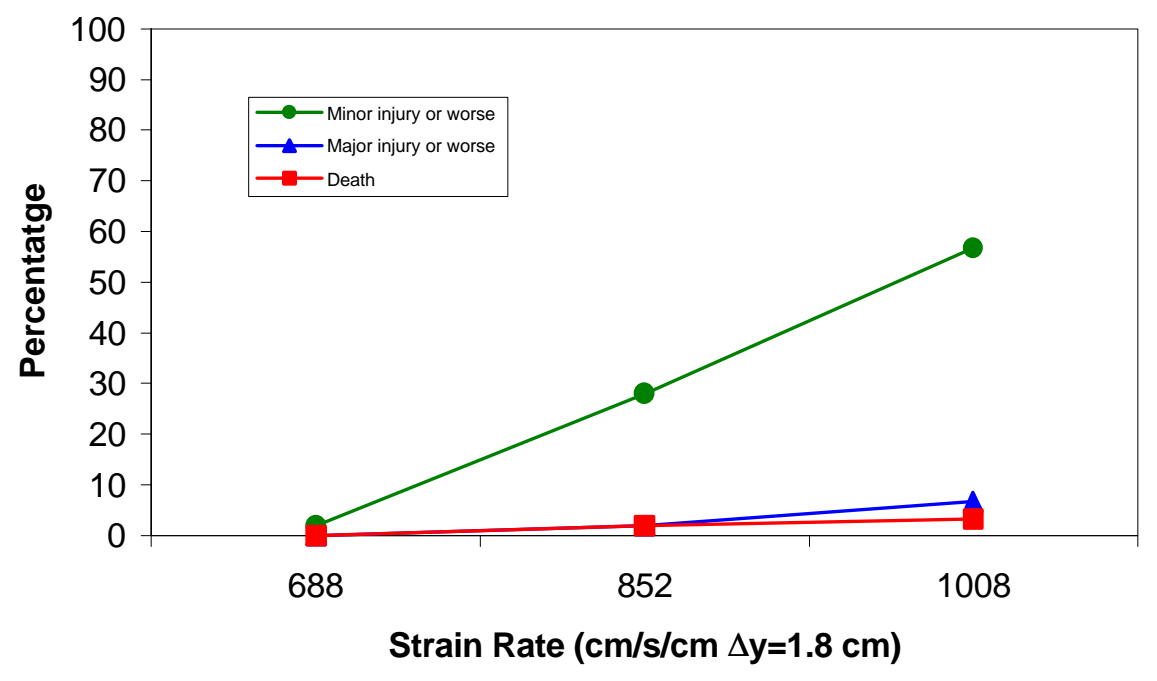

Figure 4.16. Percentage of age- 1 fall chinook salmon (mean $F L=14 \mathrm{~cm}$ ) injured or killed during tailfirst exposure to different strain rates $(\mathrm{N}=130)$.

Table 4.8. Proportions and P-values (in parentheses) for Chi-square proportion tests performed on the effects of tailfirst strain rate exposure on injury and death in fall chinook salmon. Shaded cells denote the LOEL for strain rate on injury.

\begin{tabular}{||c|c|c|c||}
\hline \multirow{2}{*}{ Injury Level } & \multicolumn{3}{|c||}{ Strain Rate $(\mathbf{c m} / \mathbf{s} / \mathbf{c m}, \Delta \mathbf{y}=\mathbf{1 . 8} \mathbf{~ c m})$} \\
\cline { 2 - 4 } & $\mathbf{6 8 8}$ & $\mathbf{8 5 2}$ & $\mathbf{1 0 0 8}$ \\
\hline Minor injury or worse & 0.02 & 0.28 & 0.57 \\
& $(0.64)$ & $(<0.001)$ & $(<0.001)$ \\
\hline Major injury or worse & 0.00 & 0.02 & 0.07 \\
& $(1.00)$ & $(0.64)$ & $(0.12)$ \\
\hline Death & 0.00 & 0.02 & 0.03 \\
& $(1.00)$ & $(0.64)$ & $(0.46)$ \\
\hline
\end{tabular}

\section{Spring Chinook Salmon}

Spring chinook salmon were relatively resistant to injury from strain rates when introduced into the shear environment in a tailfirst orientation. No major injuries or mortalities were observed in spring chinook salmon introduced tailfirst into the strain rates $>688 \mathrm{~cm} / \mathrm{s} / \mathrm{cm}$ (Figure 4.17). 


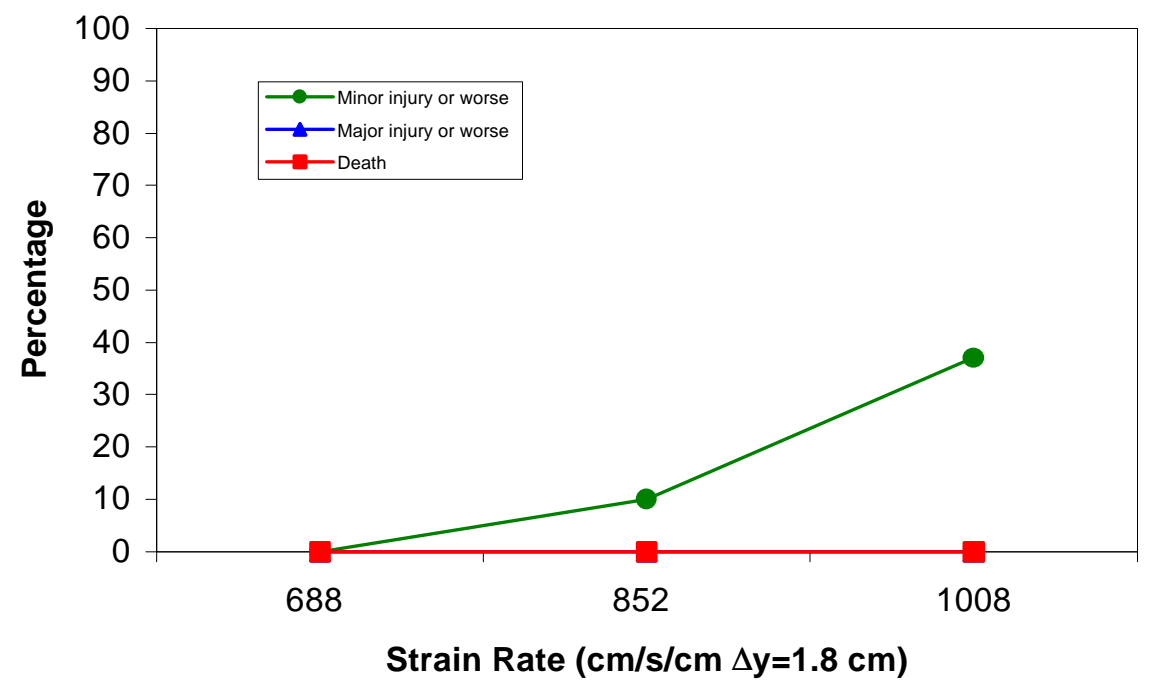

Figure 4.17. Percentage of spring chinook salmon smolts (mean $F L=14.5 \mathrm{~cm}$ ) injured or killed during tailfirst exposure to different strain rates $(\mathrm{N}=130)$.

A strain rate of $852 \mathrm{~cm} / \mathrm{s} / \mathrm{cm}(\Delta \mathrm{y}=1.8 \mathrm{~cm})$ produced a significant level of minor injury in spring chinook salmon (Table 4.9). There was no significant proportion of major injury or death in spring chinook salmon smolts for any of the strain rate levels tested $(688,852$, and $1008 \mathrm{~cm} / \mathrm{s} / \mathrm{cm}[\Delta y=1.8 \mathrm{~cm}])$.

Table 4.9. Proportions and $\mathrm{P}$-values (in parentheses) for Chi-square proportion tests performed on the effects of tailfirst strain rate exposure on injury and death in spring chinook salmon smolts. Shaded cells denote the LOEL for strain rate on injury.

\begin{tabular}{||l|c|c|c||}
\hline \multirow{2}{*}{ Injury Level } & \multicolumn{3}{|c||}{ Strain Rate $(\mathbf{c m} / \mathbf{s} / \mathbf{c m}, \Delta \mathbf{y}=\mathbf{1 . 8} \mathbf{~ c m})$} \\
\cline { 2 - 4 } & $\mathbf{6 8 8}$ & $\mathbf{8 5 2}$ & $\mathbf{1 0 0 8}$ \\
\hline \hline \multirow{2}{*}{ Minor injury or worse } & 0.00 & 0.10 & 0.47 \\
& $(1.00)$ & $(0.003)$ & $(<0.001)$ \\
\hline Major injury or worse & 0.00 & 0.00 & 0.00 \\
& $(1.00)$ & $(1.00)$ & $(1.00)$ \\
\hline Death & 0.00 & 0.00 & 1.00 \\
& $(1.00)$ & $(1.00)$ & $(1.00)$ \\
\hline
\end{tabular}

\section{Steelhead}

Steelhead were exposed to only the two highest strain rates based on their resistance to major injury in the headfirst orientation tests. Steelhead sustained only a low proportion of minor injuries when exposed to the higher rates of strain (Figure 4.18). The highest strain rates tested $(1008 \mathrm{~cm} / \mathrm{s} / \mathrm{cm}$ $[\Delta y=1.8 \mathrm{~cm}]$ ) produced a significant proportion of minor injuries in steelhead (Table 4.10). No major injuries or mortalities were observed in steelhead that were exposed to strain rates of 852 and $1008 \mathrm{~cm} / \mathrm{s} / \mathrm{cm}$ in a tailfirst orientation. 


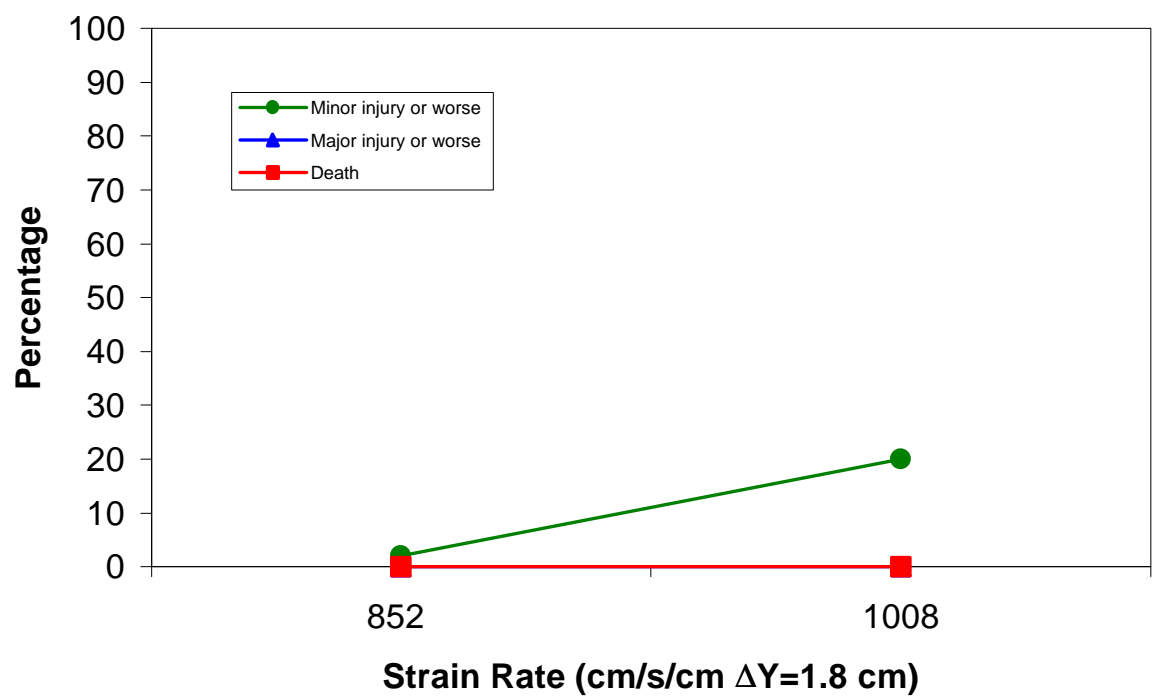

Figure 4.18. Percentage of steelhead smolts (mean $\mathrm{FL}=14.5 \mathrm{~cm}$ ) injured or killed during tailfirst exposure to different strain rates $(\mathrm{N}=80)$.

Table 4.10. Proportions and P-values (in parentheses) for Chi-square proportion tests performed on the effects of tailfirst strain rate exposure on injury and death in steelhead smolts. Shaded cells denote the LOEL for strain rate on injury.

\begin{tabular}{||l|c|c||}
\hline \multirow{2}{*}{\multicolumn{1}{|c|}{ Injury Level }} & \multicolumn{2}{|c||}{ Strain rate $(\mathbf{c m} / \mathbf{s} / \mathbf{c m}, \mathbf{\Delta y}=\mathbf{1 . 8} \mathbf{~ c m})$} \\
\cline { 2 - 3 } & $\mathbf{8 5 2}$ & $\mathbf{1 0 0 8}$ \\
\hline \hline Minor injury or worse & 0.03 & 0.20 \\
& $(0.55)$ & $(<0.001)$ \\
\hline Major injury or worse & 0.00 & 0.00 \\
& $(1.00)$ & $(1.00)$ \\
\hline Death & 0.00 & 1.00 \\
& $(1.00)$ & $(1.00)$ \\
\hline
\end{tabular}

\section{Fast Fish to Slow Water}

For rainbow trout, fast fish in slow water, the highest rate of strain without any significant minor injury (or worse) was $688 \mathrm{~cm} / \mathrm{s} / \mathrm{cm}(\Delta \mathrm{y}=1.8 \mathrm{~cm})$. This rate of strain without any injury was the same as the slow-to-fast-water rainbow trout test group. The rate of strain without any significant major injury or worse was $1008 \mathrm{~cm} / \mathrm{s} / \mathrm{cm}(\Delta y=1.8 \mathrm{~cm})$ (Figure 4.19, Table 4.11). Within the range of 688 to $1150 \mathrm{~cm} / \mathrm{s} / \mathrm{cm}(\Delta y=1.8 \mathrm{~cm})$ strain rates there was no significant rate of death. 


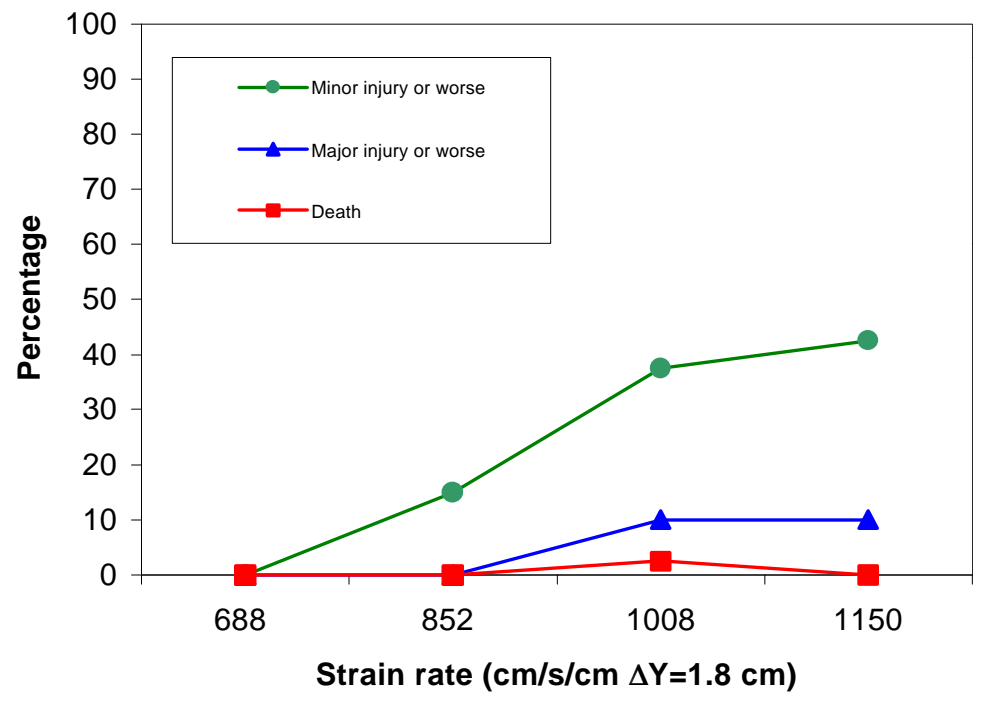

Figure 4.19. Percentage of rainbow trout (mean $\mathrm{FL}=12 \mathrm{~cm}$ ) injured or killed during a fast-fishto-slow-water exposure to shear stresses of different intensities $(\mathrm{N}=200)$.

Table 4.11. Proportions and P-values (in parentheses) for Chi-square proportion tests performed on the effects of shear stress exposure on injury and death in rainbow trout exposed during fast-fish-to-slow-water tests. Shaded cells denote the LOEL for strain rate on injury.

\begin{tabular}{||c|c|c|c|c||}
\hline \multirow{2}{*}{ Injury Level } & \multicolumn{4}{|c||}{ Strain Rate $(\mathbf{c m} / \mathbf{s} / \mathbf{c m}, \Delta \mathbf{y}=\mathbf{1 . 8} \mathbf{~ c m})$} \\
\cline { 2 - 5 } & $\mathbf{6 8 8}$ & $\mathbf{8 5 2}$ & $\mathbf{1 0 0 8}$ & $\mathbf{1 1 5 0}$ \\
\hline \hline Minor injury or worse & 0 & 0.15 & 0.375 & 0.425 \\
& $(1.000)$ & $(<0.001)$ & $(<0.001)$ & $(0.001)$ \\
\hline Major injury or worse & 0.00 & 0.00 & 0.10 & 0.10 \\
& $(1.00)$ & $(1.00)$ & $(0.008)$ & $(0.008)$ \\
\hline Death & 0.00 & 0.00 & 0.025 & 0.00 \\
& $(1.00)$ & $(1.00)$ & $(0.543)$ & $(1.00)$ \\
\hline \hline
\end{tabular}

No injuries were observed at a strain rate of $688 \mathrm{~cm} / \mathrm{s} / \mathrm{cm}(\Delta y=1.8 \mathrm{~cm})$, with all but one of this group exiting the nozzle tailfirst. At this velocity, fish were observed swimming in the clear section of tubing for approximately $5 \mathrm{~min}$ before exiting the nozzle. At a rate of strain of $852 \mathrm{~cm} / \mathrm{s} / \mathrm{cm}(\Delta y=1.8 \mathrm{~cm})$, all but one of the 60 fish tested exited the nozzle headfirst. The time spent in the tube before exiting the nozzle was $\sim 1.5 \mathrm{~min}$. Immediate injuries were minor and consisted of slight head and dorsal body bruises. At the $1008 \mathrm{~cm} / \mathrm{s} / \mathrm{cm}(\Delta y=1.8 \mathrm{~cm})$ strain rate, three of 57 fish recorded using the video system exited headfirst with the time spent in the tube averaging $22 \mathrm{~s}$. Injuries associated with this test group were head and body bruising and bleeding from the gills. The last test group was tested at a strain rate of $1150 \mathrm{~cm} / \mathrm{s} / \mathrm{cm}(\Delta \mathrm{y}=1.8 \mathrm{~cm})$. All but two fish exited tailfirst, with the fish spending about $16 \mathrm{~s}$ in the tube 
before exiting. Common injuries associated with this test group were head and body bruising (Figure 4.20), damaged and/or bleeding gills (Figure 4.21), minor isthmus tears, and loss of equilibrium. Body bruises were usually temporary, lasting no more that 1 or $2 \mathrm{~h}$. However, in a few cases at 1008 and $1150 \mathrm{~cm} / \mathrm{s} / \mathrm{cm}(\Delta \mathrm{y}=1.8 \mathrm{~cm})$ strain rates, bruises could be seen $48 \mathrm{~h}$ after exposure. In addition, two fish subjected at a rate of strain of $1150 \mathrm{~cm} / \mathrm{s} / \mathrm{cm}(\Delta \mathrm{y}=1.8 \mathrm{~cm})$ had what appeared to be a broken spine. These fish were dissected after $48 \mathrm{~h}$, and no obvious abnormalities could be detected in the spine.

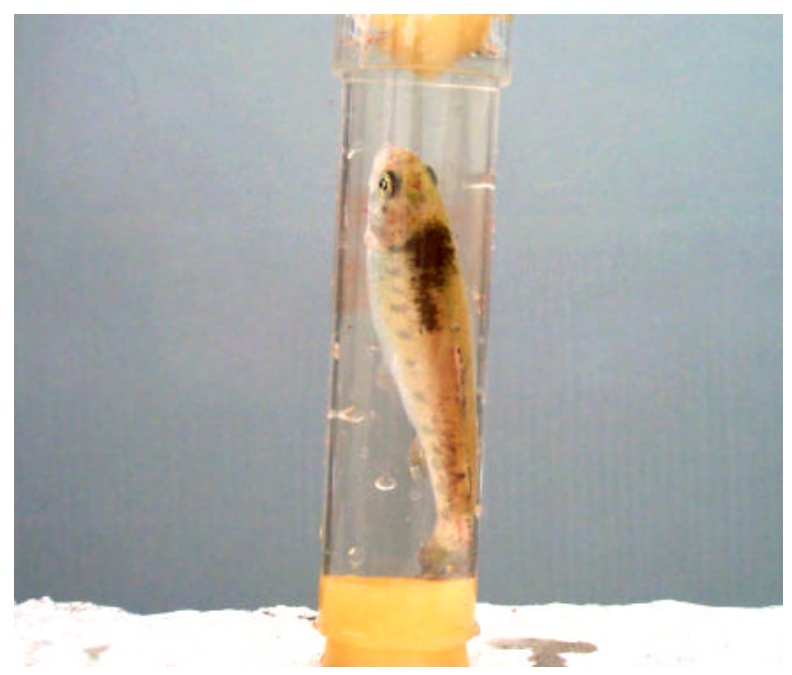

Figure 4.20. Example of rainbow trout bruising immediately after exposure to a rate of strain of $1150 \mathrm{~cm} / \mathrm{s} / \mathrm{cm}(\Delta y=1.8 \mathrm{~cm})$ during a fast-fish-to-slow-water test.

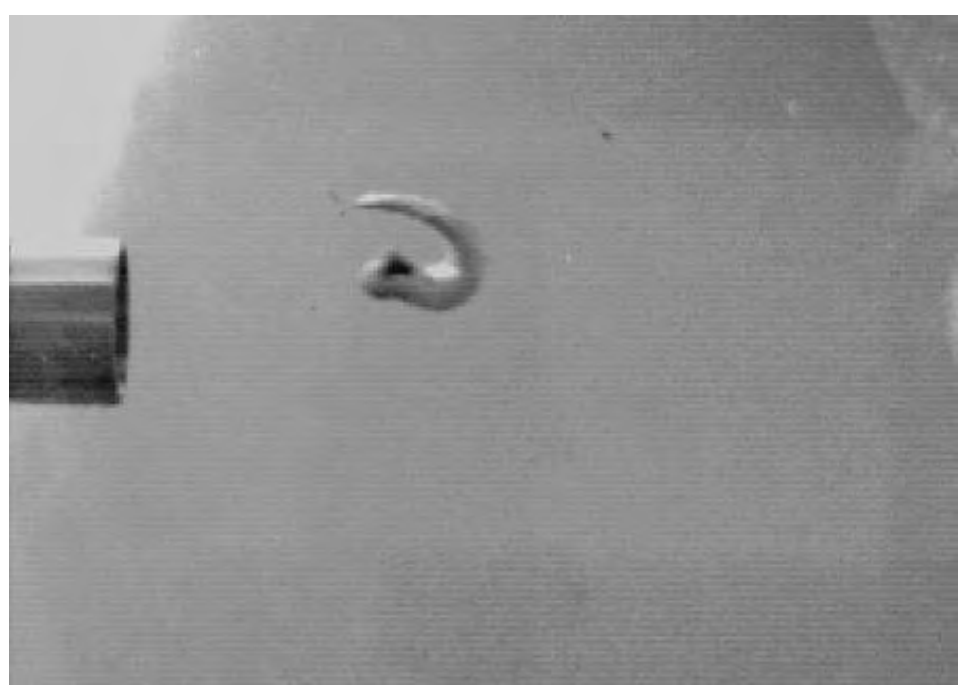

Figure 4.21. Digitized image of rainbow trout illustrating opercal flare upon exiting the nozzle during a fast-fish-to-slow-water test. 


\subsubsection{Indirect Mortality}

Fish exposed to in shear environment (headfirst, slow-fish-to-fast-water scenario) with strain rates less than those causing significant direct injuries resulted in a significant increase in susceptibility of the exposed fish to predation. Juvenile rainbow trout introduced headfirst into a strain rate of $688 \mathrm{~cm} / \mathrm{s} / \mathrm{cm}$ $(\Delta y=1.8 \mathrm{~cm})$ were preyed upon (or injured by a predatory attack) at a higher rate than control fish that were not exposed to the strain rate (Figure 4.22).

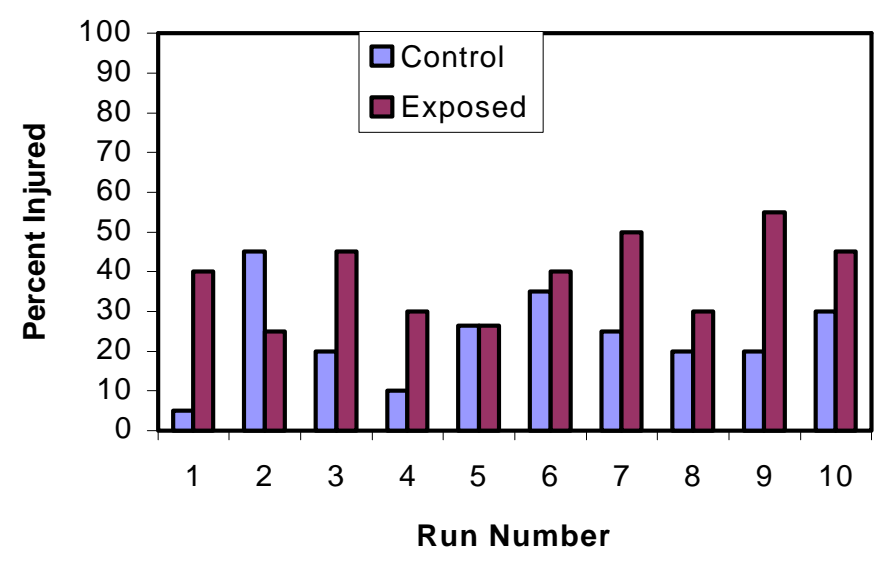

Figure 4.22. Percentage of injured (eaten and injured by a predatory attack) control and strain rate exposed (headfirst into $688 \mathrm{~cm} / \mathrm{s} / \mathrm{cm}[\Delta y=1.8 \mathrm{~cm}]$ ) juvenile rainbow trout for 10 test runs. This strain rate did not cause obvious injury or mortality in direct injury/mortality tests. Total sample size was 199 fish of each group.

In contrast to trout exposed to the higher strain rate, juvenile rainbow trout that were exposed to $517 \mathrm{~cm} / \mathrm{s} / \mathrm{cm}(\Delta \mathrm{y}=1.8 \mathrm{~cm})$ were not preyed upon at a significantly different rate than controls (Figure 4.23).

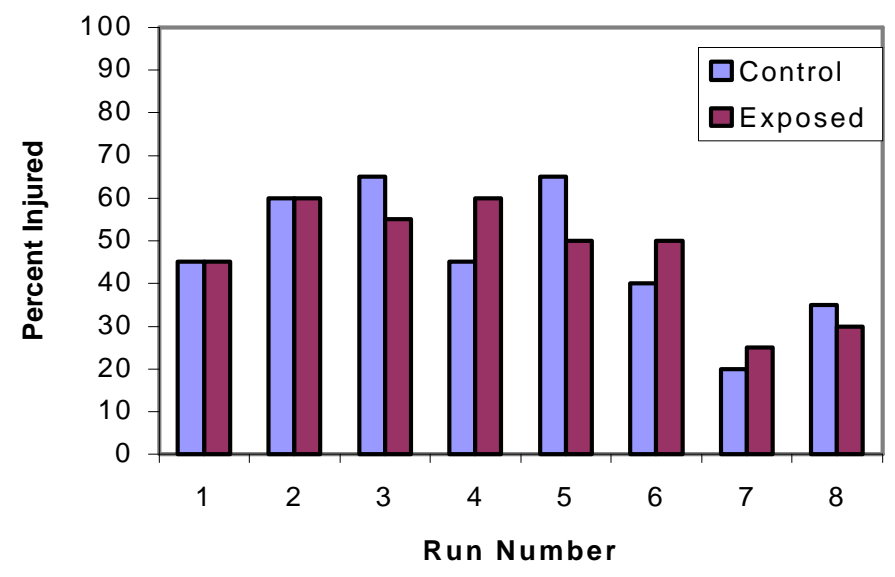

Figure 4.23. Percentage of injured (eaten and injured by a predatory attack) control and exposed (headfirst into 517 strain rate $(\mathrm{cm} / \mathrm{s} / \mathrm{cm}[\Delta \mathrm{y}=1.8 \mathrm{~cm}])$ juvenile rainbow trout for eight test runs. Total sample size was 160 fish of each group. 
The analysis of variance results (Table 4.12) indicate there was a significant treatment effect, but not a significant run number effect for the predation tests conducted at a strain rate of $688 \mathrm{~cm} / \mathrm{s} / \mathrm{cm}(\Delta y=1.8$ $\mathrm{cm})$. In contrast, Table 4.13 shows there was no significant treatment effect on predation when fish were exposed to a strain rate of $517 \mathrm{~cm} / \mathrm{s} / \mathrm{cm}(\Delta \mathrm{y}=1.8 \mathrm{~cm})$, and there was a significant run number effect. This run number effect, however, did not affect the treatment effect, and a test of the interaction between run number and treatment proved to be insignificant $(\mathrm{p}=0.93)$. The residual mean square error (experimental variance) is similar in both tests, showing a consistency in the variability between the experiments.

Table 4.12. Analysis of variance results for predator challenge tests with juvenile rainbow trout that were exposed to a strain rate of $688 \mathrm{~cm} / \mathrm{s} / \mathrm{cm}(\Delta y=1.8 \mathrm{~cm})$. Results relative to the treatment effect are shaded.

\begin{tabular}{||l|c|c|c|c|c||}
\hline \multicolumn{1}{|c|}{ Factor } & $\begin{array}{c}\text { Degrees of } \\
\text { Freedom }\end{array}$ & $\begin{array}{c}\text { Sums of } \\
\text { Squares }\end{array}$ & $\begin{array}{c}\text { Mean } \\
\text { Squares }\end{array}$ & $\begin{array}{c}\text { F (Test } \\
\text { Statistic) }\end{array}$ & p-value \\
\hline \hline Run Number & 9 & 7.65 & 0.85 & 0.83 & 0.587 \\
\hline Side & 1 & 1.14 & 1.14 & 1.11 & 0.292 \\
\hline Treatment & 1 & 11.27 & 11.27 & 11.03 & 0.001 \\
\hline Residual & 386 & 394.48 & 1.02 & & \\
\hline
\end{tabular}

Table 4.13. Analysis of variance results for predator challenge tests with juvenile rainbow trout that were exposed to a strain rate of $517 \mathrm{~cm} / \mathrm{s} / \mathrm{cm}(\Delta y=1.8 \mathrm{~cm})$.

Results relative to the treatment effect are shaded.

\begin{tabular}{||l|c|c|c|c|c||}
\hline \multicolumn{1}{|c|}{ Factor } & $\begin{array}{c}\text { Degrees of } \\
\text { Freedom }\end{array}$ & $\begin{array}{c}\text { Sums of } \\
\text { Squares }\end{array}$ & $\begin{array}{c}\text { Mean } \\
\text { Squares }\end{array}$ & $\begin{array}{c}\text { F (Test } \\
\text { Statistic) }\end{array}$ & p-value \\
\hline \hline Run Number & 7 & 19.68 & 2.81 & 2.72 & 0.009 \\
\hline Side & 1 & 0.94 & 0.94 & 0.91 & 0.341 \\
\hline Treatment & 1 & 0.08 & 0.08 & 0.08 & 0.780 \\
\hline Residual & 310 & 320.47 & 1.03 & & \\
\hline
\end{tabular}

The effects of predation on injured or disoriented fish is depicted in Figure 4.24, which shows the relative impacts of direct injuries (lines) and indirect injuries/death due to predation for juvenile rainbow trout exposed to strain rates of 517 and $688 \mathrm{~cm} / \mathrm{s} / \mathrm{cm}(\Delta y=1.8 \mathrm{~cm})$. The data points representing predation effects are the percentage of fish that were injured by predatory attacks that were attributable to exposure to the strain rate (i.e., exposed \% - control \%). 


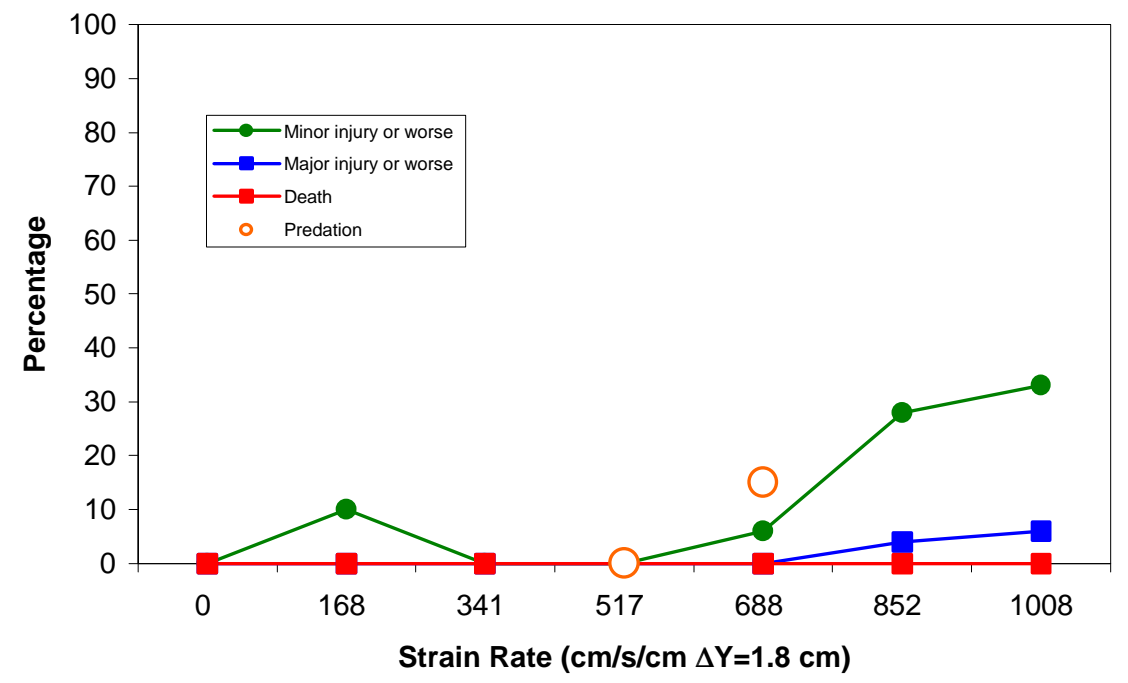

Figure 4.24. Percentage of juvenile rainbow trout (mean $F L=15.5 \mathrm{~cm}$ ) injured or killed during headfirst exposure to different strain rates $(\mathrm{N}=170)$. Open circles at strain rates of 517 and $688 \mathrm{~cm} / \mathrm{s} / \mathrm{cm}(\Delta y=1.8 \mathrm{~cm})$ represent the difference between the mean injury/mortality rates of exposed and control rainbow trout. These results were observed during predation challenges of fish exposed to those strain rates $(\mathrm{N}=160$ at 517 and $\mathrm{N}=199$ at 688 $\mathrm{cm} / \mathrm{s} / \mathrm{cm}[\Delta \mathrm{y}=1.8 \mathrm{~cm}])$. 


\subsection{Discussion}

This section includes four general topic areas. The first area summarizes what we know about shear in the natural environment and shear associated with hydroelectric power. The second area focuses on what we believe is the most appropriate index to describe the biological response of fish that enter a shear environment. Thirdly, we compare and contrast the biological response of fish to physical conditions that are known to occur during turbine passage. Specific endpoints used to describe the biological response of test fish include both direct (injury and mortality) and indirect (increased susceptibility to predation) responses to exposures of a jet of water. The final part of this discussion compares the results of our studies to previous investigations of high velocity environments.

\subsection{Natural Shear Environments and Those Associated with Hydroelectric Power}

Fluid shear and turbulence are natural phenomena important to fish. Aquatic organisms have developed numerous adaptations to the levels of shear and turbulence found in normal river flows (Vogel 1981). Rheotactic response to turbulence may promote movement among migratory fish (Coutant 1998) or prevent displacement of resident fish (Shtaf et al. 1983, Skorobogatov and Pavlov 1991).

However, elevated levels of shear and turbulence may be damaging to fish. These forces can occur in both natural and man-made environments. For example, concerns have been expressed by numerous investigators that excessive fluid forces associated with passage through hydroelectric turbines, spillways, and fish bypass systems may have adverse effects on downstream migrating fish (summarized by Nada et al. 1997).

This section defines the terms associated with these fluid phenomena and compares values reported in the literature. Table 5.1 displays values for shear stress that have been reported for a variety of natural and man-altered aquatic environments. Not surprisingly, estimated values of shear stress in streams and rivers under normal flows are generally low, most often less than $100 \mathrm{~N} / \mathrm{m}^{2}$. Because this is the natural

Table 5.1. Published estimates of shear stress $\left(\mathrm{N} / \mathrm{m}^{2}\right)$ in natural and man-altered aquatic environments.

\begin{tabular}{|l|c|l||}
\hline \multicolumn{1}{|c|}{ Environment } & Shear stress $\left(\mathbf{N} / \mathbf{m}^{\mathbf{2}}\right)$ & \multicolumn{1}{c||}{ Literature Cited } \\
\hline \hline Water column in a trout stream, average flow & $<1.0$ & Fausch and White (1981) \\
\hline Small streams, near bed & $<1-7$ & Lancaster and Hildrew (1993) \\
\hline $\begin{array}{l}\text { Medium-size streams, near bed } \\
\text { (90 measurements) }\end{array}$ & most <30, but some >200 & Statzner and Müller (1989) \\
\hline Flash floods, small basins & $61-2600$ & Costa (1987) \\
\hline Floods, large rivers & $6-10$ & Costa (1987) \\
\hline Bulb turbine draft tube & $500-5421$ & McEwen and Scobie (1992) \\
\hline Near ship hulls and wakes & $7.6-40.4$ & Morgan et al. (1976) \\
\hline Near barge propeller & $\geq 5000$ & Killgore et al. (1987) \\
\hline
\end{tabular}


environment for fish, it can be expected that these values would not be damaging. On the other hand, shear stress estimates for flash floods in small river basins may be several hundred $\mathrm{N} / \mathrm{m}^{2}$ to as high as $2600 \mathrm{~N} / \mathrm{m}^{2}$. Fish are often displaced downstream and killed in flash floods, although shear stress may not be the sole cause.

\subsection{Strain Rate and Shear Stress at Hydroelectric Power Plants}

The largest values for strain rate in a turbine water passage are likely to occur in the narrow boundary layer near structures and in association with vortices. These conditions occur near the periphery of the blade (blade tip vortex), near the hub (hub leakage vortex), and in the center of a Francis turbine (rope vortex). We have not found estimates of the magnitude of shear near such vortices. It has been suggested that shear values may be 400 to $600 \mathrm{~cm} / \mathrm{s} / \mathrm{cm}$ in a narrow boundary layer near structures such as the wicket gate, stay vane, and runner blade leading edge (Voith Hydro, Inc. 1997). However, the bulk of the flow through a Kaplan turbine may create much smaller shears, perhaps in the neighborhood of $50 \mathrm{~cm} / \mathrm{s} / \mathrm{cm}$.

Estimates of shear stress in the draft tube of a bulb turbine may exceed $5000 \mathrm{~N} / \mathrm{m}^{2}$ (Table 5.2). These large values might occur in only a small portion of the turbine passage. For example, McEwen and Scobie (1992) estimated that shear stress values in a bulb turbine would be less than $500 \mathrm{~N} / \mathrm{m}^{2}$ in about $85 \%$ of the draft tube and less than $1000 \mathrm{~N} / \mathrm{m}^{2}$ in over $90 \%$ of the draft tube. Shear stress between 4000 and $5000 \mathrm{~N} / \mathrm{m}^{2}$ would occur in only about $2 \%$ of the passage.

Table 5.2. Estimated probabilities of ranges of shear stress (expressed as percentages of the crosssectional area) in the draft tube of a bulb turbine. From McEwen and Scobie (1992).

\begin{tabular}{||l|c|c||}
\hline \multicolumn{1}{|c|}{ Shear Stress $\left(\mathbf{N} / \mathbf{m}^{\mathbf{2}}\right)$} & Off-Design Operation $\mathbf{( \% )}$ & Design Operation $\mathbf{( \% )}$ \\
\hline \hline $50-100$ & 56.9 & 52.1 \\
\hline $100-500$ & 28.1 & 31.1 \\
\hline $500-1000$ & 6.2 & 9.2 \\
\hline $1000-2000$ & 3.0 & 3.9 \\
\hline $2000-3000$ & 2.4 & 2.1 \\
\hline $3000-4000$ & 1.2 & 1.5 \\
\hline $4000-5000$ & 2.1 & 0 \\
\hline
\end{tabular}

Turbine passage for a fish involves more than swimming or moving past the turbine blades (Figure 5.1). Turbine passage begins as the fish leaves the reservoir upstream of the dam and enters the turbine intake. Different areas of the turbine system produce different fluid and mechanical stresses; for convenience, these areas can be split into five zones (Table 5.3). At some dams, bypass screens (Zone 1) direct fish through a passage system and downstream of the dam without passing the turbine blades. Fish at dams without screens, and/or fish that pass beneath the screens, then enter the scroll case (Zone 2). From here, fish pass the blades (Zone 3), enter the draft tube (Zones $4 \& 5$ ), and swim into the river downstream of the dam. 
Fish can be killed or injured in each of these zones from a number of different mechanisms. The mechanisms include water pressure changes, cavitation, shear, turbulence, and strike. Each of these mechanisms can be severe enough to kill fish directly. Some of these mechanisms may result in injured fish that cannot survive after passage because of their susceptibility to disease or predation.

\subsection{Biological Response}

Our results showed that fish entering into a shear stress environment may be killed, injured, or may die from other causes, such as predation. Fish in our tests were subjected to rates of strain up to $1185 \mathrm{~cm} / \mathrm{s} / \mathrm{cm}(\Delta \mathrm{y}=1.8 \mathrm{~cm})$. There were no significant injuries to any fish subjected to rates of strain less than $500 \mathrm{~cm} / \mathrm{s} / \mathrm{cm}(\Delta y=1.8 \mathrm{~cm})$ (Table 5.4). Of the fish tested, American shad were the most susceptible to injury, and steelhead and rainbow trout were the most resistant.

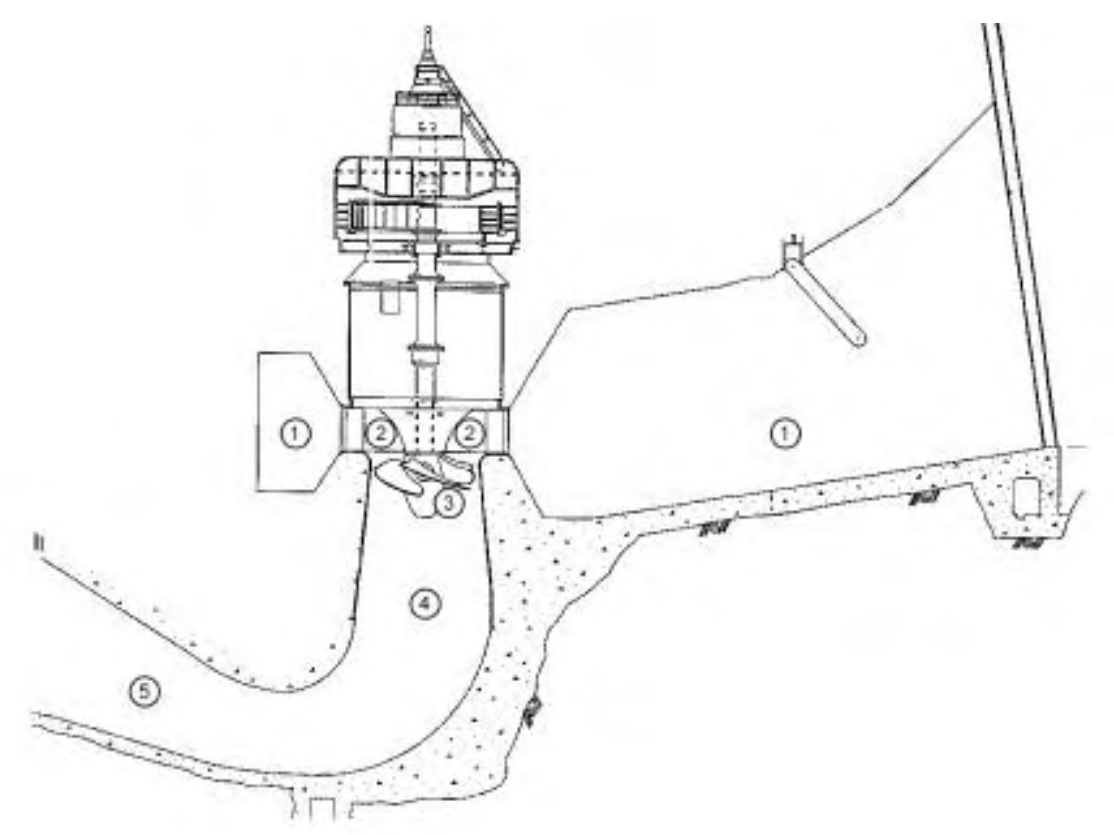

Figure 5.1. Cross-section view through a Kaplan turbine (based on a turbine at Lower Granite Dam, Snake River, Washington, U.S.A.). See Table 5.3 for a description of turbine zones 1-5 shown in this figure.

The biological response of fish entering the fluid test environment with differential velocities was different depending on its orientation. For example, spring chinook salmon were injured at a strain rate $>500 \mathrm{~cm} / \mathrm{s} / \mathrm{cm}(\Delta y=1.8 \mathrm{~cm})$ when they entered the shear zone headfirst. However, spring chinook salmon that entered the same environment in a tailfirst orientation survived rates of strain that approached $700 \mathrm{~cm} / \mathrm{s} / \mathrm{cm}(\Delta y=1.8 \mathrm{~cm})$. Typical injuries during the headfirst exposure included torn operculi and missing eyes. Similar injuries have been reported for salmonids presumed to pass the hub and mid-blade portion of turbines during recent tests at McNary Dam (Normendeau et al. 1999). 
Table 5.3. Description of turbine environment and expected shear and turbulence strains to be encountered by a fish passing through a turbine (see Figure 5.1).

\begin{tabular}{|c|c|c|}
\hline Turbine Zone & Description & Environmental Conditions \\
\hline 1 & $\begin{array}{l}\text { Turbine intake or the area from trash } \\
\text { rack to the stay vanes, including the } \\
\text { scroll case. }\end{array}$ & $\begin{array}{l}\text { Velocities increase from } \sim 1 \mathrm{~m} / \mathrm{s} \text { at the } \\
\text { entrance to } 2+\mathrm{m} / \mathrm{s} \text { at the scroll case. } \\
\text { Shear is expected to be highest along } \\
\text { the outside boundaries or near the } \\
\text { intake wall. }\end{array}$ \\
\hline 2 & $\begin{array}{l}\text { The area above and upstream of the } \\
\text { turbine blades, including around the } \\
\text { stay vanes and wicket gates. }\end{array}$ & $\begin{array}{l}\text { Velocities increase from } 2+\mathrm{m} / \mathrm{s} \text { to } \\
>6 \mathrm{~m} / \mathrm{s} \text { just above the turbine blades. } \\
\text { Both shear and turbulence are expected } \\
\text { here, but specific conditions are not } \\
\text { defined. There is some potential for } \\
\text { strike as fish pass the wicket gates. }\end{array}$ \\
\hline 3 & $\begin{array}{l}\text { Includes the area immediately } \\
\text { downstream of the turbine blades and } \\
\text { near the turbine hub. }\end{array}$ & $\begin{array}{l}\text { Velocity is highest here and } \\
\text { acceleration is rapid, increasing from } \\
>6 \text { to }>15 \mathrm{~m} / \mathrm{s} \text { over a relatively short } \\
\text { distance. The potential for strike (via } \\
\text { turbine blades) is thought to be highest } \\
\text { in this zone. There is also a pressure } \\
\text { drop from } 2 \text { to near } 0 \text { atmospheres. } \\
\text { Shear conditions are expected, but } \\
\text { undefined. }\end{array}$ \\
\hline 4 & $\begin{array}{l}\text { The vertical portion of the draft tube or } \\
\text { area immediately below and } \\
\text { downstream of the turbine hub and } \\
\text { perpendicular to the river bottom. }\end{array}$ & $\begin{array}{l}\text { Velocities decrease from }>15 \mathrm{~m} / \mathrm{s} \text { to } \\
\sim 5 \mathrm{~m} / \mathrm{s} \text {. Shear conditions are expected, } \\
\text { but undefined. }\end{array}$ \\
\hline 5 & $\begin{array}{l}\text { The horizontal portions of the draft } \\
\text { tube parallel to the river bottom. }\end{array}$ & $\begin{array}{l}\text { Velocities decrease from } \sim 5 \mathrm{~m} / \mathrm{s} \text { to } \\
\sim 3 \mathrm{~m} / \mathrm{s} \text { as the flow enters the tailrace. } \\
\text { Shear conditions may be experienced, } \\
\text { but are expected to be low. Turbulence } \\
\text { is expected to be greatest in this zone. }\end{array}$ \\
\hline
\end{tabular}

Indirect effects of passing through fluid environment with shear and turbulence forces also need to be considered to define biological specifications. For example, rainbow trout only received minor injuries at rates of strain near $900 \mathrm{~cm} / \mathrm{s} / \mathrm{cm}(\Delta y=1.8 \mathrm{~cm})$. However, rainbow trout subjected to rates of strain less than $700 \mathrm{~cm} / \mathrm{s} / \mathrm{cm}(\Delta y=1.8 \mathrm{~cm})$ were more susceptible to predation than control fish in the same test. Thus, factoring in indirect effects of exposure to shear stress to protect rainbow trout from shear stress may require providing a turbine environment with strain rates of no more than $500 \mathrm{~cm} / \mathrm{s} / \mathrm{cm}(\Delta y=1.8 \mathrm{~cm})$.

\subsection{Comparison to Previous Studies}

Direct comparisons between the strain rates reported here and values reported by other investigators are not possible because they did not measure the velocity fields. For example, Turnpenny et al. (1992) reported fluid shear stress values based on CFD simulations of their jet experiment using the FLUENT and PHOENIX codes. The simulated velocity fields were not reported for these studies, nor was the 
Table 5.4. Summary of the strain rate exposures from our tests that did not injure or kill fish.

\begin{tabular}{|c|c|c|c|c|}
\hline \multirow[b]{2}{*}{ Test Fish } & \multirow[b]{2}{*}{ Test Orientation } & \multicolumn{3}{|c|}{ Strain Rate $(\mathrm{cm} / \mathrm{s} / \mathrm{cm}[\Delta y=1.8 \mathrm{~cm}])$} \\
\hline & & $\begin{array}{c}\text { No Significant } \\
\text { Injury }\end{array}$ & $\begin{array}{l}\text { No Significant } \\
\text { Major Injury }\end{array}$ & $\begin{array}{l}\text { No Significant } \\
\text { Deaths }\end{array}$ \\
\hline Fall chinook (age-0) & Headfirst & 517 & 852 & 1008 \\
\hline Fall chinook (age-1) & Headfirst & 517 & 517 & 852 \\
\hline Spring chinook & Headfirst & 517 & 688 & 1008 \\
\hline Rainbow trout & Headfirst & 688 & 1008 & 1008 \\
\hline Steelhead & Headfirst & 517 & 1008 & 1008 \\
\hline American shad & Headfirst & 517 & 517 & 517 \\
\hline Fall chinook (age-1) & Tailfirst & 688 & 1008 & 1008 \\
\hline Spring chinook & Tailfirst & 688 & 1008 & 1008 \\
\hline Steelhead & Tailfirst & 852 & 1008 & 1008 \\
\hline Rainbow trout & $\begin{array}{l}\text { Headfirst w/ } \\
\text { predators }\end{array}$ & 517 & NA & NA \\
\hline
\end{tabular}

turbulence model used in the CFD analysis. In contrast, the strain-rate values from our experiments are based on direct measurement of the velocity field and were computed using Equation (1) (discussed in Section 2.0).

We calculated the strain rate in the zone where fish first contacted the edge of the jet based on a finite difference approximation of the formula in Equation (1). The value was determined as the change in velocity divided by the change in distance. The change in velocity was the measured jet exit velocity minus the initial fish velocity (assumed to be zero). The relevant change in distance, or measurement scale, was assumed to be the average width of the fish used in our experiments or $1.8 \mathrm{~cm}$. The jet exit velocities and associated rates of strain for our experiments are compared to those calculated for previous tests conducted by Johnson (1970, 1972), Groves (1972), and Turnpenny et al. (1992) in Table 5.5.

The data collected in this study were compared to those from a similar study conducted by Sami et al. (1967) who reported mean and turbulent flow measurements in the zone of flow establishment. The results, shown in Figure 4.7, demonstrate that similar turbulence characteristics were observed in these two studies. Note that an exit velocity of $10 \mathrm{fps}$ was selected because the Reynolds number was comparable between the two experiments. The absence of honeycomb or other means of conditioning the inflow are evidenced by initial turbulence intensities of about 5\% immediately downstream of the jet exit.

Groves (1972) reported that juvenile salmon were unaffected by exposure to jet velocities of 30 fps. We estimate this strain rate at $508 \mathrm{~cm} / \mathrm{s} / \mathrm{cm}(\Delta y=1.8 \mathrm{~cm})$. However, he also reported that the rates of disorientation, visible injury, and mortality increased as jet velocities increased above this value. Disoriented fish regained "normal capacities" within 5 to $30 \mathrm{~min}$. In our predator exposures, most 
Table 5.5. Comparison of jet exit velocities and estimated strain rates for PNNL study and our estimates of strain rate applied in four other fish/shear studies. Shaded areas indicate values where mortalities of test fish were not significantly different than controls, i.e., "safe" environments. Strain $\left(\mathrm{s}^{-1}\right)$ are described as $\mathrm{cm} / \mathrm{s} / \mathrm{cm}(\Delta \mathrm{y}=1.8 \mathrm{~cm})$. Jet velocities are described as feet per second (fps).

\begin{tabular}{|c|c|c|c|c|c|c|c|c|c|}
\hline \multicolumn{2}{|c|}{ PNNL } & \multicolumn{2}{|c|}{ Johnson (1970) } & \multicolumn{2}{|c|}{ Johnson (1972) } & \multicolumn{2}{|c|}{ Groves (1972) } & \multicolumn{2}{|c|}{$\begin{array}{c}\text { Turnpenny et al. } \\
\text { (1992) }\end{array}$} \\
\hline $\begin{array}{c}\text { Jet } \\
\text { Velocity } \\
\text { (fps) }\end{array}$ & $\begin{array}{l}\text { Strain } \\
\text { Rate } \\
\text { e }\left(\mathbf{s}^{-1}\right)\end{array}$ & $\begin{array}{c}\text { Jet } \\
\text { Velocity } \\
\text { (fps) }\end{array}$ & $\begin{array}{l}\text { Strain } \\
\text { Rate } \\
\text { e }\left(s^{-1}\right)\end{array}$ & $\begin{array}{c}\text { Jet } \\
\text { Velocity } \\
\text { (fps) }\end{array}$ & $\begin{array}{c}\text { Strain } \\
\text { Rate } \\
\text { e }\left(\mathbf{s}^{-1}\right)\end{array}$ & $\begin{array}{c}\text { Jet } \\
\text { Velocity } \\
\text { (fps) }\end{array}$ & $\begin{array}{c}\text { Strain } \\
\text { Rate } \\
\text { e }\left(\mathrm{s}^{-1}\right)\end{array}$ & $\begin{array}{c}\text { Jet } \\
\text { Velocity } \\
\text { (fps) }\end{array}$ & $\begin{array}{c}\text { Strain } \\
\text { Rate } \\
\text { e }\left(\mathbf{s}^{-1}\right)\end{array}$ \\
\hline \multirow[t]{2}{*}{10} & 168 & & & & & & & & \\
\hline & & & & & & & & 18 & 297 \\
\hline 20 & 339 & & & & & & & & \\
\hline \multirow[t]{2}{*}{30} & 508 & & & & & 30 & 508 & & \\
\hline & & & & & & & & 36 & 603 \\
\hline 40 & 688 & & & & & & & & \\
\hline \multirow[t]{3}{*}{50} & 852 & & & & & 50 & 852 & & \\
\hline & & & & & & & & 54 & 908 \\
\hline & & 58 & 974 & 58 & 974 & & & & \\
\hline \multirow[t]{3}{*}{60} & 1008 & & & & & & & & \\
\hline & & & & 67 & 1135 & & & & \\
\hline & & & & & & & & 68 & 1153 \\
\hline \multirow[t]{2}{*}{70} & 1185 & & & & & 70 & 1185 & & \\
\hline & & & & 78 & 1312 & & & & \\
\hline \multirow[t]{2}{*}{90} & & & & & & 90 & 1524 & & \\
\hline & & & & 92 & 1558 & & & & \\
\hline 100 & & & & & & 100 & 1693 & & \\
\hline 120 & & & & & & 120 & 2032 & & \\
\hline
\end{tabular}

predation activity occurred within the first few minutes after fish were subjected to the predators. This observation suggests that strain rates causing disorientation for even short periods of time may result in indirect mortality.

Turnpenny et al. (1992) reported that salmonids exposed to shear stress of 206 and $774 \mathrm{~N} / \mathrm{m}^{2}$ experienced little scale loss, no loss of mucous coating, no other apparent injuries, and no mortality. Their shear stress estimates compare to strain rate values up to $600 \mathrm{~cm} / \mathrm{s} / \mathrm{cm}(\Delta y=1.8 \mathrm{~cm})$. Johnson $(1970,1972)$ reported that salmonids subjected to velocities of $17.5 \mathrm{~m} / \mathrm{s}$ were not killed. However, mortalities were noted at exposures to velocities greater than $20 \mathrm{~m} / \mathrm{s}$ or an estimated strain rate greater than $900 \mathrm{~cm} / \mathrm{s} / \mathrm{cm}(\Delta \mathrm{y}=1.8 \mathrm{~cm})$. 


\subsection{Conclusions}

We were able to quantify, in a highly reproducible manner, the biological effects to fish exposed to a shear environment in the laboratory. Using strain rate as the index of intensity to describe the hydraulic force experienced by a fish in a shear environment, we determined that no significant injuries occurred to fish subjected to strain rates equal to or less than $500 \mathrm{~cm} / \mathrm{s} / \mathrm{cm}$. This value was based on a measurement scale of $1.8 \mathrm{~cm}$ or the average width of the juvenile salmonids used in our studies. The no-effect value of $500 \mathrm{~cm} / \mathrm{s} / \mathrm{cm}$ would not be equivalent to the fluid-strain rate computed at a finer scale resolution.

Turbulence intensities at the point of exposure ranged from only 3 to $6 \%$, indicating that strain rate values based on mean velocity are suitable for developing biological criteria.

We found that species sensitivity to strain varied. Juvenile American shad were more susceptible to hydraulic forces experienced in a shear environment than were juvenile chinook salmon, steelhead, or rainbow trout. Juvenile rainbow trout exposed to the edge of the plume in a headfirst orientation were injured at a higher rate than trout exposed tailfirst. Similarly, rainbow trout exposed to the edge of the jet plume (slow-fish-to-fast-water scenario) were injured at a higher rate than those exposed to the shear zone from the center of the jet plume (fast-fish-to-slow-water scenario). Factoring in indirect effects of exposure (i.e., increased susceptibility to predation) lowered the minimum strain rate required to protect juvenile rainbow trout exposed to a shear environment from $688 \mathrm{~cm} / \mathrm{s} / \mathrm{cm}$ to $517 \mathrm{~cm} / \mathrm{s} / \mathrm{cm}$.

Direct comparisons between our results and shear stress values reported by other investigators were not possible because they did not measure the velocity fields. Despite this limitation, collective studies reinforce the notion that a one-time exposure to jet velocities exceeding $\sim 15 \mathrm{~m} / \mathrm{s}$ are harmful to juvenile fish. The associated strain rate for $15 \mathrm{~m} / \mathrm{s}$ is $\sim 850 \mathrm{~cm} / \mathrm{s} / \mathrm{cm}$ (at a $\Delta y$ of $1.8 \mathrm{~cm}$ ).

Shear environments similar to those causing injury and mortality to test fish in our environment are known to occur in turbine environments. However, the spatial extent and the relative frequency that fish may experience such hydraulic forces are largely unknown. Similarly, larger scale hydraulic forces associated with turbulent events have not been characterized. These issues should be addressed in future studies. 


\subsection{Literature Cited}

Albertson, M.L., Y.B. Dai, R.A. Jensen, and H. Rouse. 1950. Diffusion of submerged jets. Transactions ASCE, 155:69.

Basham, L.R., M.R. Delarm, J.B. Athern, and S.W. Pettit. 1982. Fish transportation oversight team annual report, FY 1981: Transport operations on the Snake and Columbia rivers. NOAA Technical Memorandum NMFS F/NNR-2. Environmental and Technical Services Division, Northwest Regional Office, National Oceanic and Atmospheric Administration, National Marine Fisheries Services, Portland, Oregon.

Bell, M.C. 1981. Updated compendium on the success of passage of small fish through turbines. Section I: 1-201. Updated compendium on the success of passage of small fish through turbines. U.S. Army Corps of Engineers, Seattle, Washington.

Bernard, O., and L.C. Malone. 1988. Statistics in Research, University of Iowa, Ames, Iowa.

Brookshier, P.A., J.V. Flynn, and R.R. Loose. 1995. $21^{\text {st }}$ Century advanced hydropower turbine system. Pages 2003-2008 in J.J. Cassidy, editor. Waterpower'95. Proceedings of the International Conference on Hydropower. American Society of Civil Engineers, New York.

Ñada , G.F., C.C. Coutant, and R.R. Whitney, 1997: Development of biological criteria for the design of advanced hydropower turbines. DOE/ID-10578. U.S. Department of Energy, Idaho Operations Office, Idaho Falls, Idaho. 85 pp.

Chen, C.J. and W. Rodi. 1980. Vertical turbulent buoyant jets - A review of experimental data. Pergamon Press, New York, New York.

Costa, J.E. 1987. Hydraulics and basin morphometry of the largest flash floods in the conterminous United States. Journal of Hydrology 93:313-338.

Coutant, C.C. 1970. Effect of thermal shock on vulnerability to predation in juvenile salmonids. Vol. 2, A dose response by rainbow trout to three shock temperatures. BNWL-1519. Battelle, Pacific Northwest Laboratories, Richland, Washington. 12 pp.

Coutant, C.C. 1998. Turbulent attraction flows for juvenile salmonid passage at dams. ORNL/ TM-13608. Oak Ridge National Laboratory, Oak Ridge, Tennessee. 28 p.

Daily, J.W. and D.R. Harleman. 1966. Fluid mechanics. Addison-Wesley Publishing Company Inc., Reading, Massachusetts.

Fausch, K.D. and R.J. White. 1981. Competition between brook trout (Salvelinus fontinalis) and brown trout (Salmo trutta) positions in a Michigan stream. Canadian Journal of Fisheries and Aquatic Sciences 38:1220-1227. 
Fischer, H.B., E.J. List, Robert C.Y. Koh, J. Imberger, and N.H. Brooks. 1979. Mixing in Inland and Coastal Waters. Academic Press.

Gordon, N.D., T.A. McMahon, and B.L. Finlayson. 1992. Stream hydrology: An introduction for ecologists. John Wiley \& Sons, New York, New York. 526 p.

Groves, A.B. 1972. Effects of hydraulic shearing actions on juvenile salmon (Summary Report). Northwest Fisheries Center, National Marine Fisheries Service, Seattle, Washington. 7 p.

Johnson, R.L. 1970. Fingerling fish mortalities at 57.5 fps. Report No. 22. U.S. Army Corps of Engineers, North Pacific Division, Portland, Oregon. 14 p.

Johnson, R.L. 1972. Fingerling fish research, high-velocity flow through four-inch nozzle. Report No. 24. U.S. Army Corps of Engineers, Pacific Division, Portland, Oregon. 3 p.

Killgore, K.J., A.C. Miller, and K.C. Conley. 1987. Effects of turbulence on yolk-sac larvae of paddlefish. Transactions of the American Fisheries Society 116:670-673.

Lancaster, J. and A.G. Hildrew. 1993. Characterizing in-stream flow refugia. Canadian Journal of Fisheries and Aquatic Sciences 50:1663-1675.

McEwen, D. and G. Scobie. 1992. Estimation of the hydraulic conditions relating to fish passage through turbines. NPC001. National Engineering Laboratory, East Kilbride, Glasgow, Scotland. $155 \mathrm{p}$.

Morgan, R.P., II, R.E. Ulanowicz, V.J. Rasin, Jr., L.A. Noe, and G.B. Gray. 1976. Effects of shear on eggs and larvae of striped bass, Morone saxatilis, and white perch, M. americana. Transactions of the American Fisheries Society 105(1):149-154.

Munson B.R., D.F. Young, and T.H. Okiishi. 1994. Fundamentals of Fluid Mechanics. New York: John Wiley \& Sons, Inc., p 857.

Neitzel, D.A., C.S. Abernethy, and M.C. Richmond. 1998. Laboratory Studies of the Effects of Turbulence and Shear Stress on Turbine-Passed Fish: 1997-98 Progress Report. Prepared by the Pacific Northwest National Laboratory, Richland, Washington for the Idaho Engineering and Environmental Laboratory, Idaho Falls, Idaho.

Normandeau et al. (Normandeau Associates Inc., J.R. Skalski, and Mid Columbia Consulting, Inc.). 1999. Relative Passage Survival and Injury Mechanisms for Chinook Salmon Smolts Within the Turbine Environment at McNary Dam, Columbia River. Prepared for Walla Walla District, U.S. Army Corps of Engineers, Walla Walla, Washington. December 1, 1999. 14+ appendices.

RMC (RMC Environmental Services, Inc.) and J.R. Skalski. 1995. Survival of yearling fall chinook salmon smolts (Oncorhynchus tshawytscha) in passage through a Kaplan Turbine at Rocky Reach hydroelectric dam, Washington. Processed Final Report. Public Utility District No. 1 of Chelan County, Wenatchee, Washington. 
Sami, S., T. Carmody, and H. Rouse. 1967. Jet Diffusion in the region of flow establishment. J. Fluid Mech. 3(2):231-252.

Schreck, C.B. 1990. Physiological, behavioral, and performance indicators of stress. Pages 29-37, In S.M. Adams, editor. Biological Indicators of Stress in Fish. Symposium 8, American Fisheries Society, Bethesda, Maryland.

Shtaf, L.G., D.S. Pavlov, M.A. Skorobogatov, and A. S. Barekyan. 1983. The influence of flow turbulence on fish behavior. Journal of Ichthyology 23(2):129-140.

Skorobogatov, M.A. and S.D. Pavlov. 1991. A study of the orientation of young roach, Rutilus rutilus, with respect to current velocity. Journal of Ichthyology 31:142-148.

Statzner, B. and R. Müller. 1989. Standard hemispheres as indicators of flow characteristics in lotic benthos research. Freshwater Biology 21:445-459.

Turnpenny, A.W.H., M.H. Davis, J.M. Fleming, and J.K. Davies. 1992. Experimental studies relating to the passage of fish and shrimps through tidal power turbines. Marine and Freshwater Biology Unit, National Power, Fawley, Southhampton, Hampshire, England.

USACE (U.S. Army Corps of Engineers). 1995. Proceedings: 1995 turbine passage survival workshop. U.S. Army Corps of Engineers, Portland District, Portland, Oregon: 212 pp. + appendices.

Vogel, S. 1981. Life in moving fluids: The physical biology of flow. Princeton University Press. Princeton, New Jersey. 352 p.

Voith Hydro, Inc. 1997. Development of environmentally advanced hydropower turbine system design concepts. Report No. 2677-0141 to the U.S. Department of Energy, Idaho Operations Office, and Hydropower Research Foundation, Inc. 


\section{Appendix A: Shear and Turbulence Descriptions}

\section{A.1 Shear and Turbulence Descriptions}

The fluid stresses of interest in this report, i.e., strain rate, shear stress, and turbulence are fundamentally expressions of changes in water velocity. Because there are many definitions that can be used interchangeably or are often used as if they are interchangeable, we have defined the descriptors used in this report in Table A.1. We also defined other descriptors that we found being used in fisheries and other literature. We hope this list helps the reader understand how we describe the conditions in our test flume. We also ask the reader to note the descriptors that we did not use. Table A.2 lists turbulent flow descriptors. 
Table A.1. Descriptors used in this report.

\begin{tabular}{|c|c|c|}
\hline Name & Verbal Description & "Mathematical Description \\
\hline $\begin{array}{l}\text { Deformation Rate Tensor } \\
(\mathrm{cm} / \mathrm{s} / \mathrm{cm})\end{array}$ & $\begin{array}{l}\text { Rate of Fluid Rotation Plus the } \\
\text { Rate of Fluid Shearing }\end{array}$ & $e_{i j}=\frac{\partial u_{i}}{\partial x_{j}}=\frac{1}{2}=\left(\frac{\partial u_{i}}{\partial x_{j}}-\frac{\partial u_{j}}{\partial x_{i}}\right)+\frac{1}{2}\left(\frac{\partial u_{i}}{\partial x_{j}}+\frac{\partial u_{j}}{\partial x_{i}}\right.$ \\
\hline Strain rate $(\mathrm{cm} / \mathrm{s} / \mathrm{cm})$ & $\begin{array}{l}\text { Simplified Form of the } \\
\text { Deformation Rate in a Laminar } \\
\text { Flow with Velocity Gradients } \\
\text { Only in the Y Direction }\end{array}$ & $\mathrm{e}=\frac{\partial \overline{\mathrm{u}}}{\partial \mathrm{y}}$ \\
\hline Shear stress Tensor $\left(\mathrm{N} / \mathrm{m}^{2}\right)$ & $\begin{array}{l}\text { Relates the Fluid Velocity } \\
\text { Gradients to the Fluid Shear } \\
\text { stress }\end{array}$ & $\begin{aligned} \tau_{\mathrm{ij}}=\mu\left(\frac{\partial \mathrm{u}_{\mathrm{i}}}{\partial \mathrm{x}_{\mathrm{j}}}+\frac{\partial \mathrm{u}_{\mathrm{j}}}{\partial \mathrm{x}_{\mathrm{i}}}\right) \\
\text { where } \mu=\text { laminar dynamic viscosity }\end{aligned}$ \\
\hline $\begin{array}{l}\text { Laminar Shear stress } \\
\left(\mathrm{N} / \mathrm{m}^{2}\right)\end{array}$ & $\begin{array}{l}\text { Simplified Form of the Shear } \\
\text { stress Tensor in a Laminar } \\
\text { flow with Velocity Gradients } \\
\text { Only in the Y Direction }\end{array}$ & $\tau=\mu \frac{\partial \bar{u}}{\partial y}$ \\
\hline $\begin{array}{l}\text { Turbulent Shear stress } \\
\left(\mathrm{N} / \mathrm{m}^{2}\right)\end{array}$ & $\begin{array}{l}\text { Shear stress Turbulence in a } \\
\text { Turbulent Flow is the Sum of } \\
\text { the Laminar Shear stress and } \\
\text { the Turbulent Reynolds } \\
\text { Stresses }\end{array}$ & $\tau=\mu \frac{\partial \bar{u}}{\partial y}-\overline{\rho u^{\prime} v^{\prime}}$ or $\tau=\left(\mu+\mu_{T}\right) \frac{\partial \bar{u}}{\partial y}$ \\
\hline Vorticity $(\mathrm{cm} / \mathrm{s} / \mathrm{cm})$ & $\begin{array}{l}\text { Twice the Angular Speed of } \\
\text { Rotation of a Fluid Element } \\
\text { About Its Own Axis }\end{array}$ & $\boldsymbol{\omega}=\nabla \mathbf{x u}$ \\
\hline $\begin{array}{l}\text { Vorticity in a Two } \\
\text { Dimensional Flow } \\
(\mathrm{cm} / \mathrm{s} / \mathrm{cm})\end{array}$ & $\begin{array}{l}\text { Simplified Form of the } \\
\text { Vorticity in a Two } \\
\text { Dimensional Flow }\end{array}$ & $\omega_{z}=\frac{\partial v}{\partial x}-\frac{\partial u}{\partial y}$ \\
\hline $\begin{array}{l}\text { Instantaneous Velocities in } \\
\text { a Turbulent Flow (M/sec) } \\
\text { (Mean + Fluctuations) }\end{array}$ & $\begin{array}{l}\text { In a Turbulent Flow the } \\
\text { Instantaneous Velocity is } \\
\text { Composed of a Time Averaged } \\
\text { Value Plus an Instantaneous } \\
\text { Fluctuation from the Average }\end{array}$ & $\begin{array}{l}\mathrm{u}=\overline{\mathrm{u}}+\mathrm{u}^{\prime} \\
\mathrm{v}=\overline{\mathrm{v}}+\mathrm{v}^{\prime}\end{array}$ \\
\hline $\begin{array}{l}\text { Turbulence Intensity } \\
(\mathrm{M} / \mathrm{sec})\end{array}$ & $\begin{array}{l}\text { Root Mean Square of the } \\
\text { Fluctuations) }\end{array}$ & $\sqrt{\overline{\mathrm{u}^{\prime 2}}}=\left[\frac{1}{\mathrm{~T}} \int_{\mathrm{O}}^{\mathrm{T}} \mathrm{u}^{\prime 2} \mathrm{dt}\right]^{\frac{1}{2}}$ \\
\hline $\begin{array}{l}\text { Kinetic Energy of } \\
\text { Turbulence }\left(\mathrm{m}^{2} / \mathrm{sec}\right)\end{array}$ & $\begin{array}{l}\text { Turbulent Kinetic Energy per } \\
\text { Unit Mass }\end{array}$ & $\mathrm{TKE}=\frac{1}{2}\left(\overline{\mathrm{u}^{\prime 2}}+\overline{\mathrm{v}^{\prime 2}}\right)$ \\
\hline
\end{tabular}


Table A.2. Turbulent flow descriptors.

\begin{tabular}{|c|c|}
\hline Instantaneous Fluctuations & $\mathrm{u}=\overline{\mathrm{u}}+\mathrm{u}^{\prime}, \mathrm{v}=\overline{\mathrm{v}}+\mathrm{v}^{\prime}, \mathrm{w}=\overline{\mathrm{w}}+\mathrm{w}^{\prime}$ \\
\hline \multicolumn{2}{|r|}{$\overline{u^{\prime} v^{\prime}}=\frac{1}{T} \int_{0}^{T} u^{\prime} v^{\prime} d t$, where $u^{\prime}=u-\bar{u}$ and $v^{\prime}=v-\bar{v}$} \\
\hline \multicolumn{2}{|c|}{ Turbulence intensity $\quad \sqrt{\mathrm{u}^{\prime 2}}=\left[\frac{1}{\mathrm{~T}} \int_{0} \mathrm{u}^{\prime 2} \mathrm{dt}\right]^{2}$} \\
\hline \multicolumn{2}{|c|}{ Turbulent kinetic energy $\quad$ TKE $=\frac{1}{2}\left(\overline{\mathrm{u}^{\prime 2}}+\overline{\mathrm{v}^{\prime 2}}+\overline{\mathrm{w}^{\prime 2}}\right)$} \\
\hline Turbulent shear stress & $\tau=\mu \frac{\partial \overline{\mathrm{u}}}{\partial \mathrm{y}}-\rho \overline{u^{\prime} v^{\prime}}$ or $\tau=\left(\mu+\mu_{\mathrm{T}}\right) \frac{\partial \overline{\mathrm{u}}}{\partial \mathrm{y}}$ \\
\hline \multicolumn{2}{|c|}{$\begin{array}{l}\text { For } 17^{\circ} \mathrm{C} \text { freshwater: } \\
\mu=0.0010935=1.0935 \times 10^{-3} \mathrm{Nsm}^{-2} \text { or } \mathrm{Pa} \cdot \mathrm{s} \\
\nu=0.0000010949=1.0949 \times 10^{-6} \mathrm{~m}^{2} \mathrm{~s}^{-1}\end{array}$} \\
\hline
\end{tabular}




\section{Appendix B: Biological Data}

This appendix includes 1) summary tables listing all species tested, the total number of fish used for each exposure, and the number of injuries recorded at each strain rate, and 2) immediate and delayed mortality data associated for each species. These data files are on an accompanying CD. 


\section{Appendix C: Kinematic Profiles and Video Data}

This appendix (included on the accompanying CD) includes Excel spreadsheets illustrating the physical aspects of individual fish and behavior as they passed through the near field of the shear zone. The tables and associated plots include distance, velocity, and acceleration over time, fish trajectory as recorded by high-speed video cameras, and selected video clips (mpg format) for all species tested. A descriptive list of the contents of each folder is listed below. An mpeg viewer program is also included on the CD.

Table C.1. Kinematic summary table (values are in $\mathrm{cm} / \mathrm{s} / \mathrm{cm}$ ).

\begin{tabular}{||l|c|c|c||}
\hline File Folder & Acceleration Plots & Acceleration Averages & Fish Trajectory \\
\hline American shad & 517,852 & N/A & N/A \\
\hline $\begin{array}{l}\text { Fall chinook } \\
\text { pre-smolt }\end{array}$ & $517-1008$ & $517-1008$ & 517,852 \\
\hline Fall chinook smolt & 517,852 & N/A & 517,852 \\
\hline Rainbow trout & 517,852 & N/A & 517,852 \\
\hline Spring chinook & $517,852,1008$ & $517-1008$ & 517,852 \\
\hline Steelhead & 517,852 & N/A & 517,852 \\
\hline
\end{tabular}

Table C.2. Video clip summary table (values are in $\mathrm{cm} / \mathrm{s} / \mathrm{cm}$ ).

\begin{tabular}{||l|c|c|c||}
\hline \multicolumn{1}{|c|}{ File Folder } & Slow-to-Fast Headfirst & Slow-to-Fast Tailfirst & Fast to Slow \\
\hline \hline American shad & $517,688,852$ & N/A & N/A \\
\hline $\begin{array}{l}\text { Fall chinook } \\
\text { pre-smolt }\end{array}$ & 517,852 & N/A & 517,852 \\
\hline Fall chinook smolt & $517,852,1008$ & 852,1008 & 517,852 \\
\hline Rainbow trout & $688,852,1008$ & N/A & $852,1008,1150$ \\
\hline Spring chinook & $517,688,1008$ & $688,852,1008$ & 517,852 \\
\hline Steelhead & $517,852,1008$ & 852,1008 & 517,852 \\
\hline
\end{tabular}




\section{Appendix D: Pitot Tube Data and Plots}

We included a brief summary of the Pitot tube data in a file called pnnl_fish_shear.pdf on the accompanying CD. This file contains a table of velocities and Reynolds numbers for each jet speed measured, schematics of the jet nozzle and tank, and photographs of the tank, jet nozzle, and introduction tube. The file also contains both line and color-contour plots of the velocity distribution for selected pump speeds.

The data are provided in the file Pitot $18 \mathrm{~mm}$.dat, which is in tecplot format. These data files are on the accompanying CD. 


\section{Appendix E: LDV Data}

We included a summary of the LDV data in LDV_summary.pdf. The summary contains a description of our methods and equipment and a discussion of the results. Our description of methods and equipment includes the following: written summary, dimensioned plan and profile schematics of the tank and the jet; photographs of the tank, gantry, and jet nozzle; and a table describing all variables. The discussion of results includes sample color-contour and line plots of the results, plots comparing our data to other work, and our written interpretation of the results presented.

For each jet velocity measured $(10,20,30,40,50,60,70 \mathrm{ft} / \mathrm{s})$, we also included the data files containing the average values for each point measured. Table E. 1 summarizes the files included. These data files are on the accompanying $\mathrm{CD}$.

Table E.1. LDV data files.

\begin{tabular}{||l|l||}
\hline \multicolumn{1}{|c|}{ File Name } & \multicolumn{1}{c||}{ Description } \\
\hline \hline 10fps_value.dat & Actual values for $10 \mathrm{fps}$ center velocity \\
\hline 20fps_value.dat & Actual values for $20 \mathrm{fps}$ center velocity \\
\hline 30fps_value.dat & Actual values for $30 \mathrm{fps}$ center velocity \\
\hline 40fps_value.dat & Actual values for $40 \mathrm{fps}$ center velocity \\
\hline 50fps_value.dat & Actual values for $50 \mathrm{fps}$ center velocity \\
\hline 60fps_value.dat & Actual values for $60 \mathrm{fps}$ center velocity \\
\hline 70fps_value.dat & Actual values for $70 \mathrm{fps}$ center velocity \\
\hline \hline
\end{tabular}

